\title{
A Revision of Australopapuan and New Caledonian Brunettia (Diptera, Psychodidae)
}

\section{A. Duckhouse}

Department of Zoology, The University of Adelaide, Box 498, G.P.O., Adelaide, S.A. 5001, Australia.

\section{Abstract}

Brunettia Annandale (sensu Duckhouse 1966) has previously been known in Australopapua from thirty-three species, comprising twenty-eight from Papua-New Guinea, but only five from Australia, all in the southern states. This anomaly is now removed with the description of seventeen new species from Queensland and the Northern Territory, showing that the major evolutionary centre extends from Papua-New Guinea far into northern Australia, and that the southern species are not in reality separated by a disjunction. Three new species are also described from southern Australia, two from New Guinea, and two from New Caledonia (the first from this island). The phylogenetic importance of Brunettia is especially due to the inclusion in it of taxa that are cladistically basal and annectant, nearly all Australopapuan.

The mix of tribal, generic, subgeneric and species characters found in earlier descriptions is ordered into a strict hierarchical sequence, and Brunettia is divided into seven subgenera-Brunettia, s. str., Plesiobrunettia, subg, nov., Atrichobrunettia Satchell, Maurobrunettia, subg. nov., Campanulobrunettia, subg. nov., Horobrunettia, subg. nov., and Mirousiella Vaillant, stat. nov., this last resurrected from synonymy with Atrichobrunettia. Of these, Maurobrunettia occurs in northern Australia, Plesiobrunettia is New Guinean, Campanulobrunettia and Atrichobrunettia are Australopapuan, and Horobrunettia is mainly Australopapuan but has one species in the Philippines. Brunettia s. str. is more widely distributed, but extensively diversified in Papua-New Guinea, and Mirousiella is European. The ten Papua-New Guinean species placed by Quate \& Quate (1967) in Atrichobrunettia are transferred into the various subgenera of Brunetia (combs, nov.), and their Brunettia species are also assorted into these subgenera. New keys are provided covering all Australopapuan Brunettia species.

The genealogical status of Mormiini and Maruinini are discussed. It is concluded that because Mormiini are an offshoot of the Maruinini, the Maruinini are paraphyletic, but that this defect cannot be overcome until more is known of maruinine phylogeny.

\section{Introduction}

Brunettia Annandale (sensu Duckhouse 1966) is a large and phylogenetically important Old World psychodid genus of the subfamily Psychodinae, tribe Mormiini, which has previously been known in Australopapua from thirty-three species described by Satchell (1953a), Duckhouse (1966) and Quate \& Quate (1967). These comprise twenty-eight from Papua-New Guinea, five from southern Australia, but none from northern Australia. However, Brunettia abounds in the wetter parts of the north and I shall now describe, amongst others, seventeen diverse new species from Queensland and the Northern Territory, showing that the major evolutionary centre extends from Papua-New Guinea far into northern Australia, and that the southern species are not in reality separated by a disjunction. See Duckhouse $(1978 b, 1980)$ for discussion of the effect on phylogeny and biogeography of incomplete knowledge of taxa, which may be profound. 
The diversity of many groups of insects in New Guinea is spectacular (Gressitt 1982), and psychodids abound: Quate \& Quate (1967) say that the 228 Papua-New Guinean species they describe may represent no more than $25 \%$ of those that actually exist. There is no sign of such a prolific fauna anywhere in Australia. Nonetheless, since much of the Papua-New Guinean archipelago did not appear above the sea until the late Eocene (Axelrod \& Raven 1982) it is likely that Australopapuan Morminini experienced part of their primary diversification in Australia. Some elements probably became extinct as it grew hotter and drier, but conditions would have allowed others to spread into the growing land areas of PapuaNew Guinea whose rainforests now provide ideal conditions for one of the world's richest psychodid faunas. In addition to Oriental elements, this includes many elements shared with Australia alone, and an abundance of primitive elements that could not have arisen in situ. The latter include Gerobrunettia Quate and Quate, which is the plesiomorph sister group of Brunettia (Duckhouse 1987); some parts of Brunettia, e.g. subg. Campanulobrunettia, and two species of subg. Plesiobrunettia which appear to be annectant to Gerobrunettia; and the maruinine genus Didicrum Enderlein (Duckhouse 1990). There is reason to suppose that, like Nothofagus in the mountains of New Guinea, these examples are 'Antarctic' in derivation and so came from the south. Another concentration of Brunettia species exists in the Oriental region, but they are apparently far less diversified, and primitive elements are almost entirely lacking.

Beyond Australopapua, Brunettia appears to be less abundant. Edwards (1928) describes a species from Samoa, several Micronesian forms of which were named by Quate (1959). Satchell $(1950 a, 1950 b, 1953 b, 1958)$ describes a species each from New Zealand, Fiji and Samoa, and three from Borneo and the Malay Peninsula, while Quate (1962a, 1965) describes eleven species from Borneo and the Philippines. Freeman (1951) deals with two peculiar species from Fiji and northern India, and Quate $(1962 b)$ with the fragmentary remains of eight Indian species described by Annandale and Brunetti. There are two Japanese species (Tokunaga \& Komyo 1955; Tokunaga 1959), two Afrotropical species (Duckhouse 1978a) and two undescribed Neotropical species. The Oriental, Australasian and Pacific species are catalogued by Duckhouse (1973) and Duckhouse \& Lewis (1989). Four species occur, anomalously, in Europe.

Brunettia is not cosmopolitan as stated by Quate \& Quate (1967, p. 108), being unknown from the Nearctic* and the greater part of the Palaearctic. Most species inhabit wet subtropical to tropical forests, where, as observed by Quate (1962a) in Borneo, they are often seen performing a characteristic dance on the upper surfaces of broad leaves such as those of Zingiberaceae and Araceae. Individuals run rapidly and jerkily, with wings held horizontally, along a circular or figure-of-eight course that tends to keep them in the same area of the leaf. In B. biformis Edwards, they 'are often seen performing their short circular runs around each other, a mating dance that may be, but is more often not, followed by copulation' (Satchell 1953b).

The phylogenetic importance of Brunettia is due to (i) the inclusion in it of Australopapuan subgroups that are cladistically basal, (ii) its genealogical relationship to Setomima Enderlein, established by Duckhouse (1987), and (iii) its life-history, which provides evidence that may lead towards an understanding of the origins of the Psychodinae (Duckhouse, unpublished).

Duckhouse (1987) discusses the genealogical relationships of the primarily Afrotropical Setomima and shows that it forms the plesiomorph sister group of a clade consisting of Gerobrunettia Quate and Quate, Brunettia and Mormia Enderlein-the tribe Mormiini (Fig. 1). Cladistically, it may seem that Setomima should therefore be ranked either as a separate tribe, Setomimini, or as a subtribe of the Mormiini. The problem is that it is also one of the morphologically distinctive group of southern hemisphere genera which includes Maruina Müller, the type genus of the Maruinini, and that the phylogenetic relationships of this group are largely unknown. Hence, it is not possible to say which genera arose before

* Quate (1955) places two Nearctic species in Brunettia. One (Psychoda nitida Banks) belongs to Setomima Enderlein and the other, sycophanta Quate, to Platyplastinx Enderlein (Duckhouse 1966). 
the Setomima-Mormiini bifurcation, so belonging to one or more separate tribes (Fig. 1,a), and which arose after the bifurcation (Fig. $1, b$ ) as part of the Setomima lineage. If Maruina, the type genus of Maruinini, forms part of $b$, then the Setomima lineage itself $($ Setomima $a)$ would be the Maruinini s. str.

I consider that the number of tribes should not be increased until there is some phylogenetic basis for it, and for the present shall therefore continue to use the term 'Maruinini' for the entire morphological group, including Setomima but excluding Mormiini. The Maruinini is then paraphyletic. This is undesirable, but not a serious defect. While the phylogeny of groups remains unknown, or several equally plausible phylogenies are still tenable, a hybrid classification between the Aristotelian and Hennigian ideals is inevitable (Gauld \& Mound 1982). In this instance, paraphyly appears to be avoided if Mormiini are treated as part of the Maruinini, but these tribes are so radically different that the Maruinini would then be impossible to define. It is, moreover, probable that other major tribes besides Mormiini have arisen as offshoots of the Maruinini, so inclusion of the Mormiini would not necessarily make the Maruinini monophyletic. This subject is outside the scope of the present paper and I shall return to it elsewhere.

Phylogenetic and biogeographical hypotheses depend upon sound taxonomic groundwork. It is therefore unfortunate that although, prior to this paper, sixty-eight Brunettia species had been named, the descriptions were mostly rudimentary. They were also heterogeneous and therefore not comparative. These are serious defects because a high proportion of the type specimens are flattened and distorted through contraction of mountant, often Hoyer's medium, and consequently cannot be adequately redescribed. However, the species dealt with in the present paper include representatives of nearly all major subgroups, that between them show most of the important evolutionary transformations, and the descriptions are comparative. The mix of tribal, generic, subgeneric and species characters encountered in most earlier descriptions has been sorted into a strict hierarchical sequence. I also introduce a host of new characters and provide revised genus-group concepts, three new subgenera and entirely new keys covering all Australopapuan species.

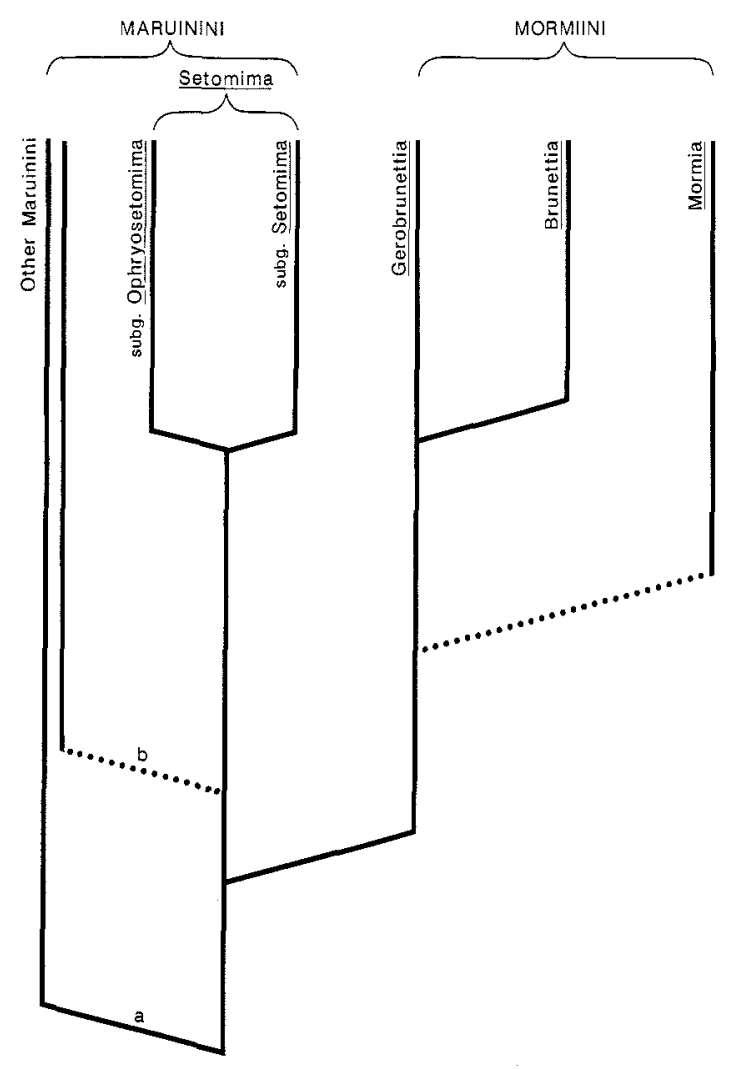

Fig. 1. Inferred genealogical relationships between Maruinini and Mormiini, modified from Duckhouse (1987) ( $a$, line arising before the Setomima-Mormiini bifurcation, giving rise to one or more separate tribes; $b$, line arising after the Setomima-Mormini bifurcation, forming part of Setomima lineage). 
Including species described in this paper, there are now ninety-three Brunettia species, fifty-five (59\%) of which are Australopapuan, while $45 \%$ of those are Australian. Because of the extreme patchiness of collecting, there is little point in attempting to further discuss patterns of distribution at the species level. It is possible, however, to draw tentative conclusions about the distribution of genus-groups, although some are undoubtedly more widespread than now appears.

Gerobrunettia is the sister group of Brunettia and cladistically the most basal genus of Mormiini (Fig. 1). It appears to be restricted to New Guinea. Brunettia has seven subgenera: Plesiobrunettia, subg. nov., is its most basal subgenus and is also apparently restricted to New Guinea; Campanulobrunettia, subg. nov. and subg. Atrichobrunettia Satchell include relatively basal elements and are Australopapuan; Maurobrunettia, subg. nov, is only found in northern Australia; Horobrunettia, subg. nov. is mainly Australopapuan but has one species, B. amoena (Quate), in the Philippines; and subg. Brunettia is more widely distributed but most diversified in Papua-New Guinea. As explained below, the four European species previously placed in Atrichobrunettia are different from any Australopapuan species and form a separate subgenus, Mirousiella Vaillant.

\section{Materials and Methods}

All specimens are mounted in Canada Balsam, used liberally enough to ensure that they will not be flattened even when it has completely dried.

Morphological terminology for adults follows Duckhouse (1987, 1990), except that the epandrial pseudospiracular openings of earlier papers are now described as the epandrial apertures.

All holotypes and allotypes and some paratypes are in the Australian National Insect Collection (ANIC); other paratypes, where available, are in the British Museum (Natural History) (BMNH), the Bishop Museum (BPB), and my own collection (DD).

\section{Measurement of Specimens}

Except for wing lengths, which are given as ranges for the entire type series, dimensions are of the holotype and allotype. Length of head is the distance from apex of occipital region to tip of clypeus. Length of aedeagus is measured from anterior end of aedeagal apodeme to tip of valves; parameres are measured from point of articulation with aedeagus to tip. Wing length is measured from base of costal node to wing tip. Length of epandrium is the distance from posterior margin to middle of anterior concavity. Length of subgenital plate is the distance from middle of anterior margin of basal thickening to level of tips of apical lobes.

\section{A Note on the Keys}

The keys, which include all Australopapuan and New Caledonian species, apply only to males because most females are unknown. The stated distributions do not discriminate between Irian Jaya (west New Guinea) and east New Guinea because apparent differences in distribution, especially the high proportion of species described from Irian Jaya alone, almost certainly reflect differences in the amount and kind of collecting, rather than true differences in distribution.

\section{Tribe MORMIINI Enderlein}

Mormiini Enderlein, 1937: 98. - Duckhouse, 1987: 267.

Brunettiini Vaillant, 1975: 156 (synonymy by Duckhouse, 1987).

\section{Remarks}

Vaillant (1974) places Mormia, type genus of the Mormini, in the Paramormiini (Telmatoscopini of Vaillant, 1971), but it is a member of the same tribe as Brunettia. Hence, Vaillant's more recent tribe Brunettiini (Type genus, Brunettia) is a synonym of Mormiini (Duckhouse 1987).

Vaillant (1975: 158) classifies most of the 'brunettoid genera' listed by Duckhouse (1968, $1978 a$ ) as Mormiini. However, use of the term brunettoid was a taxonomic device for referring collectively to morphologically similar taxa whose affinities were still being examined, and I emphasised that this was not a monophyletic assemblage. Four of the taxa (Gerobrunettia, Brunettia, Mormia and Rhadinoscopus Quate and Quate) are Mormiini. 
The others (Alepia Enderlein, Parasetomima Duckhouse, Paratelmatoscopus Satchell, Setomima and Nemoneura Tonnoir) show degrees of similarity or relatedness, but also unequivocally show the facies of Maruinini. Cladistically basal Mormiini (Gerobrunettia and some Brunettia species) resemble Setomima more-or-less closely in wing venation, and so does Gerobrunettia in other characteristics; but both have lost the ancestral ball and socket linkage between aedeagal and gonocoxal apodemes.

\section{Definition}

Head. Eyebridges usually with 3 facet rows (occasionally 4), contiguous in Mormia and males of many Brunettia species. 13 or 14 flagellomeres; basal ones, except sometimes the first, about as broad as scape and pedicel, subspherical to fusiform or flask-shaped; last 2 often small, narrowly separated; if flagellomeres are flask-shaped, necks of 1-2 penultimate usually reduced. Ascoids diverse; digitate and very elongate, variously flattened (leaf-like), or with 2-many anterior branches (bifurcated or palmate). Scar patch on frons partly or completely divided by median scar-free band. Cornicula (cephalic allurement organs) absent.

Thorax. Thoracic pore of Duckhouse (1985) often visible (e.g. Fig. 102t), perhaps omnipresent in Mormiini. Mesothoracic allurement organs present sporadically. Wings held horizontally; no second costal node; $\mathbf{R}_{\mathrm{s}}$ pectinate; forks usually more or less basal in position, $\mathbf{R}_{2}$ usually two or more times as long as $\mathbf{R}_{2+3}$, and $\mathbf{R}_{2+3}$ shorter than distance from $\mathrm{r}-\mathrm{m}$ to $\mathrm{M}$ fork; wing membrane often partially or completely hairy or scaly.

Terminalia. No 'ball and socket' articulation as in Maruinini (Duckhouse 1990) or furca as in Paramormiini (Duckhouse 1987). Aedeagus usually quite, or almost, symmetrical, basically racquet-shaped, except for tapered valves distally, which are like forceps blades (Brunettia and Gerobrunettia); or valves forming part of ring of racquet, or their tips just projecting (many Mormia); or aedeagus forming long tubular organ (Mormia, subg. Rhadinoscopus Quate and Quate). Aedeagal apodeme narrow, parallel-sided, or showing lateral wings (some Brunettia). Aedeagus articulating with triangular parameres that flank it, or that are occasionally wholly or partially integrated into aedeagus (some Mormia). Several to many retinacula, variable in type.

\section{Genus Brunettia Annandale}

Brunettia Annandale, 1910: 141. Type species: Diplonema superstes Annandale, 1908, by designation of Brunetti (1911: 310), figured by Quate (1962b: 168).

Parabrunettia Brunetti, 1911: 310. Type species: Psychoda squamipennis Brunetti, 1908, by designation of Brunetti (1912: 251).

Parabrunettia Enderlein, 1937: 106. Type species: Brunettia indica Eaton, 1913, by original designation.

Trichobrunettia Tonnoir, 1939: 70. Type species: Psychoda albonotata Brunetti, 1908, by original designation.

Trichobrunettia. - Vaillant, 1975: 158.

\section{Remarks}

Tonnoir (1939), Satchell (1958) and Quate (1963) viewed Brunettia as a broad genus, including both Oriental (mainly Indian) species related to the type species, $B$. superstes, and also several African species related to lithocolleta Enderlein, type species of Setomima. Tonnoir thought Setomima might be acceptable as a second subgenus of Brunettia, but in practice it was abandoned until Duckhouse (1966) recognised that it is evolutionarily distinct from Brunettia, and reinstated it as a full genus.

Vaillant (1975: 164) reverted to the concept of earlier workers by again placing all Setomima species in Brunettia, this time in a new subgenus, Parabrunettia Vaillant; but Parabrunettia Vaillant is the junior homonym of both Parabrunettia Brunetti and Parabrunettia Enderlein, as well as a synonym of Setomima. Duckhouse (1978a) criticised Vaillant's classification; Setomima was accepted by Vaillant (1982). 


\section{Revised Definition}

Mormiini with 13 flagellomeres, the 1st flask-shaped and as long as or longer than the 2nd; gonopods nearly always naked.

Male. Eyebridges widely separated to contiguous. Palpi elongate; palpomere 2 over 2.5 and generally over $3 \times$ length of 1 . Clypeus usually broad. Labellum fleshy, setose, posterior setae tending to enlarge and form a distinct transverse line, often associated with development of a zone of dark sclerotisation laterally (e.g. Fig. 155). Antenna: scape without lateral articulatory process at base; 13 flagellomeres, flask-shaped except sometimes the penultimate, usually not markedly eccentric, necks usually short and poorly delimited from bulbs; flagellomere 1 flask-shaped like the rest, as long as or longer than 2; ascoids paired.

Thorax. Anepisternite with dorsal 'wing' overlapping rim of mesonotum (e.g. Fig. 103w); no scars on prothorax; mesothoracic allurement organs ('tegulae') often present* provided with knobs or pits and therefore probably emitting aphrodisiac pheromones (Elger 1981). Wing membrane often wholly or partially hairy or scaly; usually more or less darkened, with distinct hair lines of unsclerotised cuticle running (i) along outer side of Sc (Fig. 2h.l) and (ii) along $\mathrm{R}_{1}$ towards base of wing (h.2), joining small dark triangular sclerotisation $(t)$ at level of base of Sc, then passing around basal medial cell and distally again along $\mathrm{CuA}_{1}$ (h.3).

Terminalia. Gonopods naked except in B. (Campanulobrunettia) goliath Quate and Quate, which has scattered vestiture on underside of coxite, a partial reversion to the ancestral condition. Style usually with 2 , or occasionally 3 or more, strong pre-apical setae on outer side; tip usually broadly rounded. Aedeagus almost always nearly symmetrical, basically racquet-shaped, with long, slightly unequal posterior valves arising from 'rim' in midline, on opposite side to 'handle' (aedeagal apodeme); valves usually parallel or slightly convergent like forceps blades, or occasionally divergent (e.g. Fig. 15); basal apodeme with or without lateral wings. Hypandrium usually arched strongly backwards and attached to bases of coxites, probably through fusion with parabasal processes; more or less fused with a broad, often distally tenuous, post-hypandrial plate between bases of coxites; posthypandrial plate with distal sensory setae. Aedeagus flanked by broad-based divergent parameres, often very large; parameres articulating with aedeagus and also with underside of post-hypandrial plate. Epandrium usually short and, except in subg. Horobrunettia, naked; except in $B$. morigera Duckhouse, anterior corners not reaching hypandrium but articulating separately with undersides of coxites; no sclerotised connection between epandrium and gonocoxal apodemes; ventral epandrial plate not present as separate structure, very probably fused with tenth tergite, here abnormally large and extending far anteriorly. Cercopods short; 2-many retinacula with variously expanded tips, stems of some are often strongly curved or angled.

Female. Subgenital plate shorter than broad; distal lobes short, parallel, usually not connected at base; genital flap usually low, triangular, rounded apically; a median rod or sclerotisation, usually stout and dark, extending backwards to tip of flap, between distal lobes. Spermathecae with saw-tooth-like internal sclerotisations ventrally (e.g. Fig. 52/st)

\section{Remarks}

The male terminalia are specialised: almost symmetrical, structurally simple, and in most respects conservative. Also, their appearance is partly determined by the extent to which the aedeagus is protracted. During protraction the parameres splay sideways and forward and rotate on their longitudinal axes, so that they are seen in half profile, and may appear to have quite a different shape: usually more slender and occasionally uncinate apically. Sometimes the same collection contains specimens showing various degrees of protraction. For these reasons, terminalia may provide little help at the species level. This is especially so in parts of subgenera Maurobrunettia, Brunettia and Atrichobrunettia.

\footnotetext{
* Quate $(1962 a, 1965)$ and Quate \& Quate (1967) refer to the allurement organs of Brunettia species as 'patagia', but since they are on the mesothorax they are 'tegulae'. As described by Feuerborn (1922), who first applied these terms to Psychodidae, patagia are placed on the prothorax.
} 
The retinacula vary considerably. In some species they are 'bell-tipped' as in Trichopsychoda and some Alepia species, the tip having the shape of a half-opened toadstool or umbrella, with more or less equally developed radial flutings running from rim to tip on all sides. In some species of Alepia, Setomima and Brunettia subg. Campanulobrunettia, the flutings may be less developed on one side, giving in frontal view a bell-like appearance, but in lateral view an asymmetrical 'hooded' appearance (e.g. Fig. 163). In other species the flutings in the neck region of the hood are extended in the form of two diminishing files running towards the base of the retinaculum, on either side of the main axis (e.g. Fig. 142). Finally, in some species the flutings are in the form of flattened semicircular lamellae that run as a series up one side, across the top and down the other. Where such lamellae are concentrated apically, except in direct frontal view, they give the fern spore capsule appearance of typical Atrichobrunettia species (e.g. Fig. 21).

The Brunettia species that are most basal cladistically appear to be the New Guinean B. bisulca (Quate and Quate) and B. bisulcoides (Quate and Quate) (subg. Plesiobrunettia) which share features with the primitive Gerobrunettia (Duckhouse 1987).

\section{Key to Males of Australopapuan Subgenera of Brunettia}

1. Pedicel distinctly longer than broad, pyriform or reniform; scape usually reaching beyond level of anterior margin of eye. Except in B. eximia, sp. nov., retinacula with heads entire, not lobed or fringed (Figs 96, 133) ............................... Maurobrunettia, subg. nov.

Pedicel subspherical (e.g. Fig. 35), never pyriform or reniform; scape rarely reaching level of anterior margin of eye, or if it does, heads of retinacula mostly appearing lobed or fringed

2. Apical region of style without conspicuously enlarged setae; ending in 1 or 2 sclerotised points; if only 1 , a second point is present on inner side, $\frac{3}{4}$ distance from base to apex. Wing narrow, not expanded in anal and humeral regions ..................... Plesiobrunettia, subg. nov.

Apical region of style usually with 2 or more conspicuously enlarged setae and without sclerotised points; if enlarged setae are absent, wing is expanded in anal and humeral regions ...... 3

3. Species with sparse hair, or in denuded specimens, scars, on ventral surface of epandrium, and cercopod with only 2-4 short, straight retinacula. Wings slender, membrane naked and $\mathrm{CuA}_{2}$ usually not reaching wing margin .............................. Horobrunettia, subg. nov.

Epandrium naked, cercopod with more than 4 retinacula, often some with angled stems. Wings frequently broad and vestiture usually present on membrane, at least marginally; $\mathrm{CuA}_{2}$ reaching wing margin

4. Bulbs of flagellomeres usually enlarged where ascoids are inserted, forming shoulders or, in extreme cases, wing-like projections (e.g. Figs 153, 156) bearing palmate ascoids. If flagellomeres are not obviously shouldered, some retinacula are truly bell-tipped (e.g. Fig. 163), or styles are paddle-shaped with broad rounded tips (e.g. Fig. 159), or have more than 2 enlarged distal setae, or retinacula are in 2 widely separated groups of different kinds (e.g. Fig. 142), or several of these features are present .................. Campanulobrunettia, subg. nov.

Bulbs of flagellomeres usually eccentric, but never forming paired shoulders. Ascoids very rarely palmate. Retinacula never truly bell-tipped, nor styles paddle-shaped or with more than 2 enlarged distal setae, nor retinacula segregated into widely separated groups ............ 5

5. $\quad \mathrm{R}$ fork basal to $\mathrm{M}$ fork, or if not, wing conspicuously enlarged in anal and usually also humeral region. Wing membrane covered fairly densely in hair or scales. Retinacula clustered distally, never uniseriate .............................................. subg. Brunettia Annandale

$\mathrm{R}$ fork above or distal to $\mathrm{M}$ fork and wing narrow, never enlarged in anal and humeral regions. Wing membrane naked, or with patches of hair between tips of veins, sometimes extending in bands towards base of wing; never entirely hairy, and never scaly. Retinacula usually uniseriate (Fig. 51) subg. Atrichobrunettia Satchell

There are four European Brunettia species, classified by Wagner \& Vaillant (1983) and Wagner (1984) in Atrichobrunettia but conspicuously different from Australopapuan Atrichobrunettia. They have (i) 8-10 retinacula, not uniseriate but clustered dorsally at apex of cercopod; (ii) a row of 4-5 setae at tip of style, instead of the usual pair; (iii) aedeagal apodeme elongate, laterally flattened, without lateral wings; (iv) distal region of aedeagus without the elongate forceps-like sclerotised blades of Australopapuan species.

Vaillant (1974) erected a genus, Mirousiella, to accommodate the first European Brunettia described, Pericoma angustipennis Tonnoir. Wagner \& Vaillant (1983) synonymise Mirousiella 
with Atrichobrunettia. Since Mirousiella has no special affinity with Atrichobrunettia, I here classify it as a further subgenus of Brunettia, provisionally defined by the above characters, (i)-(iv) (stat. nov.).

Subgenus Brunettia Annandale, s. str.

Brunettia Annandale, 1910: 141 (as genus). Type species: Diplonema superstes Annandale, 1908, by designation of Brunetti (1911: 310).

\section{Revised Definition}

Eyebridges of 3 facet rows, often strongly arched. Ascoids digitate, most often C-shaped.

Wings usually showing sexual dimorphism, that of $\sigma$ enlarged in anal and humeral regions and the whole sometimes exceptionally broad; wing membrane covered in prostrate hair or scales. Veins, especially $R_{1}, R_{5}$ and $\mathrm{CuA}_{1}$, generally well-sclerotised, appearing stout but less clearly delimited from membrane than in Atrichobrunettia; typically, $R_{2}-R_{4}$ and $\mathrm{M}_{1}-\mathrm{M}_{3}$ are narrowest basal to forks and appear to broaden distally, mainly due to a broadening band of sclerotisation flanking region of vein bearing scars; denuded wing with scars on veins mostly no larger or denser than on membrane between, except at bases of veins. $R$ fork almost always basal to $M$ fork; $R_{S}$ often ending at wing apex.

Male. Eyebridges frequently contiguous. Scape rarely reaching level of anterior margin of eye; pedicel subspherical.

Mesothoracic allurement organs sometimes present, sessile or raised on stalks.

Style with enlarged pre-apical setae on outer side, almost always 2 , in $B$. superstes 3 . Aedeagal apodeme rarely with lateral wings. Epandrium naked; epandrial apertures generally small, separate or occasionally linked by slit. Cercopods usually short with (i) distal cluster of longer retinacula with fringed and usually hooded tips, some generally with angled stems, and (ii) some short straight retinacula adjacent to main cluster but placed more distally or ventrally (e.g. Fig. 20).

\section{Remarks}

Quate \& Quate (1967) state that $\mathrm{CuA}_{2}$ is absent in $B$. onerata Quate and Quate, but show it clearly in their figure. Examination of a paratype $O$ of $B$. onerata from the type locality confirms that, except for the thickened base of the vein, it is absent (Fig. 152).

In B. squamipennis (Brunetti), an Indian species, the venation is radically modified by the base of $R_{3}$ switching from $R_{2}$ to $R_{4}$, precisely as in the Australian Telmatoscopus aberrans Tonnoir group. Quate $(1962 b)$ is therefore incorrect when he says that the venation of $B$. squamipennis 'is close to that of other species of Brunettia'. This apomorphism, which he overlooked, is not known in any other Brunettia.

\section{Distribution}

Subg. Brunettia is concentrated in New Guinea and the Oriental Region, but there are a few other species scattered across the southern hemisphere in southern Australia, New Caledonia, New Zealand, southern Africa, South America and the Pacific. It also occurs in Japan, although not the remainder of the Palaearctic, nor the Nearctic. Possibly some of these 'outliers' could be explained as 'the descendants of a single more dispersive ancestral form' (Duckhouse 1978a). This is undoubtedly the origin of the B. biformis group on various Pacific islands, but $\mathrm{I}$ now think that most of the others may be relicts (see below).

\section{Key to Males of Australopapuan and New Caledonian Species of subg. Brunettia}

1. $\mathrm{CuA}_{2}$ absent (without scars) except for enlarged basal region (Fig. 152) (New Guinea) .........

$\mathrm{CuA}_{2}$ present (marked by band of scars) B. onerata Quate and Quate

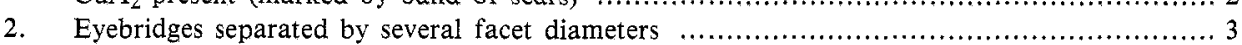

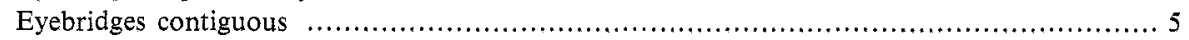

3. Eyebridges strongly arched (Fig. 16); parameres paddle-shaped and deeply notched on outer side (New Guinea) B. sedlacekae Quate and Quate Eyebridges not especially arched; parameres not paddle-shaped and not notched 
4. Scars on vertex absent from large medial area behind eyebridges and extending backwards two-thirds distance to hinder margin of head (New Guinea)

B. pumilis Quate and Quate

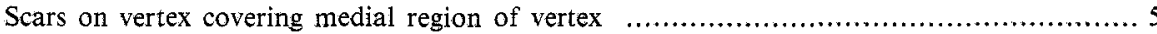

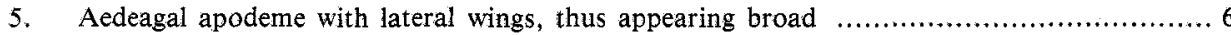

Aedeagal apodeme without lateral wings, appearing narrow (New Guinea)

B. exigua Quate and Quate

6. $\mathrm{R}$ fork distal to $\mathrm{M}$ fork (New Caledonia)

B. soror, sp. nov.

$\mathrm{R}$ fork basal to $\mathrm{M}$ fork (New Caledonia) ................................ aliceae, sp. nov.

7. $\mathrm{R}$ fork distal to $\mathrm{M}$ fork; distal blades of aedeagus about half as long as apodeme (New Guinea)

B. chydaea Quate and Quate

$\mathrm{R}$ fork basal to $\mathrm{M}$ fork; distal blades of aedeagus about as long as apodeme .............. 8

8. Wing exceptionally broad, breadth greater than distance from base of $\mathrm{R}_{2+3}$ to wing tip (New Guinea) .................................................... B. jeffliensis Quate and Quate

Wing breadth less than distance from base of $R_{2+3}$ to wing tip ............................ 9

9. Wing enlarged in anal area: distance from middle of $\mathrm{CuA}_{2}$ to wing margin nearly $2 \times$ distance from $\mathrm{CuA}_{1}$ to $\mathrm{CuA}_{2}$ at same level .................................................... 10

Wing not enlarged in anal area: distance from middle of $\mathrm{CuA}_{2}$ to wing margin about equal to

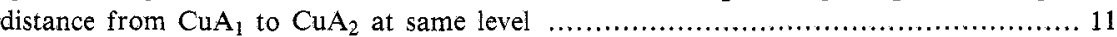

10. Style broad and rounded apically; tips of parameres rounded, broader than distal blades of aedeagus (New Guinea) .......................................... B. iota Quate and Quate

Style narrow and tapered apically; tips of parameres pointed, no broader than distal blades of aedeagus (Papua, Murua; New Guinea) ..................... B. orbicularis Quate and Quate

11. In dorsal view, style strongly concave on outer side at base (Papua, Murua; New Guinea) ... B. phainops Quate and Quate

Style straight backed, not concave on outer side at base (South Australia)

B. vivax Duckhouse

\section{Brunettia (Brunettia) vivax Duckhouse}

Brunettia vivax Duckhouse, 1966: 188.

\section{Material Examined}

Holotype. $\sigma^{\circ}$, South Australia: Hackham, 10.xii.57 (D. Duckhouse) (ANIC, type No. 6074).

This relatively plesiomorphic southern form is the only known Australian species of subg. Brunettia. Similar species occur in New Zealand (B. novae-zealandica Satchell), southern Africa $[B$, transvaalensis Duckhouse and a species said to be $B$. albonotata (Brunetti)], and South America. These may comprise a further Antarctic or Gondwanian group.

The following two New Caledonian species could be specialised offshoots of a B. vivaxlike common ancestor but also resemble the Philippine $B$. mateola Quate. They are the first psychodids to be described from this island, a fact which is of great interest because of New Caledonia's early separation from Australia-Antarctica, about 80 million years ago (Raven 1979). Its biota is continental in character, and archaic elements abound.

\section{Material Examined}

Brunettia (Brunettia) aliceae, sp. nov.

Holotype. $\bigcirc$, New Caledonia: $\mathrm{Ck}$ at Nassirah, on Bouloupari-Thio Rd, 14.xii.83, A. Wells (ANIC, type No. 6075).

Paratype. $10^{\circ}$, stream nr turnoff to Tribu Kouarga on Bouloupari-Thio Rd, 19.xii.83, A Wells (ANIC).

\section{Description}

Characterised by its strongly beaked style and very slender, parallel distal blades of the aedeagus.

Male. Head (Fig. 3) $0.82 \times$ as long as broad. Vertex rather conical, with narrow occipital lobe, scars not separated medially. Eyebridges only separated by $1 \cdot 5$ facet 
diameters, connected by sclerotisation which tends to form 2 parallel posterior spurs flanking clear spot. Frontal scar patch divided medially, shallowly cleft anteriorly; posterior prolongation to level of first facet row. Anterior tentorial pit with opening directed posterolaterally, fluted internally, connected to inner margin of eye by sclerotisation. Cibarium (Fig. 4) short and broad, thick-walled anteriorly, slightly tapered posteriorly, arms well

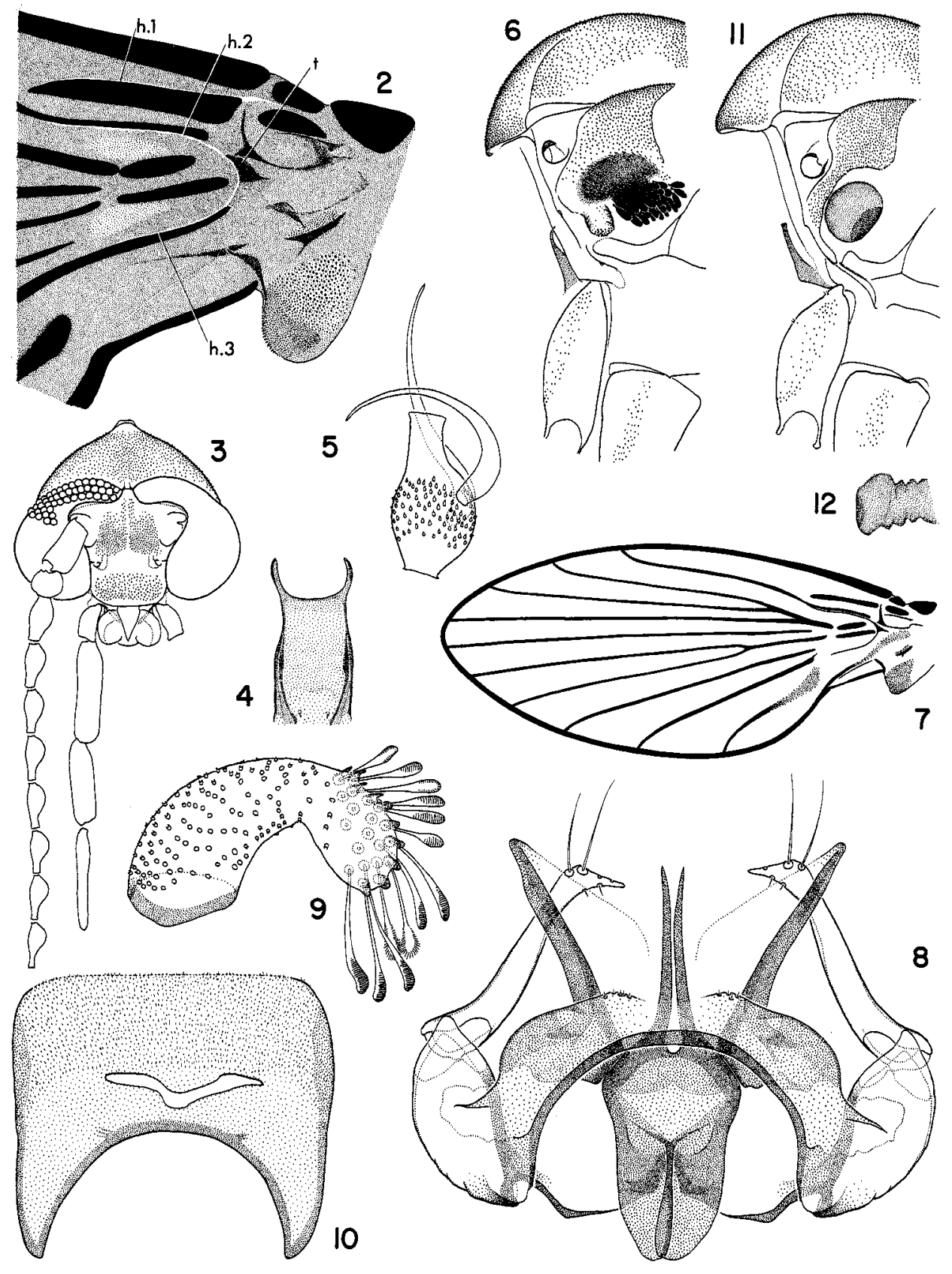

Figs 2-12. 2, Generalised diagram of base of wing in Brunettia species, showing hair lines of unsclerotised cuticle $(h .1, h .2, h .3)$ and triangular sclerotisation $(t)$. 3-10, Brunettia (Brunettia) aliceae, sp. nov., male: 3 , head; 4 , cibarium; 5 , median flagellomere and ascoids; 6 , anterior thorax, lateral; 7 , wing; 8 , gonopods and aedeagus, dorsal; 9, cercopod; 10 , epandrium, ventral. 11,12 , Brunettia (Brunettia) soror, sp. nov., male: 11, anterior thorax, lateral; 12, mesothoracic allurement organ. 
separated, curved and divergent. Palpi $(1 \cdot 0-2 \cdot 7-2 \cdot 2-2 \cdot 7) 1 \cdot 8 \times$ length of head, palpomeres 1-3 stout. Antenna incomplete; scape $1.9 \times$ length of pedicel; pedicel reaching just beyond level of anterior margin of eye. Flagellomeres (Fig. 5) with necks reaching $0.7 \times$ lengths of bulbs (flag. 8); ascoids long, paired, inflated basally, tapered beyond to slender distal halves.

Thorax (Fig. 6) uniquely specialised: allurement organs on anepisternite consisting of short, cylindrical external structure with downwardly directed apex covered in pits, adjacent to dense mass of short black scales, mostly beneath cuticle and presumably eversible. Wing (Fig. 7) abnormally narrow for this subgenus, $2 \cdot 3 \times$ as long as broad, little enlarged in anal and humeral regions; $R$ fork well basal to $M$ fork, $R_{2} 7 \cdot 6 \times$ length of $R_{2+3}, M$ only slightly basal to level of tip of $\mathrm{CuA}_{2}$. Wing veins all marked by tracts of large scars, but base of $\mathrm{CuA}_{2}$ very broad and ill-defined; membrane with bands of hair scars between veins, separated from them by scar-free zones a little broader than veins. Wing length $2 \cdot 1-2 \cdot 2 \mathrm{~mm}$.

Terminalia (Figs 8-10). Coxite short, unusually rounded; style slender, $1 \cdot 3 \times$ length of coxite, apical region enlarged, with long acute beak on inner side, arrangement of setae as shown. Aedeagus: distal blades very slender, mostly parallel, narrowly separated, or adpressed but divergent in apical quarter; apodeme broad, but narrower than aedeagus between bases of parameres; keel bifurcated posteriorly. Post-hypandrial plate short. Parameres long, strongly constricted at base then gradually tapered to tip. Epandrium (Fig. 10) microsetose in distal half; two apertures, partly or completely connected across region between. Cercopod (Fig. 9) strongly curved, roughly C-shaped; c. 20 retinacula clustered medioventrally towards apex, stems short and mostly straight, tips pale, of sporecapsule type.

Material Examined

Brunettia (Brunettia) soror, sp. nov.

Holotype. $\odot$, New Caledonia: stream nr turnoff to Tribu Kouarga on Bouloupari-Thio Rd, 19.xii.83, A Wells (ANIC, type No. 6076).

Paratype. 10 , with holotype (ANIC).

\section{Remarks}

Sister species of $B$. aliceae, distinguished by broader wing with $\mathrm{R}$ fork beyond $\mathrm{M}$ fork, style tip less beaked, and far stouter distal blades of aedeagus.

\section{Description}

Male. Head (Fig. 13) $0.9 \times$ as long as broad. Vertex larger than $B$. aliceae; broader occipital lobe, scars not separated medially. Eyebridges like $B$. aliceae, but separated by 3.6 facet diameters; sclerotisation between variable but posterior spurs convergent. Frontal scar patch broader, posterior prolongation weak and not reaching level of facets. Palpi $(1 \cdot 0-4 \cdot 0-3 \cdot 0-3 \cdot 8) 1 \cdot 9 \times$ length of head, palpomere 2 more elongate than $B$. aliceae. Antenna incomplete, similar to $B$. aliceae, necks reaching $0.54 \times$ lengths of bulbs (flag. 8 ).

Thorax (Fig. 11) with mushroom-shaped allurement organ (Fig. 12) on anepisternitestalk coarsely and irregularly annulated, presumably extensible; head densely microsetose with area of pits on one side. Compared with $B$. aliceae, wing (Fig. 14) $2 \cdot 2 \times$ as long as broad, anal region more enlarged, anterior margin more convex; $R$ fork beyond $M$ fork, $R_{2}$ $4 \cdot 1 \times$ length of $\mathrm{R}_{2+3}$; most distal fork further basal to tip of $\mathrm{CuA}_{2}$ than $B$. aliceae; other details as for $B$. aliceae. Wing length $2.1 \mathrm{~mm}$.

Terminalia (Fig. 15). Compared with $B$. aliceae: coxite slightly longer, less rounded; style $1 \cdot 3 \times$ length of coxite, apical region less beaked, uncinate, arrangement of setae as shown. Distal blades of aedeagus stouter, shorter, mostly parallel, adpressed in middle, divergent in apical third; apodeme very broad, about equal to width of aedeagus between bases of parameres, anterior end truncate; keel not bifurcated anteriorly. Parameres broader-based, more strongly tapered to tips. Epandrium similar, but anterior arms connected with ends of hypandrium by hair-like sclerotisations (Fig. 15s); apertures united, forming dumb-bell shape. Cercopod less curved, only c. 13 retinacula, clustered as in B. aliceae; tips darkly sclerotised. 
Brunettia (Brunettia) sedlacekae Quate and Quate

Brunettia sedlacekae Quate and Quate, 1967, 113-6.

\section{Material Examined}

Holotype. of, New Guinea: Wau, $1200 \mathrm{~m}$, Malaise trap, 13-17.xii.61, J. Sedlacek (BPB, type No. 7290).

Paratype. $\sigma$, with holotype (ANIC).

Other specimen. 10, Morobe Prov., Wau Ecology Inst., pond by zoo, $1200 \mathrm{~m}$, light trap, 29.v.86, A. Wells (ANIC).

\section{Remarks}

Differing from other Brunettia species in the partial separation of eyebridges from main parts of eye-intermediate facets reduced to a single row; paired distal setae of style very enlarged; paramere notched basally, with prominent sclerotised process from lobe on outer side of notch extending anteromedially and almost meeting process on other side. The Quates' figure of gonopods and aedeagus is sketchy and does not show the latter process. Their description is augmented as follows:

\section{Description}

Male. Head (Fig. 16) $0.95 \times$ as long as broad. Vertex bulging behind eyes, no median scar-free band. Eyebridges strongly arched, reduced at bases to single row of facets or two incomplete rows of widely separated facets, bridges, thus, almost divided from main parts of eyes; separation of 7.6 facet diameters. Frontal scar patch divided by median scar-free band; anteriorly, forming 2 rounded lobes. Anterior tentorial pit small, opening directed posterolaterally; tube thin, elbowed beyond pit, small lateral sclerotisation arising where tube joins rim of ventral aperture. Cibarium almost unsclerotised in posterior half. Labellum with enlarged posterior setae forming precise line as in B. heterostylis sp. nov. (Fig. 155) but setae shorter. Palpi $(1 \cdot 0-4 \cdot 9-5 \cdot 9-6 \cdot 1) 1 \cdot 7 \times$ length of head. Scape long, almost reaching anterior margin of eye; $2.7 \times$ length of pedicel. Flagellomeres with necks reaching $0.4 \times$ lengths of bulbs (flag. 6). Ascoids finely annulated.

Thorax (Fig. 17). Allurement organ not a 'patagium' (=prothoracic organ) as stated by Quate and Quate, but originating from dorsal region of anepisternite; clavate, bulb bearing numerous pits; stalk long, membranous, finely and irregularly annulated, presumably extensible. Wing, Fig. $18,2 \cdot 1 \times$ as long as broad; $R_{2} 6 \cdot 9 \times$ length of $R_{2+3}$. Wing length $2.07 \mathrm{~mm}$.

Terminalia (Figs 19, 20, 22). Gonopods short; style $1 \cdot 1 \times$ length of coxite, enlarged in distal quarter; paired setae massive, bases touching, shafts little tapered, blunt-tipped. Aedeagus: distal blades exceptionally short, adpressed; racquet region broad anteriorly with exaggerated shoulders for articulation with parameres, constricted posteriorly; apodeme long, laterally flattened, in dorsal view appearing strongly keeled, without lateral wings. Parameres very broad and paddle-shaped, outer side with triangular lobe at base of paddle, separated by notch; prominent sclerotised process from lobe extending anteromedially, almost meeting process on other side. Hypandrium arched strongly backwards on either side but reaching less far than in most Brunettia species; curved forward again in midline. Epandrium (Fig. 19): two tiny apertures; ventral surface transversely wrinkled, finely microsetose. Cercopod (Fig. 20) short, clear differentiation between 4 clavate ventral retinacula and distal cluster of $c$. 15 retinacula with angled stems and fringed, hooded tips.

Subgenus Plesiobrunettia, subgen. nov.

Type species: Atrichobrunettia bisulca Quate and Quate, 1967, by present designation.

\section{Remarks}

The two species of Plesiobrunettia were described by Quate and Quate as species of Atrichobrunettia. They are very basal cladistically and it was partly because of this that Duckhouse (1987) referred to Atrichobrunettia as the most plesiomorphic subgenus of Brunettia'. 
Whilst re-examining Brunettia species for this revision it became apparent that $B$. bisulca (Quate and Quate) and its sister species, B. bisulcoides (Quate and Quate) share little except plesiomorphisms with Atrichobrunettia. They also lack important characteristics of the genus Brunettia, and are strikingly similar to Gerobrunettia in male and female genital characters. Hence, it is incorrect to treat them as Atrichobrunettia species.
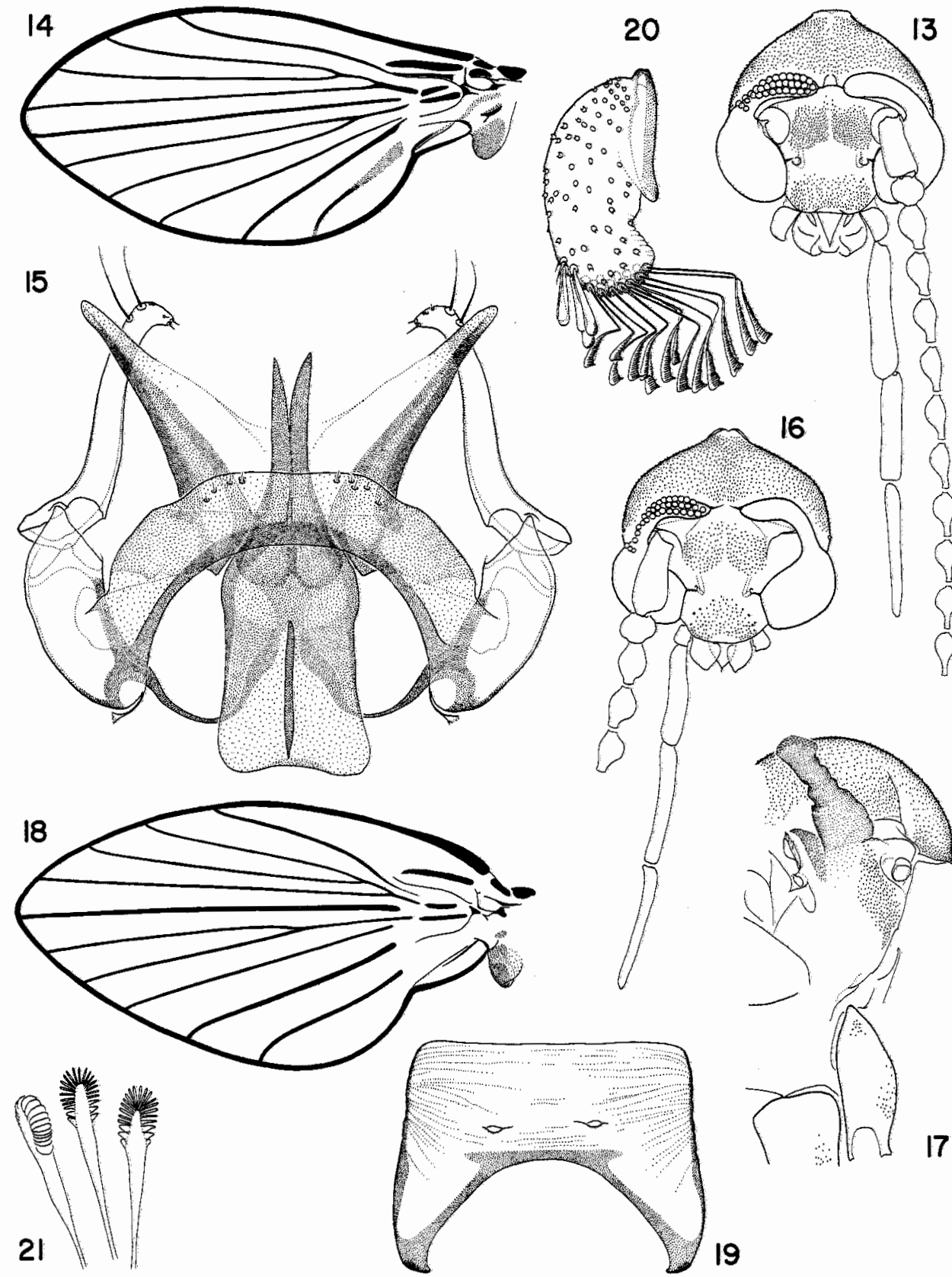

Figs 13-21. 13-15, Brunettia (Brunettia) soror, sp. nov., male: 13, head; 14, wing; 15, gonopods and aedeagus, dorsal. 16-20, Brunettia (Brunettia) sedlacekae Quate and Quate, male: 16, head; 17, anterior thorax, lateral; 18 , wing; 19, epandrium, ventral; 20, cercopod. 21, Brunettia (Atrichobrunettia) scitula Duckhouse, male: retinacula in frontal and oblique views. 
Definition

Male. Eyebridges with 3 facet rows, separated by 3-4 facet diameters, tending to attenuate medially. Scape short, not reaching level of anterior margin of eye; pedicel subspherical; ascoids palmate.

Wing narrow, not enlarged in anal or humeral region; $\mathbf{R}$ fork slightly distal to $\mathrm{M}$ fork, at about level of tip of $\mathrm{CuA}_{2}$; wing apex pointed, just anterior to tip of $\mathrm{R}_{5}$.

Style uncinate, curved outwards distally, concave on outer side; apical region without the enlarged setae typical of Brunettia, but with 2 darkly sclerotised points forming a pair as in some Gerobrunettia species, or second point about $\frac{3}{4}$ way from base to apex. Aedeagal blades form turning-fork shape as in Gerobrunettia (bisulcoides) or blades adpressed in typical Brunettia fashion (bisulca); parameres not visible as separate blades; in dorsal view, aedeagal apodeme narrow, parallel-sided. Cercopod short as in many species of subg. Brunettia; numerous retinacula, mostly fringed distally and with hooded tips, others capitate, some strongly curved or angled.

Female. Subgenital plate very short; distal lobes short, broad, convergent, not connected at base, flanking large digitate genital flap that is without median rod or sclerotisation.

\section{Distribution}

Plesiobrunettia is so far only known from Irian Jaya.

\section{Key to Males of Australopapuan Species of subg. Plesiobrunettia}

1. Style bifurcated apically, giving 2 points of almost equal size (New Guinea)

B. bisulca (Quate and Quate), comb. nov. Style not bifurcated but with small spike-like spur on medial margin, $\frac{3}{4}$ way from base to apex (New Guinea) G. bisulcoides (Quate and Quate), comb. nov.

\section{Subgenus Atrichobrunettia Satchell}

Atrichobrunettia Satchell, 1953a: 413 (as genus). Type species: Atrichobrunettia alternata Satchell, 1953 , by original designation.

Atrichobrunettia Satchell, Duckhouse, 1987: 263 (as subgenus).

\section{Remarks}

Duckhouse (1966) considered that because Atrichobrunettia has typical Brunettia-type venation, genitalia and antennae, and some species also have patches of hair on the wing membrane, it has no value as more than a species group. Quate \& Quate (1967) treat it as a separate genus and say it is well separated from its sister group (p. 212), but their definition consists almost entirely of characters shared with Brunettia s. str. Of those that are not fully shared, 'eyes separated' also occurs very commonly in Brunettia s. str., while some Atrichobrunettia have no separation between the eyes ( $B$. alternata group). Finally, 'thorax without patagium' (prothoracic allurement organ) is incorrect: species of both taxa commonly have mesothoracic allurement organs, but prothoracic organs are unknown in Mormiini. Thus, although like Satchell before them the Quates sensed a distinction, like him they did not succeed in defining it. Wagner \& Vaillant (1983) rank Atrichobrunettia as a genus without comment. My earlier view of Atrichobrunettia was later revised to the extent of recognising it as a subgenus of Brunettia (Duckhouse 1987) but I emphasise (i) that the limits between this and other subgenera are ill-defined, and (ii) that some of its most conspicuous characters appear to be plesiomorphisms (wing narrow, that of $0^{*}$ not broadened in anal and humeral regions; eyebridges often widely separated; retinacula uniseriate; aedeagal apodeme with lateral wings).

\section{Revised Definition}

Male and Female. Eyebridges with 3 or 4 facet rows, never strongly arched; contiguous or separated. Scape rarely reaching level of anterior margin of eye; pedicel subspherical. Ascoids digitate, or flattened and leaf-like with longitudinal striations, or rarely palmate. 
Wing narrow, not enlarged in anal or humeral region; membrane often with marginal patches of prostrate hair but never entirely hairy, and never scaly; veins rather uniform in thickness; $\mathrm{R}$ fork above or distal to $\mathrm{M}$ fork; wing apex usually rather rounded and placed between tips of $R_{4}$ and $R_{5}$.

Male. Mesothoracic allurement organs sometimes present, always sessile.

Style curved inwards distally, always with pair of enlarged pre-apical setae on outer side. Aedeagal apodeme usually with strong lateral wings. Epandrium: posterior margin straight; apertures enlarged and frequently confluent, sometimes forming enormous ovate aperture (e.g. Fig. 26). Cercopod with 5 or more retinacula, usually uniseriate, stems rarely angled (B. foliacea group); tips generally as in Fig. 21, having central axis with fringe of stout radiating leaflets forming distal enlargement, and except in direct frontal view reminiscent of spore capsule of Pteridium; but tips of hooded type in B. foliacea group. Cercopod usually with area of sclerotisation on inner side, running along middle of row of retinacula, and cluster of shaftless sensilla abutting sclerotisation (e.g. Fig. 27).

\section{Distribution}

Atrichobrunettia is restricted to Australia and Papua-New Guinea. It apparently reaches its greatest diversity in northern New South Wales and eastern Queensland. There are as yet no records for northwestern Australia or the Northern Territory.

\section{Key to Males of Species of subg. Atrichobrunettia}

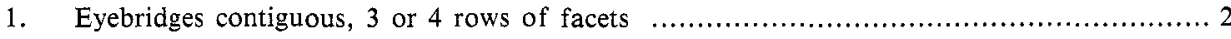

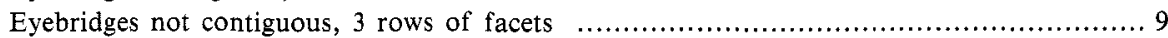

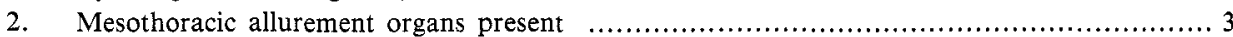

Mesothoracic allurement organs absent (southwestern Australia) .... B. subalternata (Satchell)

3. Eyebridges of 3 facet rows (southeastern Australia, Tasmania)

B. alternata (Satchell) and $B$. scitula Duckhouse

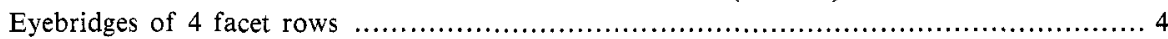

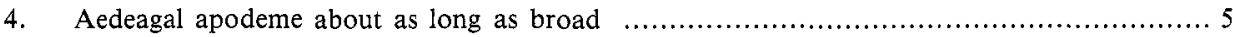

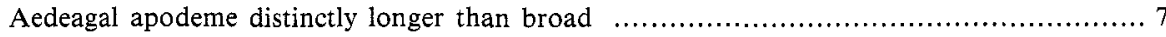

5. Distal blades of aedeagus not extending beyond post-hypandrial plate (South Australia) .......

B. napaea, sp. nov.

Distal blades of aedeagus not extending beyond post-hypandrial plate, appearing enclosed

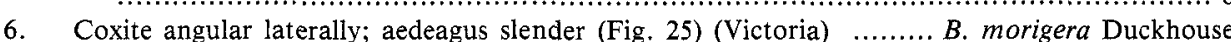
Coxite rounded laterally; aedeagus exceptionally stout (Fig. 56) (New South Wales, Queensland)

B. curta, sp. nov.

7. Aedeagal apodeme about $3 \times$ as long as broad; ascoids leaf-shaped (Queensland)

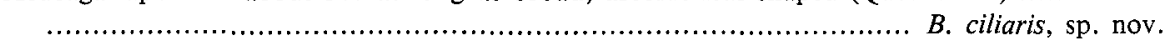

Aedeagal apodeme less than $2 \times$ as long as broad, ascoids digitate ........................ 8

8. Style squat, not longer than coxite (Fig. 39) (Queensland) ................ B. robusta, sp. nov.

Style slender, longer than coxite (Fig. 58) (New South Wales) ............. B. collessi, sp. nov.

9. Scape reaching far beyond anterior margin of eye (Queensland) ......... B. albifrons, sp. nov.

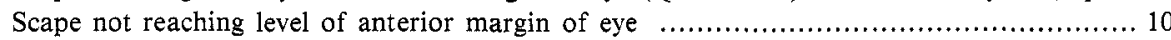

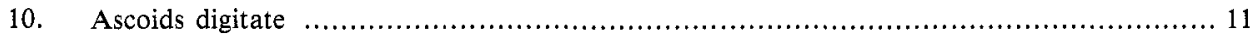

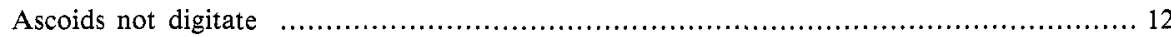

11. Aedeagal apodeme short and sharply truncated (New South Wales, Queensland) ................

B. tricorniculata, sp. nov.

Aedeagal apodeme neither short nor truncated (New Guinea)

12. Ascoids leaf-shaped and striated........................... B. solita (Quate and Quate), comb. nov.

Ascoids palmate ....................................................................... 15

13. In dorsal view, profile of style strongly concave basally on outer side; aedeagus with apodeme broader than middle region (Fig. 68) (Queensland) ................. B. angulosa, sp. nov.

Profile of style not strongly concave on outer side; aedeagus with apodeme narrower than middle

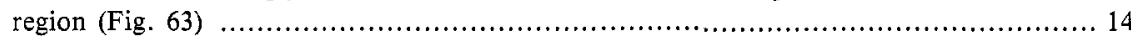

14. Distal blades of aedeagus slender and convergent (Queensland) .......... B. foliacea, sp. nov

Distal blades of aedeagus stout and parallel (New Guinea; Papua, Murua)

B. spadix (Quate and Quate), comb. nov. 
15. Eyebridges separated by distance greater than their width (New Guinea)

B. pallescens (Quate and Quate), comb. nov.

Eyebridges separated by distance less than their width (New Guinea)

B. antennata (Quate and Quate), comb. nov.

\section{alternata Satchell group}

Male eyebridges of 4 or occasionally 3 facet rows, contiguous; ascoids leaf-shaped with longitudinal striations, or digitate; retinacula uniseriate, spore-capsule type (Fig. 21).

\section{Brunettia (Atrichobrunettia) alternata (Satchell)}

Atrichobrunettia alternata Satchell, 1953a: 413.

Brunetia alternata.-Duckhouse, 1966: 188.

Material Examined

Holotype. ơ, Tasmania: Natl Pk, 6.xii.22 (not 11.xii.22, as stated by Satchell), A. L. Tonnoir (ANIC).

\section{Remarks}

The holotype was mounted by Tonnoir on celluloid strips in his characteristic way, and from the condition and aspect of the various parts, probably only one of Satchell's figures, that of the gonopods and aedeagus, was drawn from this specimen. As pointed out by Duckhouse (1966), the ascoids of the holotype are leaf-shaped, not digitate as shown by Satchell, who was actually dealing with a mixed series of two similar species. Other points in the description that should be corrected or amplified are as follows: the holotype has lateral wings on the aedeagal apodeme; the paired spines on the style are at least twice as long as in Satchell's figure; the epandrium has a single large ovate aperture; the wing is less pointed than Satchell shows and the $\mathrm{M}$ fork is far basal to the tip of $\mathrm{CuA}_{2}$.

Duckhouse (1966) described a second subspecies, B. alternata scitula, from the Grampian Mtns, Victoria, whose mesothoracic allurement organs are small, with less than 50 pores. In $B$. alternata alternata they are over twice that size. Duckhouse \& Lewis (1989) recognise $B$. alternata scitula as a full species.

\section{Brunettia (Atrichobrunettia) subalternata (Satchell)}

Atrichobrunettia subalternata Satchell, $1953 a: 416$.

Material Examined

Holotype. ơ, Western Australia: Pemberton, 2.xii.36, K. R. Norris (ANIC).

Allotype. \%, with holotype.

\section{Remarks}

Duckhouse (1966) suggested that $B$. subalternata might be only subspecifically distinct from $B$. alternata, but greater knowledge of this group now convinces me that it is a separate species. The holotype is as follows:

\section{Description}

Male. Eyebridges of 3 facet rows, separated by about $1 \cdot 5$ facet diameters. Vertex without median scar-free band. Frontal scar patch undivided except anteriorly, posterior prolongation to between eyebridges. Anterior tentorial tubes elbowed forward. Cibarial arms widely separated, very long, $0.3 \times$ length of cibarium. Antenna with ascoids leaf-shaped, longitudinally striated.

Thorax without allurement organs. Wing with $\mathrm{M}$ fork well beyond level of tip of $\mathrm{CuA}_{2}$.

Terminalia (Fig. 23). LH gonopod missing; RH gonopod with style $0.96 \times$ length of coxite; tip of style with paired spines far longer and thinner than shown by Satchell. Aedeagal apodeme not divided medially as shown by Satchell, but with well defined median keel. Epandrium with pair of close-set rounded apertures.

My characterisation of the allotype as untenable (Duckhouse 1966) was incorrect. It was collected with the holotype and appears to be conspecific. 


\section{Brunettia (Atrichobrunettia) morigera Duckhouse}

Brunettia morigera Duckhouse, 1966: 192.

\section{Material Examined}

Holotype. $\sigma$, Victoria: Cann R, light trap, 21.iii.62, N. Dobrotworsky (ANIC, type No. 6078).

\section{Description}

The following details supplement the original description.

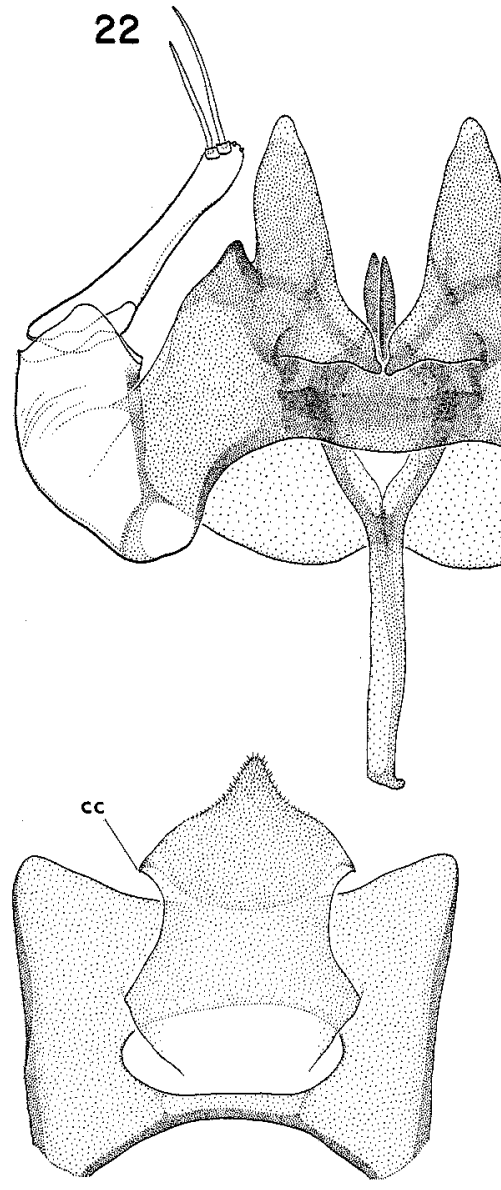

26

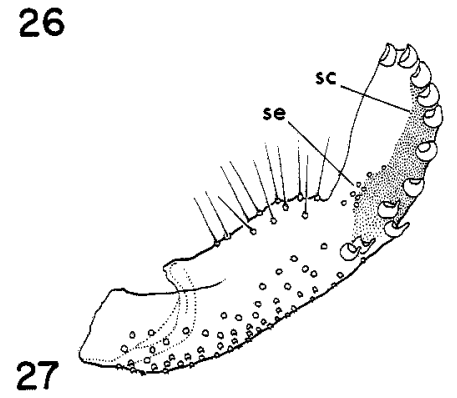

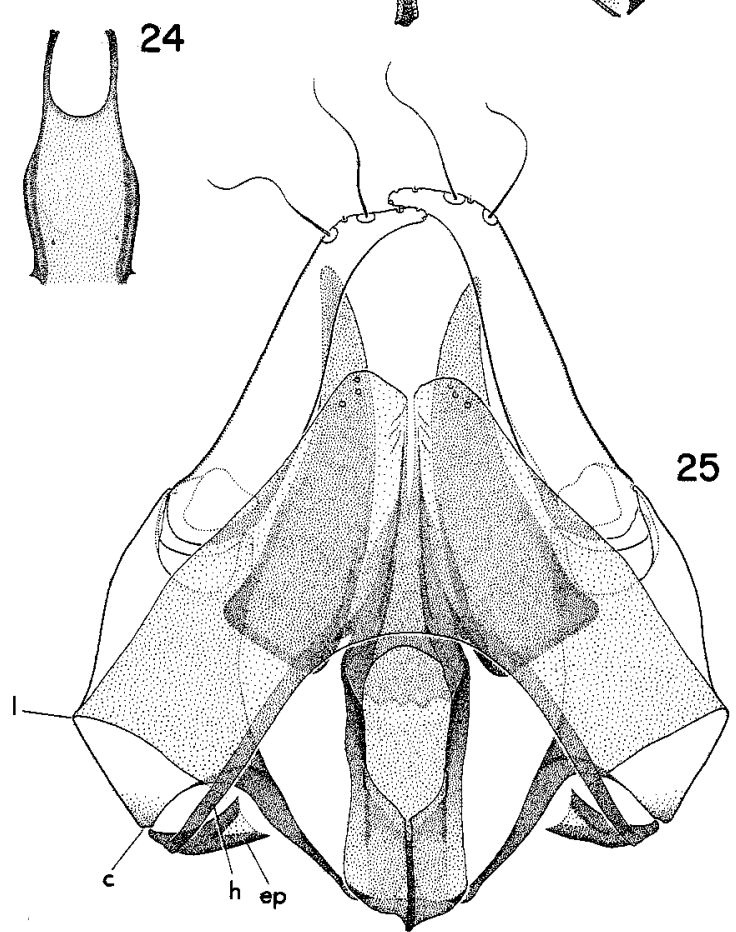

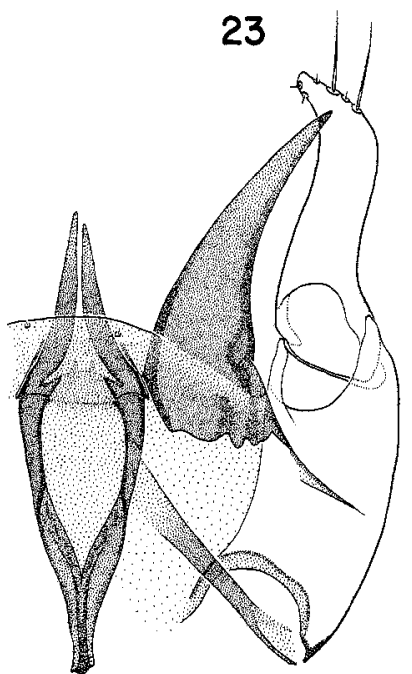

Figs 22-27. 22, Brunettia (Brunettia) sedlacekae Quate and Quate, male: gonopods and aedeagus, dorsal. 23, Brunettia (Atrichobrunettia) subalternata (Satchell), male: LH gonopod and aedeagus, dorsal. 24-27, Brunettia (Atrichobrunettia) morigera Duckhouse: 24, cibarium; 25, gonopods and aedeagus, dorsal ( $l$, lateral projection; $c$, condyle; $e p$, epandrium; $h$, hypandrium); 26 , epandrium and tenth tergite, dorsal ( $c c$, condyle for articulation with cercopod); 27 , cercopod ( $s c$, area of sclerotisation; se, shaftless sensilla). 
Male. Cibarium (Fig. 24). Walls not thick anteriorly; arms very long, slender; posterior margin between arms strongly concave.

Wing: $R_{2}$ equal to $2 \cdot 5 \times$ length of $R_{2+3}$. Wing length $2 \cdot 15 \mathrm{~mm}$.

Terminalia (Figs 25-27). Coxite showing angular lateral projection at point of fusion with post-hypandrial plate (Fig. 25l); angular anterior projection bearing apical condyle (c) for articulation with anterior arms of epandrium ( $e p$, discussion below). Ends of hypandrium (h) attached to anterior arms of epandrium. Style long, $1.2 \times$ length of coxite, evenly tapered to level of first of paired setae, then curved strongly inwards and more abruptly constricted to narrow tip; paired setae long, flexible. Apex of post-hypandrial plate drawn out to form paired lobes closely flanking blades of aedeagus, which they exceed. Aedeagus $1.45 \times$ length of parameres; blades long, thin, needle-like distally; lateral arms anterior to bases of parameres straight; apodeme broad, strongly keeled. Parameres stout, curved and very evenly tapered to rounded tips. Epandrium (Fig. 26) with single large ovate aperture, $0.55 \times$ its width; long tapered anterior arms articulating with condyles on coxites; cercopod (Fig. 27) with 11 retinacula. Tenth tergite with sharply angular lateral condyles for articulation with cercopods (Fig. 26cc).

\section{Remarks}

The normal arrangement in subg. Atrichobrunettia is for the anterior ends of the hypandrium to fuse with the bases of the coxites (possibly their parabasal processes) above, and for the anterior arms or angles of the epandrium to articulate with the bases of the coxites below. The terminalia of $B$. morigera differ in that the coxite has an angular anterior projection (condyle) with which the combined ends of the epandrium and hypandrium articulate. At first sight, I thought that this arrangement might be an artefact caused by fracturing, the normal condition being for the angular projection to be continuous with the epandrium. However, the specimen is precisely the same on both sides, and the tips of the processes on the coxites and the epandrial arms have rounded, not broken, edges. A similar arrangement appears to be present in B. subalternata (Fig. 23). In effect, the condyles for articulation of the epandrium have shifted from ventral to anterior, so that in a dorsal view they are now seen in profile rather than being hidden on the underside of the coxite.

\section{Material Examined}

Brunettia (Atrichobrunettia) ciliaris, sp. nov.

Holotype. $\sigma^{\circ}$, Queensland: Lamington Natl Pk, Binna-Burra to Coomera Falls, 15.vi.70, D. and S. Duckhouse (ANIC, type No. 6079).

Paratypes. $1 \%$ (allotype) and $30^{\circ}$, with holotype (ANIC, BMNH, BPB); $30^{\circ}$, New South Wales: Dorrigo-Coramba $24 \mathrm{~km}, 17$. .iii.71, Duckhouse.

\section{Description}

Similar to $B$. morigera but with longer, narrower aedeagal apodeme, tips of styles broadly rounded, and head with prominent occipital lobe.

Male. Head (Fig. 28) $0.85 \times$ as long as broad; vertex swollen on either side, no median scar-free band, occipital lobe prominent. Eyebridges of 4 facet rows; dot of sclerotisation in midline posterior to eyebridges. Frontal scar patch divided, no posterior prolongation. Anterior tentorial pit thick-lipped. Cibarium (Fig. 29) thick-walled anteriorly, strongly tapered posteriorly and arms accordingly very close-set; posterior edge of cibarium between arms a straight line. Anterior margin of clypeus rounded. Microsetae on margin of labrumepipharynx large and prominent, seen in dorsal view as extending far beyond edges of labrum (Fig. 30). Palpi $(1 \cdot 0-3 \cdot 4-3 \cdot 2-4 \cdot 2) 1 \cdot 8 \times$ length of head. Antennal tip missing from all specimens; scape slender, $2.0 \times$ length of pedicel; pedicel not reaching level of anterior margin of eye; flagellomeres (Fig. 31) with paired longitudinally striated leaf-shaped ascoids.

Thorax: allurement organ on anepisternite sessile; large, but less so than $B$. morigera. Wing (Fig. 32) similar to $B$. morigera; $\mathrm{R}_{2} 2 \cdot 2 \times$ length of $\mathrm{R}_{2+3}$; R fork beyond $M$ fork, both basal to level of tip of $\mathrm{CuA}_{2}$; marginal patches of scars on membrane as in most Atrichobrunettia spp. Wing length $2 \cdot 2-2 \cdot 75 \mathrm{~mm}$.

Terminalia (Fig. 33). Style $0.9 \times$ as long as coxite, stouter than $B$. morigera, region beyond paired setae very short and rounded; paired setae about equal in length. Aedeagus 
long, $1.8 \times$ length of parameres; distal blades stout, convergent, not overlapping, tips close-set; lateral arms straight and divergent, apodeme exceptionally long, narrow, strongly keeled. Hypandrium narrow, forming characteristic acute angle between coxites. Parameres very stout, tapered strongly in basal halves: deep concavity on outer side, midway from base to tip. Epandrium and associated structures similar to $B$. morigera but epandrial aperture less distinct; cercopod with 8-9 retinacula.
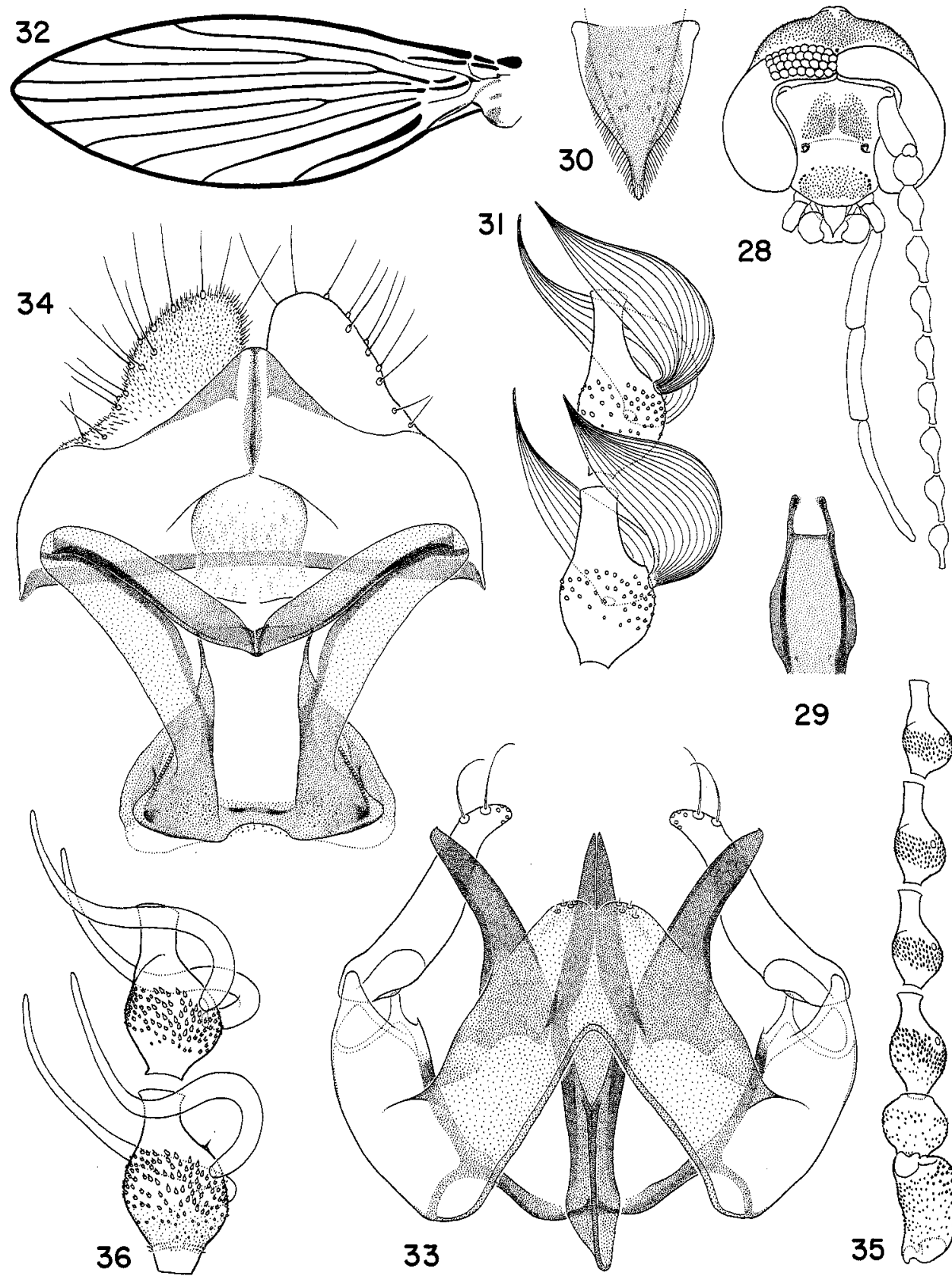

28
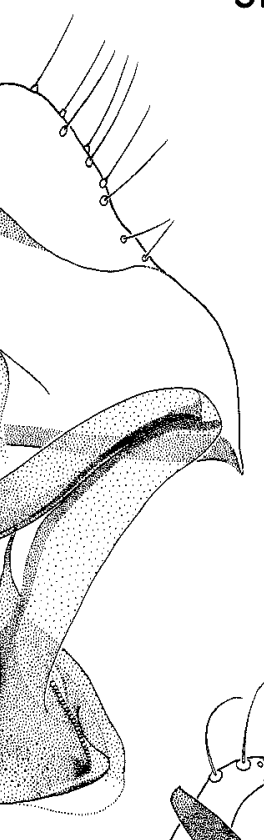

29
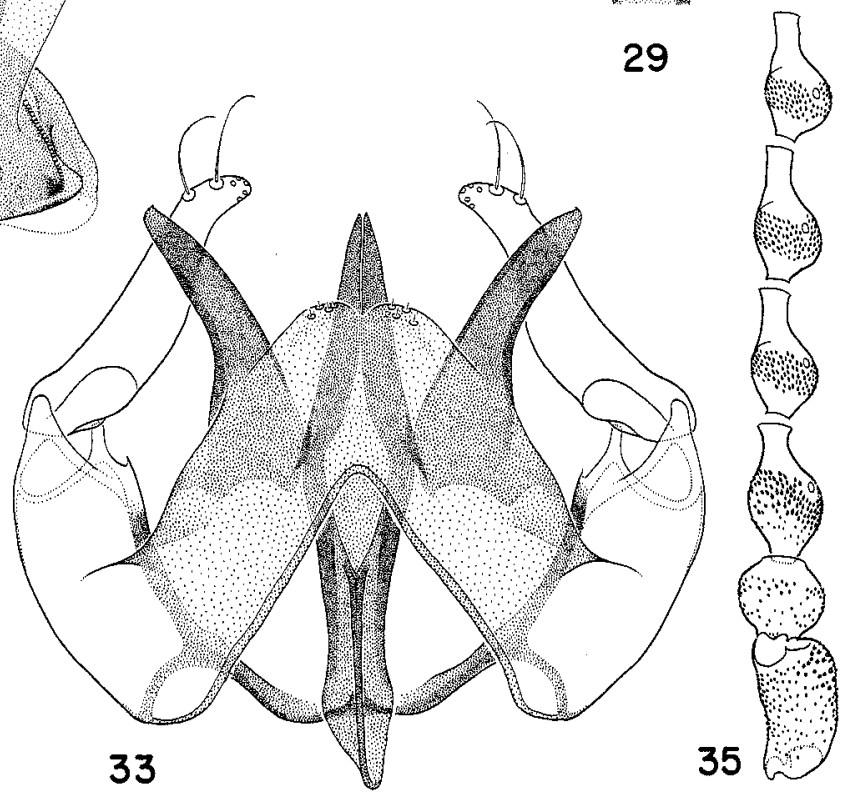

35

Figs 28-36. 28-33, Brunettia (Atrichobrunettia) ciliaris, sp. nov., male and 34, female: 28, head; 29 , cibarium; 30, labrum and labrum epipharynx; 31 , flagellomeres 2 and $3 ; 32$, wing; 33, gonopods and aedeagus, dorsal; 34, subgenital plate and associated structures, dorsal. 35, 36, Brunettia (Atrichobrunettia) robusta, sp. nov., male: 35, base of antenna; 36, flagellomeres 1 and 2 . 
Female. Head: eyebridges with only 3 rows of facets, separated by 1.4 facet diameters. Cibarium as in $\sigma^{*}$. Antennal flagellomeres far smaller than $\sigma^{\prime}$, ascoids not discernible.

Wing narrower than or; $\mathrm{R}$ fork beyond level of $\mathrm{CuA}_{2} ; \mathrm{R}_{2}$ equal to $2 \cdot 3 \times$ length of $\mathrm{R}_{2+3}$. Wing length $2 \cdot 1 \mathrm{~mm}$.

Subgenital plate and spermathecae, Fig. 34. Distal lobes of plate close-set, narrowing from base to apex, dorsal surface with 2 sensory setae (RHS) and 1 (LHS). Apodemes very large in proportion to plate. Spermathecae angular, connected by stout median bridge, ladder thickening slender. Ovipositor $2.7 \times$ length of subgenital plate.

\section{Material Examined}

\section{Brunettia (Atrichobrunettia) robusta, sp. nov.}

Holotype. or, Queensland: Mt Hypipamee St. For., 1050 m, 29.iv.71, D. and S. Duckhouse (ANIC, type No., 6080).

Paratypes. $60^{\circ}$, with holotype (ANIC, BMNH, BPB); $20^{\circ}$, same locality, 14.iv.71, Duckhouse (ANIC).

\section{Description}

A species with robust style, very distinctive in shape, basal half concave on outer side and correspondingly swollen on inner side; male eyebridges of 4 facet rows, contiguous.

Male. Head (Fig. 37) $0.9 \times$ as long as broad. Vertex compact, very rounded on either side, but not appearing swollen; occipital lobe large, indented apically; scars indistinctly separated medially. Eyebridges with 4 rows of large facets. Frontal scar patch without median extension, narrowly divided medially, triangular cleft anteriorly. Anterior tentorial pit small, linked to median edge of eye by faint sclerotisation (lateral extremity of frontoclypeal suture). Cibarium (Fig. 38) slender, posterior arms long, sclerotised distally. Clypeus very narrow, rounded. Palpi $(1 \cdot 0-2 \cdot 9-2 \cdot 5-3 \cdot 3) 1 \cdot 4 \times$ length of head; sparse sensory rods on palpomere 1 . Antenna $2 \cdot 2 \times$ length of palp and $0.6 \times$ length of wing. Base of antenna, Fig. 35; scape $1.75 \times$ length of pedicel; pedicel not nearly reaching level of anterior margin of eye; flagellomeres with ascoids (Fig. 36) digitate, sinuous, stout, far longer than flagellomeres.

Thorax: spiracle set low, in concavity of anepisternite. Anepisternite with small allurement organ anteriorly, flush with surface. Wing very similar to $B$. napaea (Fig. 49 ); $3 \cdot 1 \times$ as long as broad; $R_{2} 2.45 \times$ length of $R_{2+3}$; large patches of scars on membrane between tips of $\mathrm{R}_{1}-\mathrm{CuA}_{2}$. Wing length $1 \cdot 85-2 \cdot 1 \mathrm{~mm}$.

Terminalia (Figs 39-42). Style $0.9 \times$ length of coxite, robust; basal half strongly concave on outer side and correspondingly swollen on inner side; strong longitudinal ridge (Fig. 39r) on upper surface, apex short and very broad, paired apical setae long; variation, Figs 39-41. Coxite stout, with strong lateral groove $(l g)$. Aedeagus normal in length $(1 \cdot 6 \times$ length of parameres) but narrow, with straight lateral arms; distal blades almost parallel, not overlapping, tips widely separated; apodeme about $1.5 \times$ as long as broad, spatulate, wings rounded in outline, keel strong. Parameres slightly divergent, parallel-sided in distal halves, then abruptly narrowed to pointed tips. Post-hypandrial plate a high truncated cone. Epandrium (Fig. 42) $0.5 \times$ as long as broad; single very large aperture, $0.5 \times$ width of epandrium. Cercopod squat, 6-8 retinacula.

Brunettia (Atrichobrunettia) napaea, sp. nov.

\section{Material Examined}

Holotype. Ơ, South Australia: Adelaide Hills, Turners Gully, nr Clarendon, 2.ix.77, Duckhouse (ANIC, type No. 6081).

Paratype. 10 (allotype), same loc., at light, 16.ix.78, Duckhouse (ANIC); 10*, same loc., 11.ix.78, Duckhouse (ANIC).

\section{Description}

Similar to $B$. robusta but styles less heavily constructed, with apical region longer; antennae more elongate and ascoids digitate. 
Male. Head (Fig. 43) $0.9 \times$ as long as broad. Vertex less rounded on either side than $B$. robusta; occipital lobe smaller, deeply indented apically; scars distinctly separated medially. Eyebridges with 4 rows of large facets. Frontal scar patch clearly divided. Anterior tentorial pits larger than B. robusta. Cibarium (Fig. 44) stout with characteristic lateral thickenings; constricted posteriorly; posterior arms divergent from constriction, knobbed and sclerotised distally. Clypeus broader than $B$. robusta, angular. Palpi $(1 \cdot 0-$ $2 \cdot 5-2 \cdot 1-2 \cdot 6) 1 \cdot 33 \times$ length of head; transverse row of 3 sensory rods on dorsal side of

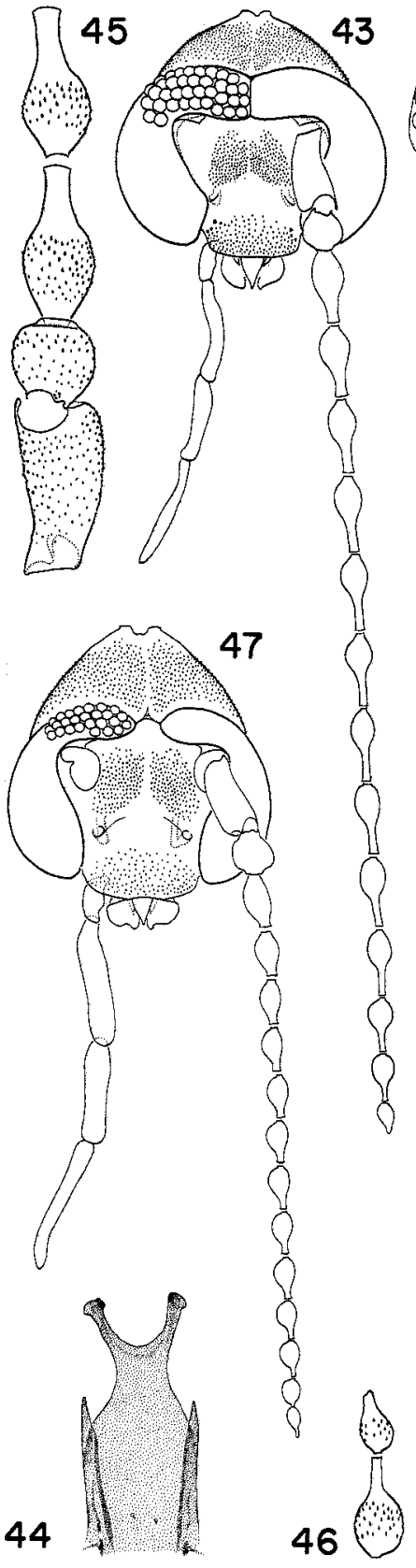

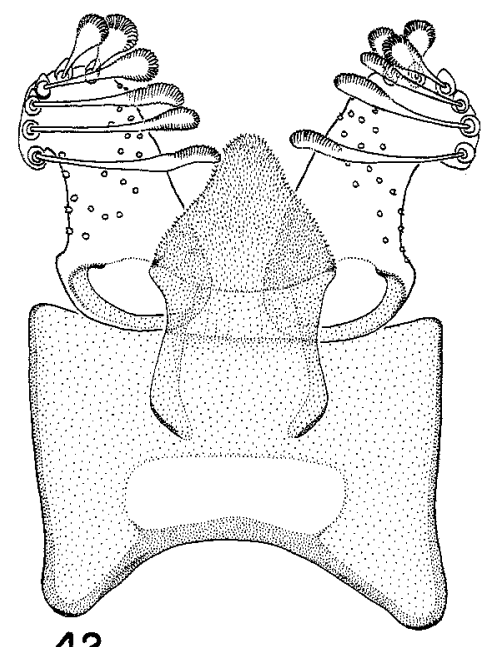

42
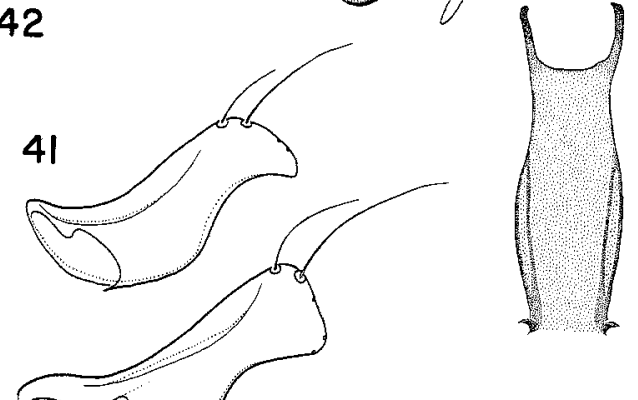

38

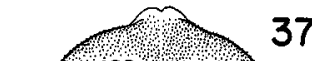

37

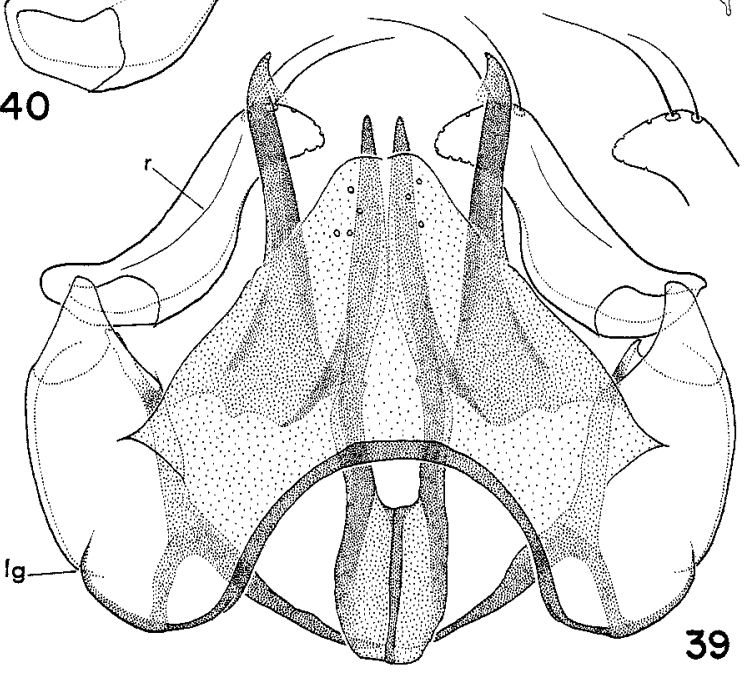

Figs 37-47. 37-42, Brunettia (Atrichobrunettia) robusta, sp. nov., male: 37, head; 38, cibarium; 39 , gonopods and aedeagus, dorsal, inset showing tip of style ( $r$, longitudinal ridge; $l g$, lateral groove); 40,41 , variation in form of style; 42 , epandrium, tenth tergite and cercopods, dorsal. 43-46, Brunettia (Atrichobrunettia) napaea, sp. nov., male and 47, female: 43 , head; 44 , cibarium; 45 , base and 46 , tip of antenna; 47 , head. 
palpomere 1 . Antenna $2.9 \times$ length of palp and $0.66 \times$ length of wing. Base of antenna, Fig. 45 ; scape $2 \cdot 0 \times$ length of pedicel, pedicel reaching level of anterior margin of eye; median flagellomeres (Fig. 48) longer than B. robusta (flag. 6 of holotype with neck $1 \cdot 1 \times$ length of bulb). Antennal tip, Fig. 46; penultimate flag. with neck $0.5 \times$ length of bulb. Bulbs only slightly eccentric; verticillar scars weaker than $B$. robusta and ascoids less developed, digitate.

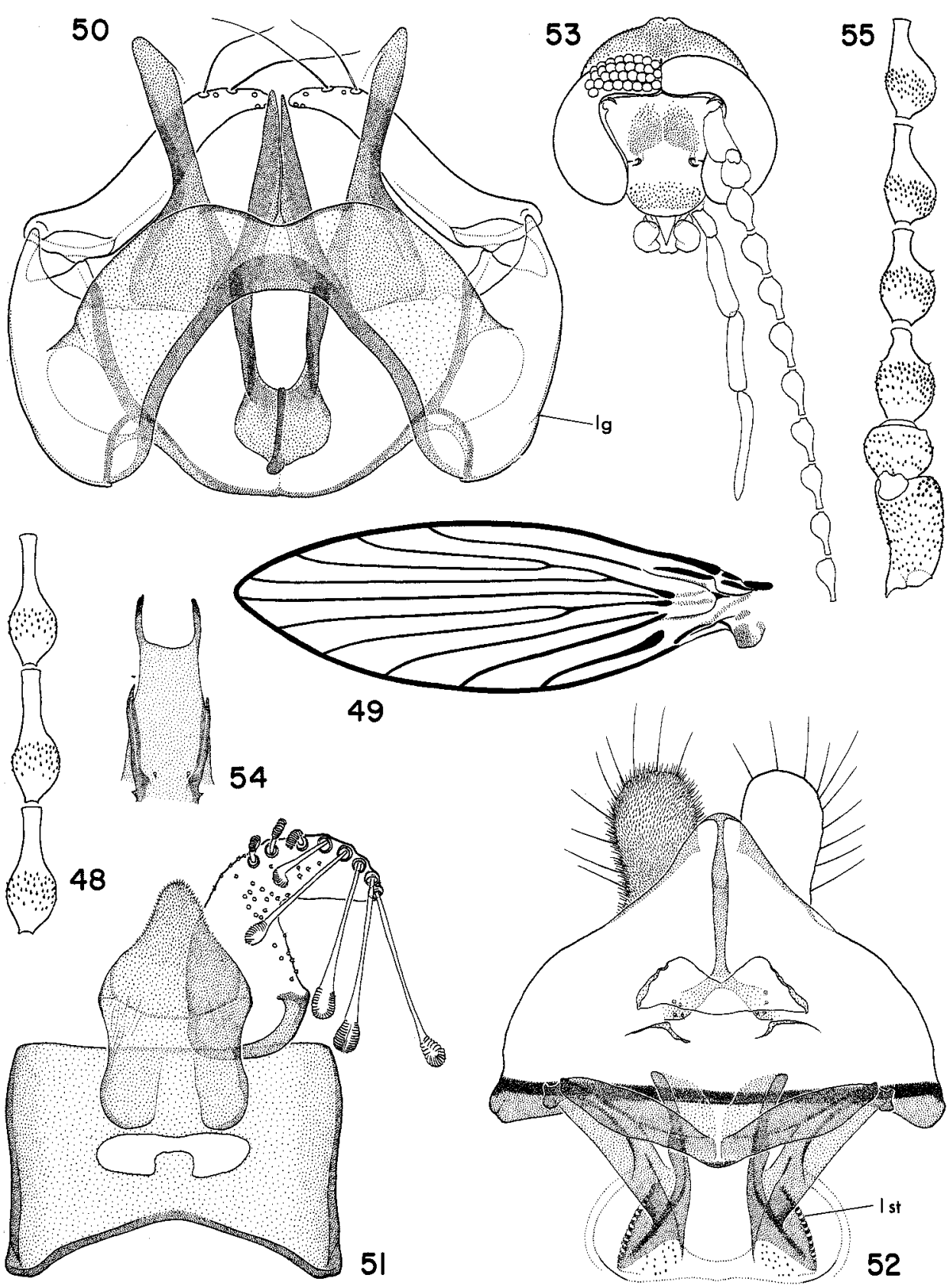

Figs 48-55. 48-51, Brunettia (Atrichobrunettia) napaea, sp. nov., male and 52, female: 48, median flagellomeres; 49, wing; 50, gonopods and aedeagus, dorsal ( $\mathrm{lg}$, lateral groove); 51 , epandrium, tenth tergite and cercopod, dorsal; 52, subgenital plate and associated structures, dorsal (lst, ladder-like ventral structure). 53-55, Brunettia (Atrichobrunettia) curta, sp. nov., male: 53, head; 54, cibarium; 55 , base of antenna. 
Thorax: spiracle set low, in concavity of anepisternite. Anepisternite with very large protuberant allurement organ anteriorly, c. 330 pits. Wing (Fig. 49) slender, $3 \cdot 2 \times$ as long as broad. $\mathrm{R}_{2} 3 \cdot 1 \times$ length of $\mathrm{R}_{2+3}$; $\mathrm{R}$ fork at level of tip of $\mathrm{CuA}_{2}$; patches of scars on membrane as in $B$. robusta. Wing length $2 \cdot 6-2 \cdot 85 \mathrm{~mm}$.

Terminalia (Figs 50, 51). Style $1 \cdot 1 \times$ length of coxite, stout but much less so than $B$. robusta, no longitudinal ridge, apex long and rather broad, apical setae long. Coxite stout, with very weak lateral groove (Fig. 50lg). Post-hypandrial plate short, bilobed, exposing distal blades of aedeagus. Aedeagus about $1.8 \times$ length of parameres, distal blades stout, close-set distally but not overlapping; apodeme about as long as broad, at end of long straight lateral arms that converge anteriorly; wings rounded in outline, keel strong with projecting apical knob. Parameres clavate in holotype; tapered strongly in basal halvesvery deep concavity on outer side, midway from base to tip. Epandrium (Fig. 51) $0.53 \times$ as long as broad; single large aperture, $0.47 \times$ width of epandrium, almost dumb-bell shaped, widely separated from anterior rim. Cercopod with 8 retinacula, those distal unusually long.

Female. Head (Fig. 47) longer than broad (allotype, 112: 108). Eyebridges of 3 complete and 1 incomplete facet rows, separated by $2 \cdot 5$ facet diameters, connected by Y-shaped suture. Frontal and clypeal regions proportionately broader and antennae wider apart than in $\sigma^{\circ}$. Frontoclypeal suture more clearly visible than in $\sigma^{\circ}$. Cibarium with characteristic lateral thickenings as in $\sigma^{\prime}$; less constricted posteriorly with posterior arms consequently less divergent, but still enlarged and sclerotised distally. Palpi with small cluster of sensory rods dorsolaterally on 1 st palpomere. Antenna only $1.7 \times$ length of palp and $0.42 \times$ length of wing; flagellomeres with very short necks, up to $0.34 \times$ length of bulb (flag. 9).

Thorax with spiracle set lower than in or; wing of anepisternite narrow and curved far more steeply upwards. Wing narrower than in o"; veins thicker and darker; $R_{2} 2 \cdot 5 \times$

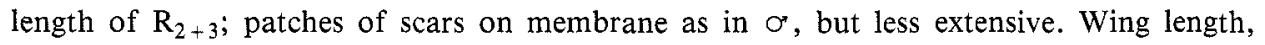
$2 \cdot 55 \mathrm{~mm}$.

Subgenital plate and spermathecae (Fig. 52), similar to many species of genus. Distal lobes not noticeably constricted basally. Spermathecae with ladder-like ventral structure (lst) and punctate markings anteriorly. Ovipositor $2.3 \times$ length of subgenital plate; cerci each with sclerotised basal peg.

\section{Remarks}

The male paratype has penultimate flagellomere with neck $0.7 \times$ length of bulb (longer than in holotype) and its aedeagus is retracted, with parameres rotated into the closed position around it so that their distal halves are seen in profile, thus appearing to be tapered to points instead of clavate.

\section{Material Examined}

\section{Brunettia (Atrichobrunettia) curta, sp. nov.}

Holotype. O Q Queensland: Mt Hypipamee St. For., rainf., 1050 m, 29.iv.71, D. and S. Duckhouse (ANIC, type No. 6082).

Paratypes. $40^{\circ}$, with holotype (ANIC, BMNH, BPB); 40, same locality, 14.iv.71 (ANIC).

Other material. All New South Wales: 10, Mt Warning Natl Pk, rainf,, $430 \mathrm{~m}, 18 . i i i .71$, Duckhouse (ANIC); $10^{*}$, Bruxner Pk, lowland rainf., $110 \mathrm{~m}$, swept $\mathrm{nr}$ main ck, 17.iii.71, Duckhouse (ANIC); 10 , Dorrigo-Coramba Rd, $29 \mathrm{~km}, 18 . \mathrm{iv} .70$, D. H. Colless (ANIC); 10, Upper Allyn R, 14.ii.68, Colless (ANIC); 4o, Upper Allyn R, 22.iv.70, Colless (ANIC, BMNH, BPB).

\section{Description}

Aedeagal apodeme very broad, keel bifurcating posteriorly to form Y-shape; flagellomeres short-necked.

Male. Head (Fig. 53) similar to B. napaea; $0.89 \times$ as long as broad; vertex more inflated laterally, its scars not separated medially; occipital lobe broader. Eyebridges with 4 rows of large facets; spot of sclerotisation in midline posterior to eyebridges. Frontal scar patch narrowly divided, no posterior prolongation. Anterior tentorial pit thick-lipped, connected to median edge of eye by line of sclerotisation. Cibarium (Fig. 54) not thick- 
walled anteriorly, slightly tapered posteriorly, arms well-separated, nearly parallel, long. Anterior margin of clypeus very rounded, almost semicircular. Palpi $(1 \cdot 0-2 \cdot 8-2 \cdot 7-3 \cdot 7)$ $1.5 \times$ length of head. Antenna short, $2.1 \times$ length of palp and $0.65 \times$ length of wing. Base of antenna, Fig. 55; scape $1.9 \times$ length of pedicel; pedicel not nearly reaching level of anterior margin of eye; flagellomeres with short necks, reaching $0.7 \times$ lengths of bulbs; bulbs eccentric; ascoids digitate, very long, less curved than most species.

Thorax with sessile allurement organ on anepisternite essentially as in other species of group (e.g B. albifrons, sp. n., Fig. 83), smaller than B. napaea, only $c .100$ pits. Wing $3 \cdot 1 \times$ as long as broad, slender, similar to $B$. napaea but position of forks variable; $M$ basal to $\mathrm{R}$ or occasionally both at same level, basal to tip of $\mathrm{CuA}_{2} ; \mathrm{R}_{2} 3 \cdot 0 \times$ length of $\mathrm{R}_{2+3}$; marginal patches of scars on membrane as in most Atrichobrunettia spp. Wing length $1 \cdot 7-2 \cdot 27 \mathrm{~mm}$.

Terminalia (Fig. 56). Style $1 \cdot 1 \times$ length of coxite; in dorsal view with slight concavity on outer side at base. Post-hypandrial plate a low truncated cone enclosing distal blades of aedeagus. Aedeagus with short, slender distal blades, evenly tapering and converging to tips, which touch; region basal to blades very broad, lateral arms widely separated and diverging slightly towards anterior; apodeme broader than coxite, keel bifurcating posteriorly to form Y-shape. Parameres not appearing clavate, at least in position shown. Cercopod with only $5-6$ retinacula.

\section{Material Examined}

Brunettia (Atrichobrunettia) collessi, sp. nov.

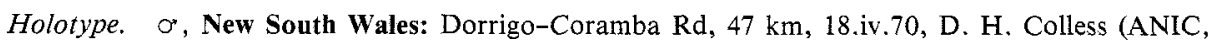
type No. 6083).

Paratypes. $10^{\circ}$, with holotype (ANIC); $10^{\circ}, 37 \mathrm{~km}$ WSW. of Coramba, 26.vi.76, Z. Liepa (ANIC).

Other material. $40^{\circ}$, Dorrigo-Coramba Rd, 24 km, 17,iii.81, D. and S. Duckhouse; 10 , Hornsby, light trap, 9.ii.57, D. J. Lee (ANIC).

\section{Description}

Closest to $B$. curta, sp. nov., but recognised by its unusually distinctive terminalia, especially the etiolated aedeagal apodeme, and the very long, almost cylindrical styli with clavate tips.

Male. Head as in B. curta except for the following: anterior tentorial pit not thicklipped, not connected to median edge of eye; anterior margin of clypeus less rounded. Palpi $(1 \cdot 0-2 \cdot 6-2 \cdot 2-)$ (last palpomere missing from all specimens). Antennae short, but tips missing from all specimens. Base of antenna, Fig. 57; scape $1.7 \times$ length of pedicel; pedicel reaching level of anterior margin of eye; flagellomeres with exceptionally short necks, reaching only $0.55 \times$ length of bulbs (flag. 8); bulbs eccentric; ascoids digitate, long, sinuous.

Thorax similar to other members of group; allurement organ on anepisternite smaller than B. napaea, only c. 120 pits. Wing about $3 \cdot 1 \times$ as long as broad, slender; $\mathrm{R}$ fork beyond $M$ fork and at level of tip of $\mathrm{CuA}_{2}$ or just before; $R_{2} 2.6 \times$ length of $R_{2+3}$; patches of scars on membrane as in previous species. Wing length $1.8-1.95 \mathrm{~mm}$.

Terminalia (Fig. 58). Style very long, $1.2 \times$ length of coxite, almost cylindrical beyond base, tip clavate. Aedeagus $1.7 \times$ length of parameres; distal blades slender, closely adpressed throughout; lateral arms curved adjacent to bases of distal blades, converging anteriorly to base of aedeagal apodeme; wings of apodeme narrowing progressively towards anterior end, which is tail-like; keel prominent, produced posteriorly into triangular point between lateral arms. Post-hypandrial plate produced backwards to beyond tip of aedeagus, but emarginated medially, exposing distal blades. Parameres very stout, tapered strongly in basal half then expanding slightly in distal half, giving clavate form; apex emarginated on inner side. Epandrium with single slit-shaped aperture. Tenth tergite with microsetose distal lobe rounded at base. Cercopod with only 5 retinacula. 


\section{foliacea group}

Males of the next two species differ from other Australian Atrichobrunettia species in having widely separated eyebridges, frontal scar patch with posterior prolongation to between eyebridges, and parameres sharply tapered to narrow pointed tips. They are close to three of Quate and Quate's New Guinean species: B. spadix, which has 'large, foliate' ascoids, and $B$. antennata and $B$. pallescens, which have palmate ascoids. $B$. foliacea, sp. nov., is like
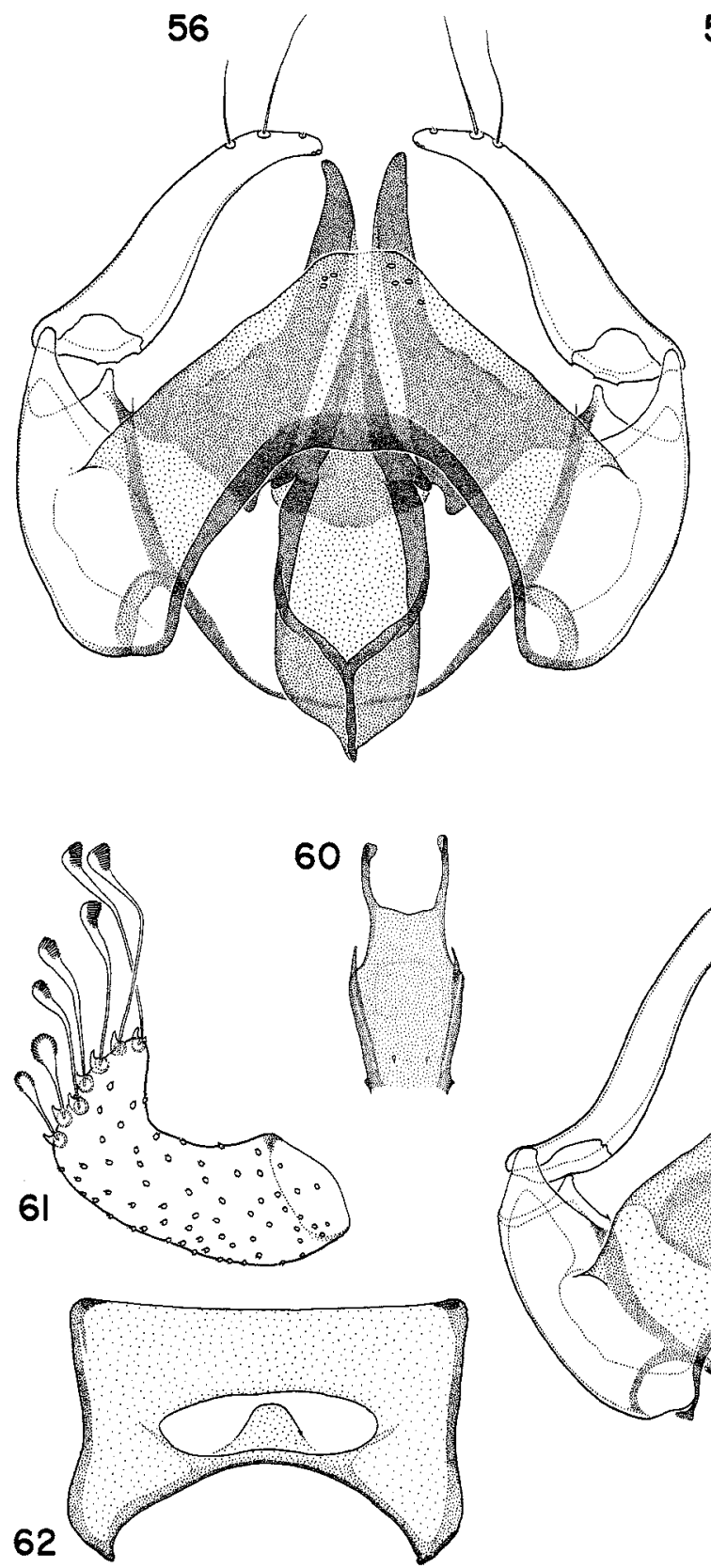
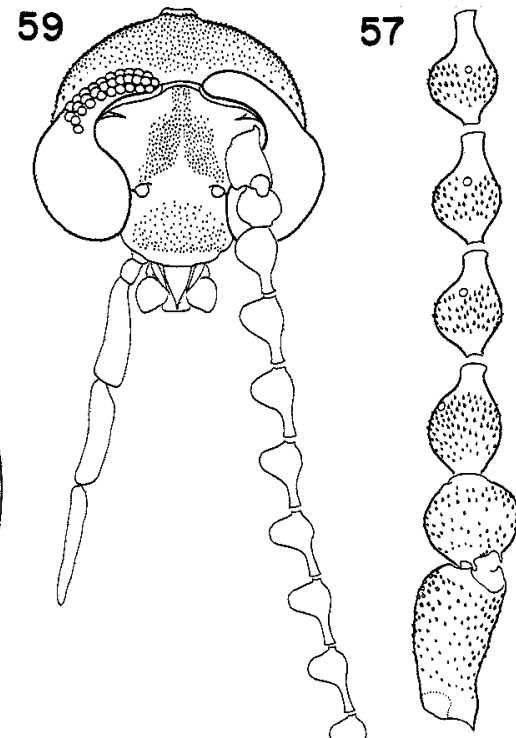

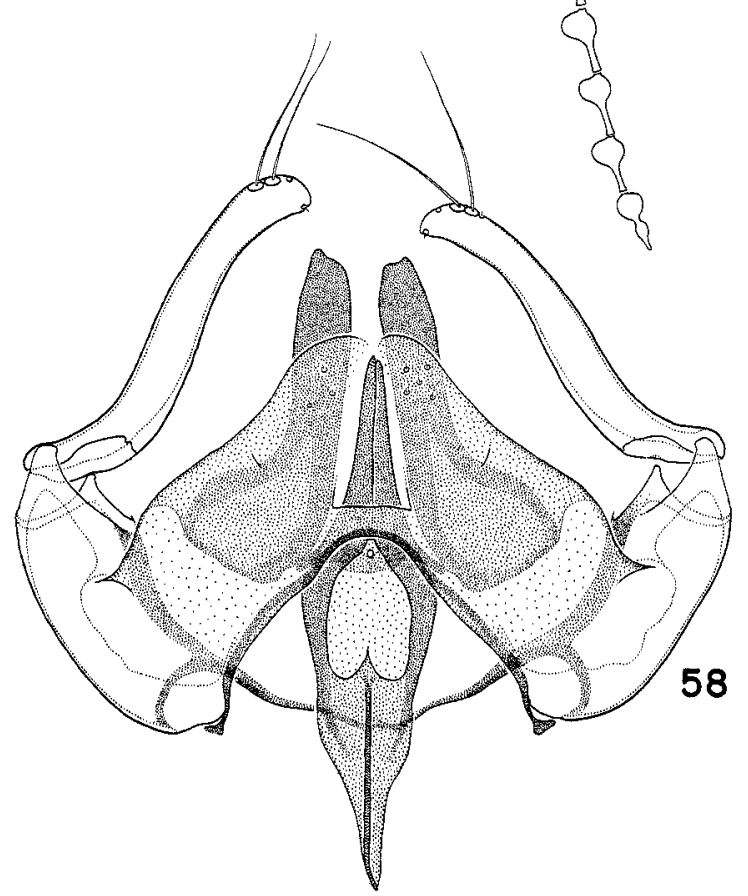

Figs 56-62. 56, Brunettia (Atrichobrunettia) curta, sp. nov., male: gonopods and aedeagus, dorsal. 57, 58, Brunettia (Atrichobrunettia) collessi, sp. nov., male: 57, base of antenna; 58, gonopods and aedeagus, dorsal. 59-62, Brunettia (Atrichobrunettia) foliacea, sp. nov., male: 59, head; 60, cibarium; 61, cercopod; 62, epandrium. 
$B$. spadix and $B$. pallescens in having the last 2 flagellomeres fused; $B$. angulosa, sp. nov., is like all three in the shape of the style tip. In some respects, especially the form of the retinacula and the separation between the eyebridges, these species resemble subg. Campanulobrunettia and, to a lesser extent, subg. Horobrunettia.

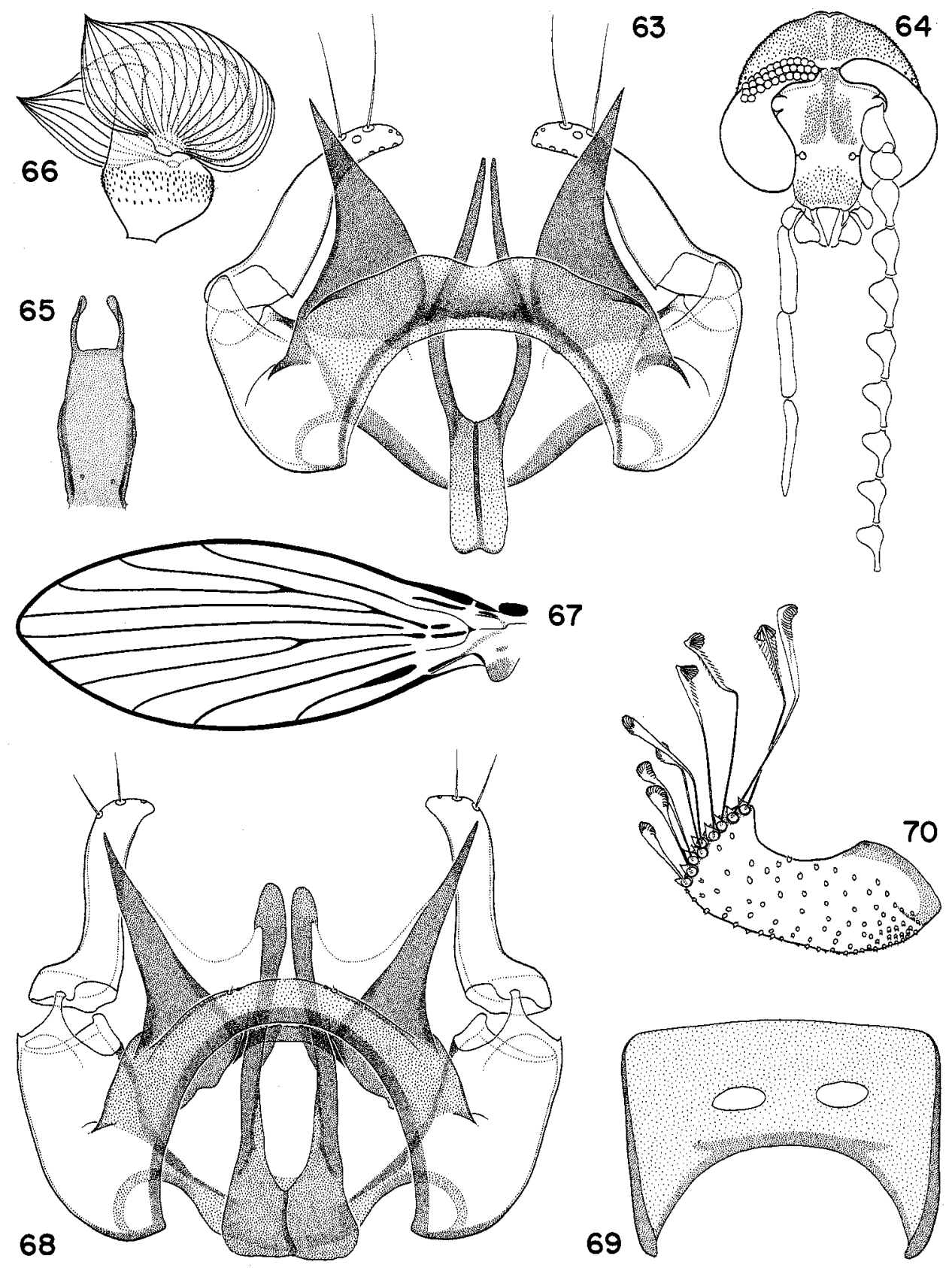

Figs 63-70. 63, Brunettia (Atrichobrunettia) foliacea, sp. nov., male: gonopods and aedeagus, dorsal. 64-70, Brunettia (Atrichobrunettia) angulosa, sp. nov., male: 64, head; 65, cibarium; 66, flagellomere and ascoids; 67 , wing; 68 , gonopods and aedeagus, dorsal; 69, epandrium; 70 , cercopod. 
Brunettia (Atrichobrunettia) foliacea, sp. nov.

Material Examined

Holotype. $\sigma$, Queensland: Babinda, lowland rainf., 12.iv.71, D. and S. Duckhouse (ANIC, type No. 6084).

Paratypes. $150^{\circ}$, with holotype (ANIC, BMNH, BPB). Most specimens taken dancing on upper leaf surfaces.

\section{Description}

Close to $B$. angulosa, sp. nov. (below) and Quate and Quate's New Guinean species $B$. spadix and $B$. antennata. Separated from these by broad, low vertex, shape of style, and slender, forceps-like blades of the aedeagus.

Male. Head (Fig. 59) $0.9 \times$ as long as broad. Vertex broad, outline semicircular except for interruption by occipital lobe, scars not separated medially. Eyebridges of 3 rows of facets, widely separated by 4.2 facet diameters, connected by curved interocular suture. Frontal scar patch divided medially, deeply cleft anteriorly, broad posterior prolongation to between eyebridges. Anterior tentorial pit large, adjacent to inner margin of eye to which it is connected by sclerotisation. Posterior limit of antennal insertion area marked by long sclerotised point. Cibarium (Fig. 60) tapered posteriorly, arms well separated, long and divergent. Palpi $(1 \cdot 0-3 \cdot 6-3 \cdot 5-4 \cdot 1) 1 \cdot 4 \times$ length of head. Antenna long, $2 \cdot 6 \times$ length of palp and $0.8 \times$ length of wing; scape very short, $1.95 \times$ length of pedicel; pedicel not nearly reaching level of anterior margin of eye. Flagellomeres with very large, eccentric bulbs; necks up to $0 \cdot 9-1 \cdot 0 \times$ lengths of bulbs (flags 8-11); last flagellomere (13th) fused with 12th (Fig. 59); ascoids large, leaf-shaped, longitudinally striated, as in B. angulosa (Fig. 66).

Thorax without allurement organs. Wing $2 \cdot 8 \times$ as long as broad; almost as in $B$. angulosa, sp. nov. (Fig. 67), but forks more basal relative to tip of $\mathrm{CuA}_{2} ; \mathrm{R}_{2} 2 \cdot 1 \times$ length of $\mathrm{R}_{2+3}$; very small or no marginal patches of scars on membrane. Wing length $1 \cdot 3-1 \cdot 4 \mathrm{~mm}$.

Terminalia (Figs 61-63). Style thickset, about 1.2× length of coxite; apex broadly rounded, not noticeably snouted, distal setae long. Dorsal distal articulatory process of coxite broad. Aedeagus about $1.45 \times$ length of parameres; distal blades usually slender, narrowing and converging towards tips; apodeme narrow, parallel-sided or widening anteriorly, appearing peg-like. Post-hypandrial plate short. Parameres long; very broadbased, tapering to finely pointed tips. Hypandrium forming regular semicircular curve. Epandrium (Fig. 62) with single aperture, over half width of plate, partly divided by tongue-like process. Tenth tergite rounded laterally. Cercopod (Fig. 61) with 7-8 retinacula along truncate apex; proximal retinacula short, straight, with spore capsule tips, grading to long with hooded tips distally.

\section{Brunettia (Atrichobrunettia) angulosa, sp. nov.}

Material Examined (all collected D. and S. Duckhouse)

Holotype. $\sigma^{\circ}$ Queensland: Mt Hypipamee St. For., rainf., $1050 \mathrm{~m}, 29 . \mathrm{iv} .71$ (ANIC, type No. 6085).

Paratypes. $10^{\circ}$, same locality, 14.iv.71 (BPB); $10^{*}$, Palmerston Natl Pk, rainf., $625 \mathrm{~m}, 13$.iv.71 (ANIC); 10 , Lake Barrine Natl Pk, rainf., $730 \mathrm{~m}$, light trap, 29.iv.71 (ANIC).

Other material. $10^{\circ}$, Dunk I. Natl Pk, rainf., light trap, 23.iv.71; 40, Lake Barrine Natl Pk, rainf., $730 \mathrm{~m}$, light trap, 29.iv. 71 .

\section{Description}

Similar to $B$. foliacea, sp. nov., but distal blades of aedeagus stout, enlarged at tips, and wings of basal apodeme considerably broader than racquet region of aedeagus. Style beaked as in the New Guinean $B$. spadix and, to a lesser extent, $B$. antennata and B. pallescens. 
Male. Head (Fig. 64) $0.88 \times$ as long as broad. Vertex appearing less nearly semicircular in outline than $B$. foliacea and occipital lobe smaller; scars separated medially. Eyebridges of 3 rows of facets, separated by only $2 \cdot 3$ facet diameters. Compared with $B$. foliacea: frontal scar patch divided medially but less deeply cleft, clypeus narrower, anterior tentorial pit similar but smaller, sclerotised point shorter. Cibarium (Fig. 65) with arms close-set and convergent. Palpi $(1 \cdot 0-3 \cdot 7-3 \cdot 4-3 \cdot 8) 1 \cdot 48 \times$ length of head. Antenna incomplete, but proportions similar to $B$. foliacea; necks reaching about as long as bulbs (flags 8-9); typical flagellomere and ascoids, Fig. 66.

Thorax without allurement organs. Wing (Fig. 67) $2.66 \times$ as long as broad; $R_{2}$ $1.76 \times$ length of $R_{2+3}$; very small marginal patches of scars on membrane. Wing length $1.5-1.9 \mathrm{~mm}$.

Terminalia (Figs 68-70). Style thickset, only $0.89 \times$ length of coxite, shouldered at basestrongly concave on outer side; apex 'snouted', distal setae short and straight. Dorsal distal articulatory process of coxite, a narrow peg. Aedeagus heavily constructed, $1.3 \times$ length of parameres; lateral arms almost straight and distal blades broadening to enlarged rounded tips, both thickset; apodeme with massive wings, wider than region of lateral arms, apex truncate. Post-hypandrial plate short, very rounded. Parameres long, finely pointed, more slender than $B$. foliacea. Hypandrium arched very strongly backwards to level of tips of coxites, far deeper than semicircular curve of $B$. foliacea. Epandrium (Fig. 69) short; 2 separate apertures. Tenth tergite with prominent lateral processes at base of microsetose region. Cercopod (Fig. 70) similar to $B$. foliacea, but apex more sharply truncated and with more retinacula; tips of retinacula at distal end of row conspicuously hooded as in subg. Campanulobrunettia.

\section{Remarks}

A further species, closely similar to $B$. angulosa, was collected in Queensland from Dinner $\mathrm{Ck}$, near Innisfail, but is only represented by a single incomplete male. Further material will be sought.

Ungrouped species of Atrichobrunettia

Brunettia (Atrichobrunettia) tricorniculata, sp. nov.

Material Examined

Holotype. $\sigma^{\circ}$, New South Wales: Dorrigo-Coramba Rd, $53 \mathrm{~km}, 18 . \mathrm{iv} .70$, D. H. Colless (ANIC, type No. 6086).

Paratypes. $40^{\circ}$, with holotype (ANIC, BMNH, BPB); $110^{\circ}$, Dorrigo-Coramba Rd, $24 \mathrm{~km}, 17 . \mathrm{iii} .71$, D. and S. Duckhouse (ANIC, DD); $20^{\circ}$, Chillingham-Numinbah, $1.6 \mathrm{~km}, 80 \mathrm{~m}$, stream in residual for., 21.iii.71, Duckhouse (ANIC); 10, Queensland: Eungella Natl Pk, open shade, 460-610 m, 5.v.71, Duckhouse (ANIC).

Other material. New South Wales: $10^{\circ}$, Bruxner Pk, lowland rainf., $120 \mathrm{~m}$, swept from streamside veget., 17.iii.71, Duckhouse (ANIC); 20, Warrah, light trap, 2.x.67, Holst (ANIC).

\section{Description}

Characterised by its trilobed tenth tergite; aedeagus shorter than parameres, truncate anteriorly; eyebridges of 3 facet rows, not contiguous.

Male. Head (Fig. 71) about $0.86 \times$ as long as broad. Vertex large and inflated in appearance, forming one smooth curve; occipital knob small, low, as in figure (holotype) or not visible (others); scars not separated medially. Occipital aperture large. Eyebridges with 3 rows of small facets, separated by 2.8 facet diameters, connected by faint $V$-shaped suture with curved arms. Frontal scar patch large, divided medially by scar-free band, median extension between eyebridges, deep triangular cleft anteriorly. Anterior tentorial pit linked to medial edge of eye by prominent sclerotisation. Cibarium (Fig. 72) stout, posterior arms long and narrow. Clypeus broad, emarginated apically. Palpi $(1 \cdot 0-3 \cdot 4-3 \cdot 3-4 \cdot 1) 1 \cdot 6 \times$ length of head; palpomere 2 thickset; no sensory rods. Antenna short, $1.7 \times$ length of palp and $0.48 \times$ length of wing; basal region (Fig. 73 ) with scape very small, $1.5 \times$ length of pedicel; flagellomeres small, bulbs poorly developed; ascoids (Fig. 74) digitate, slender, sinuous, about as long as flagellomeres. 
Thorax without allurement organs. Wing (Fig. 75) slender, $3 \cdot 2 \times$ as long as broad, anterior and posterior margins converging at acute angle; tip very narrow, placed just anterior to tip of $R_{5}$; hair scars extending slightly onto membrane between tips of longitudinal veins, membrane otherwise naked. $\mathrm{R}$ fork beyond $\mathrm{M}$ fork, $\mathrm{R}_{2} 2 \cdot 1 \times$ length of $\mathrm{R}_{2+3}$. Wing length $1 \cdot 8-2 \cdot 1 \mathrm{~mm}$.

Terminalia (Figs 76-78) exceptionally short. Style $1.06 \times$ length of coxite, slender, evenly tapered, rather straight; paired apical setae unusually short. Coxite stout, without lateral

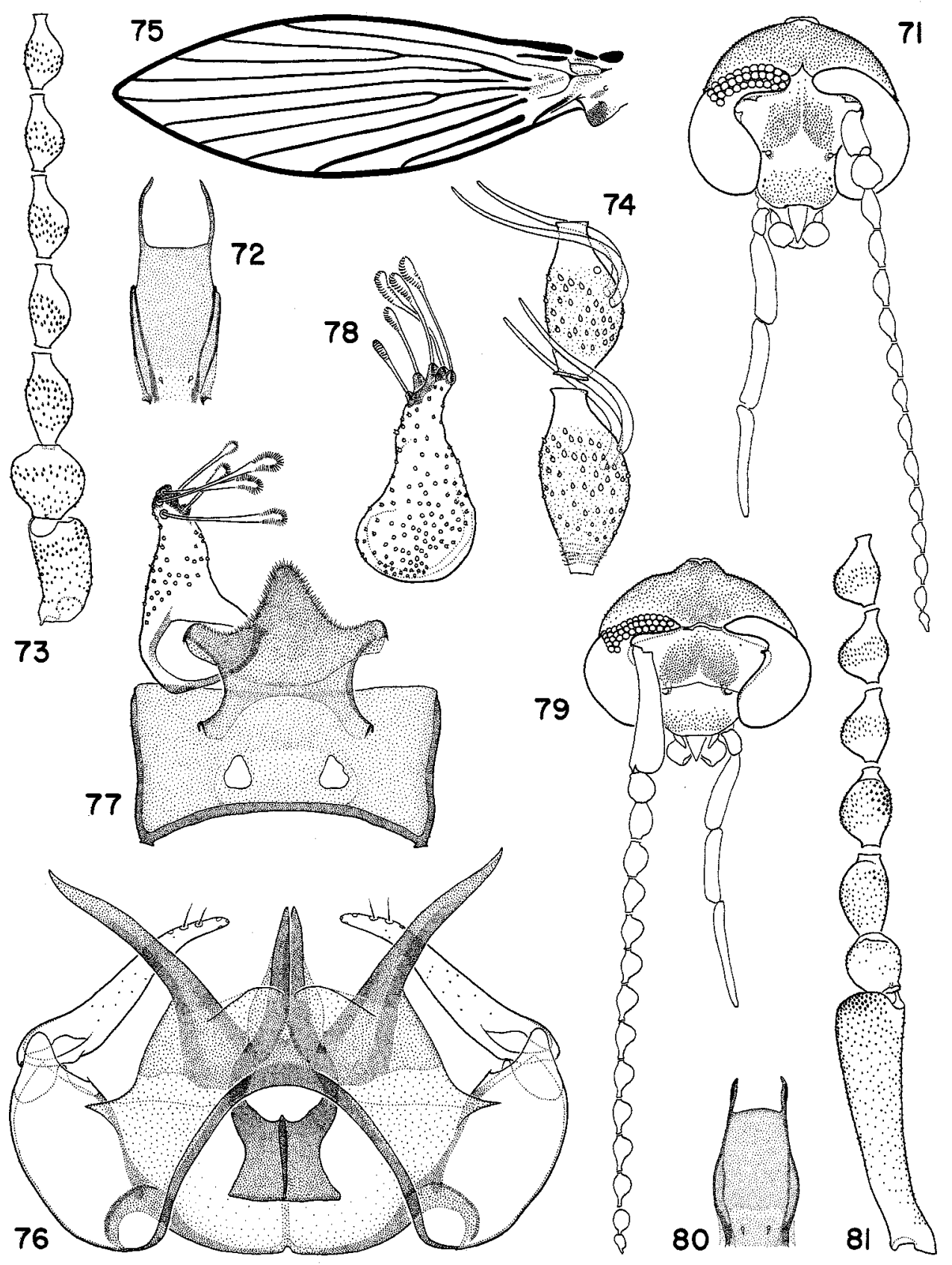

Figs 71-81. 71-78, Brunettia (Atrichobrunettia) tricorniculata, sp. nov., male: 71 , head; 72 , cibarium; 73, base of antenna; 74, flagellomeres 2 and 3; 75, wing; 76, gonopods and aedeagus, dorsal; 77, epandrium, tenth tergite and cercopod, dorsal; 78, cercopod, lateral. 79-81, Brunettia (Atrichobrunettia) albifrons, sp. nov., male: 79 , head; 80 , cibarium; 81 , base of antenna. 
groove. Aedeagus $1.46 \times$ length of parameres; broad, with curved lateral arms giving pronounced racquet shape; distal blades parallel, arranged like nearly closed scissor blades. Aedeagal apodeme squat, truncate, wings triangular; keel strong. Parameres slender, evenly tapered to points; spread far to sides in all but one of 38 specimens examined. Epandrium (Fig. 77) nearly twice as broad as long; apertures separate, in large area without microsetae, about equal in extent to single aperture in such species as $B$. morigera. Tenth tergite excavated anteriorly, trilobed posteriorly; median posterior lobe corresponding with apex of normal tenth tergite, exaggerated lateral lobes articulating with cercopods. Cercopod (Fig. 78) squat with very large rounded base; 5 retinacula, not uniseriate, clustered apically.

Brunettia (Atrichobrunettia) albifrons, sp. nov.

\section{Material Examined}

Holotype. ơ, Queensland: Mt Hypipamee St. For., rainf., 1050 m, 14.iv.71, Duckhouse (ANIC, type No. 6087).

Paratypes. $1 \%$ (allotype) and $30^{\circ}, 4 \%$, with holotype (ANIC, BMNH, BPB); $30^{\circ}$, same locality, 29.iv.71, Duckhouse (ANIC, BMNH).

\section{Description}

Male with the usual short pedicel, but a very elongate scape, about four times its length; widely separated eyebridges; wings of aedeagal apodeme exceptionally narrow.

Male. Vestiture mainly dark, unvariegated, but head with conspicuous white vestiture on frons and central region of vertex, flanked by dark vestiture. Denuded head (Fig. 79) $0.77 \times$ as long as broad; frons, clypeus and vertex wide; widely separated antennae. Vertex very rounded on either side, scars clustered medially, especially behind interocular suture, marking position of white vestiture in intact fly; occipital lobe large, shallow indentation apically. Eyebridges with 3 rows of small facets, separated by 6.6 facet diameters, tapered to median points, connected by long curved suture. Frontal scar patch with deep anterior indentation but undivided posteriorly. Frontoclypeal suture faintly marked; tentorial pits well separated from eyes. Cibarium (Fig. 80) inflated in middle; posterior arms widely separated but convergent. Clypeus rounded. Palpi $(1 \cdot 0-2 \cdot 8-2 \cdot 7-3 \cdot 7)$ $1.6 \times$ length of head; sensory rods apparently present on palpomere 1 but not clearly visible. Antenna $2.1 \times$ length of palp and $0.66 \times$ length of wing. Base of antenna, Fig. 81; scape very long and slender, $0.7 \times$ length of head, reaching far beyond anterior edge of eye; large dark tuft distally on inner side; pedicel with prominent basal rim. Flagellomeres short-necked, bulbs strongly eccentric; flags 1-2 disproportionately large; ascoids (Fig. 82) digitate, longer than flagellomeres, enlarged and strongly curved at base, almost straight in distal half.

Thorax (Fig. 83). Spiracle set high, in deep concavity of anepisternite. Anepisternite with large allurement organ anteriorly, slightly protuberant. Wing (Fig. 84) slender, about $2 \cdot 9 \times$ as long as broad; costal node almost triangular; long, thick, dark jugal tuft, about as long as head and mouthparts combined, denuded jugum specialised as in Fig. 84, inset; $R_{2} 2.8 \times$ length of $\mathrm{R}_{2+3}$; $\mathrm{R}$ fork well basal to level of tip of $\mathrm{CuA}_{2}$ but still beyond $\mathrm{M}$; a very few scars extending just onto membrane from costa. Wing length $1 \cdot 8-2 \cdot 0 \mathrm{~mm}$.

Terminalia (Figs 85,86 ) short. Style $0.95 \times$ length of coxite, rather straight, almost triangular, no longitudinal ridge, apical setae long. Aedeagus $1.55 \times$ length of parameres, distal blades slender, not overlapping; curved lateral arms giving racquet shape; apodeme with strong keel but wings very narrow throughout, giving peg-like appearance (holotype) or tapered towards tip, where they are absent. Parameres slightly divergent, slender, tapered. Hypandrium arched strongly backwards to level of tips of coxites; post-hypandrial plate forming prominent $180^{\circ}$ curve. Epandrium (Fig. 86) $1.75 \times$ as broad as long; paired apertures large, separated by narrow sclerotised bridge tapering to point posterior to them. Cercopod squat with long row of 11-12 retinacula.

Female. Head (Fig. 87) $0 \cdot 8 \times$ as long as broad. Eyebridges separated by $9 \cdot 2$ facet diameters, connected by almost straight suture. Vertex more constricted at base of occipital 
region than in $\sigma^{\circ}$, scars larger and less dense. Cibarium as in $\sigma$. Sensory rods on palpomere 1 , not clearly visible. Antenna only $1.2 \times$ length of palp and $0.4 \times$ length of wing; scape $1.95 \times$ length of pedicel; pedicel reaching to just beyond anterior margin of head; flagellomeres with very short necks.

Thorax without allurement organ: area occupied by it in $\sigma$ covered in hair scars. Wing $2.95 \times$ as long as broad, jugum unmodified, without jugal tuft seen in $\sigma^{\prime} ; R_{2} 2 \cdot 24 \times$ length of $\mathrm{R}_{2+3}$; slight incursions of scars from costa onto membrane along posterior edge of wing. Wing length $1 \cdot 8-1 \cdot 9 \mathrm{~mm}$.
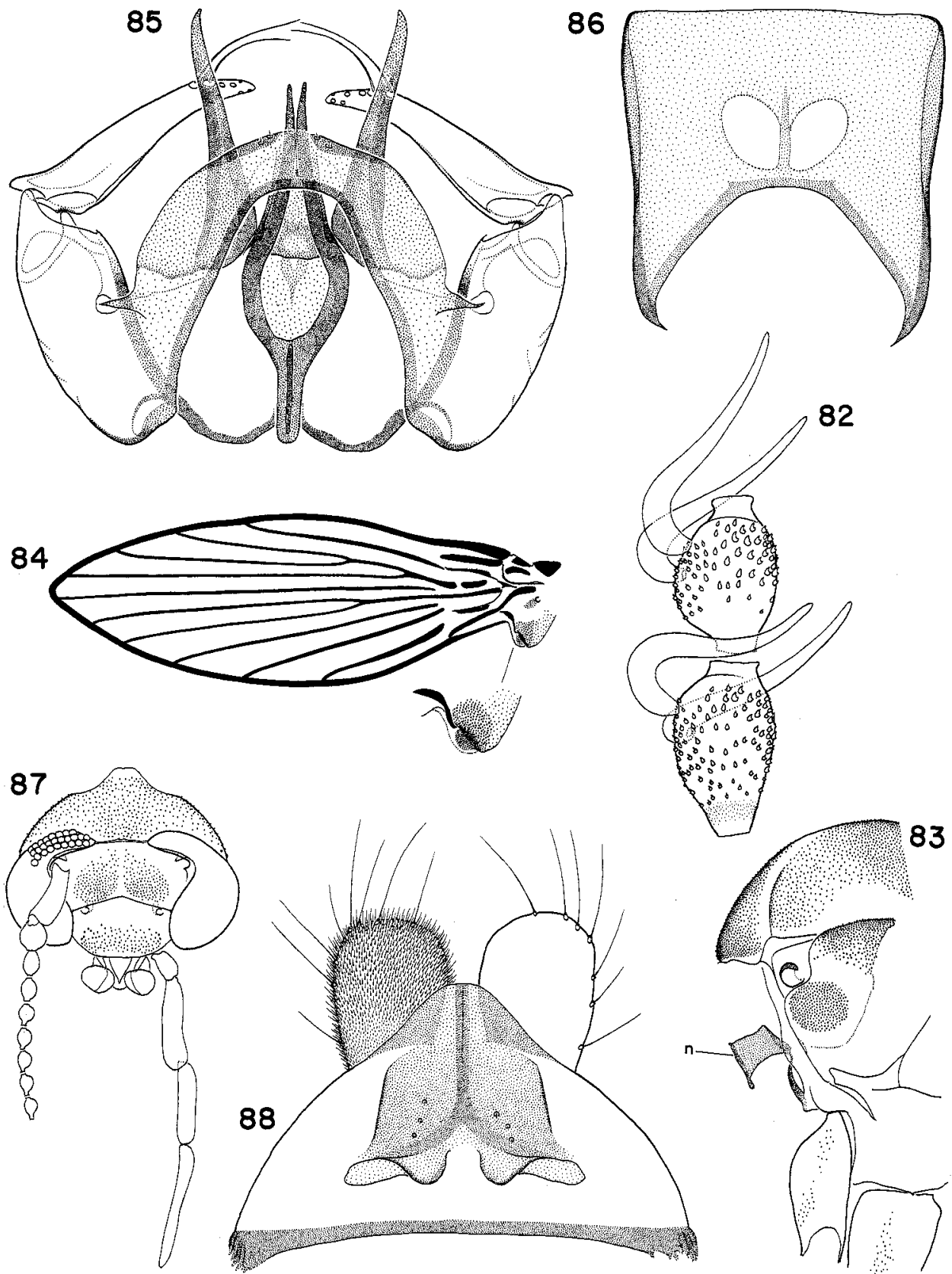

Figs 82-88. 82-86, Brunettia (Atrichobrunettia) albifrons, sp. nov., male and 87, 88, female: 82 , flagellomeres 1 and $2 ; 83$, anterior thorax, lateral ( $n$, neck sclerite); 84 , wing, inset showing structure of jugal lobe (jugal tuft removed); 85 , gonopods and aedeagus, dorsal; 86 , epandrium; 87 , head; 88 , subgenital plate. 
Subgenital plate, Fig. 88, similar to many species but distal lobes distinctly constricted basally. Spermathecae with ladder-like ventral structures of spermathecae coarse. Ovipositor $2 \cdot 14 \times$ length of subgenital plate.

Subgenus Maurobrunettia, subg. nov.

Type species: Brunettia impudica, sp. nov., by present designation.

Probable apomorph sister group of subg. Atrichobrunettia.

\section{Definition}

Male. Head very broad, antennae widely separated and frontal scar patch large. Eyebridges of 3 facet rows, strongly arched, constricted basally, never contiguous. Scape and pedicel generally elongate and enlarged, thickly clothed with scales; scape reaching to or beyond level of anterior margin of eye; pedicel pyriform or reniform; ascoids digitate, often inflated.

Mesothoracic allurement organs present, always raised on stalks. Anepisternite generally of characteristic shape (e.g. Fig. 93), forming spiniform process $(s p)$ below spiracle and with enlarged antero-ventral scars $(a)$ adjacent to spiracle.

Wing tending to enlarge in anal and humeral regions but never massively broad as in some species of subgenera Brunettia and Campanulobrunettia; costal node almost triangular; membrane with vestiture restricted to marginal region, or in some species also extending in sparse bands towards forks. Veins $R_{2}-R_{4}$ and $M_{1}-M_{3}$ broadest in region basal to forks, about uniform in thickness beyond this level; $R$ fork above or slightly basal to $M$ fork; wing apex rounded and placed between tips of $\mathrm{R}_{4}$ and $\mathrm{R}_{5} ; \mathrm{CuA}_{2}$ poorly defined, unsclerotised, a diffuse band of scars, very broad at base. Jugum bearing large compact tuft or pencil of fine dark hair on anterior lobe (e.g. Fig. 121), supported by sclerotised struts, hairs leaving dense mass of small, close-packed scars.

Gonopods slender. Style with apical paired setae very unequal; the more distal seta over twice as long as the other, and about as long as blades of aedeagus. Aedeagal apodeme normally without lateral wings. Epandrium longer than in other subgenera, its apertures small, separate. Except in $B$. eximia, sp. nov., cercopods with numerous long, slender, flexible retinacula, their tips simple and rounded as in many species of Alepia Enderlein, not uniseriate but clustered on enlarged distal region; small sclerotisation adjacent to retinacula on medial side (e.g. Fig. 111sc) and small cluster of shaftless sensilla abutting sclerotisation (se).

\section{Distribution}

Maurobrunettia is only known from North Queensland, south to $20^{\circ} 55^{\prime} \mathrm{S}$.

\section{Key to Males of Species of subg. Maurobrunettia}

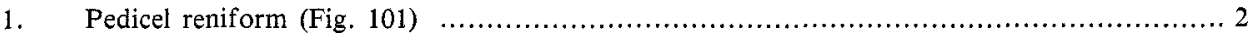

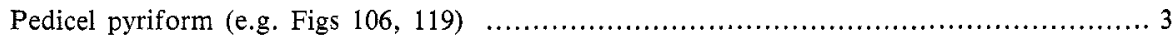

2. Mesothoracic allurement organs (Fig. 93) enormous, oval, greatest width exceeding length of scape; scape (Fig. 91) slender, slightly waisted in basal third ....... B. impudica, sp. nov. Mesothoracic allurement organs (Fig. 103) small, greatest width only equal to about half length of scape; scape (Fig. 106) very stout, not waisted in basal third

B. concubinalis, sp. nov,

3. Flagellomeres 3-5 with large brushes of spines on outer sides . ............................ 4

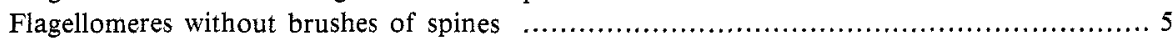

4. Outer side of scape concave; retinacula clustered on apical region of cercopod

B. salax, sp. nov.

Outer side of scape convex; retinacula uniseriate (Fig. 127) ............... B. eximia, sp. nov.

5. Scape not reaching level of anterior margin of eye ................... . consobrina, sp. nov.

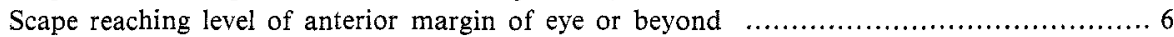

6. Pedicel elongate pyriform, length greatly exceeding combined length of first 2 flagellomeres

B. immodesta, sp. nov.

Pedicel not elongate pyriform, length less than combined length of first 2 flagellomeres .......

B. cinaeda, sp. nov. 
Brunettia (Maurobrunettia) impudica, sp. nov.

Material Examined

Holotype. $\%$, Queensland: Mt Hypipamee St. For., 1050 m, 29.iv.71, D. and S. Duckhouse (ANIC, type No. 6088).

Paratypes. $8 \sigma^{\circ}$, with holotype (ANIC, BMNH, BPB); $2 \sigma^{\circ}$, same loc., 14.iv.71, Duckhouse (ANIC).

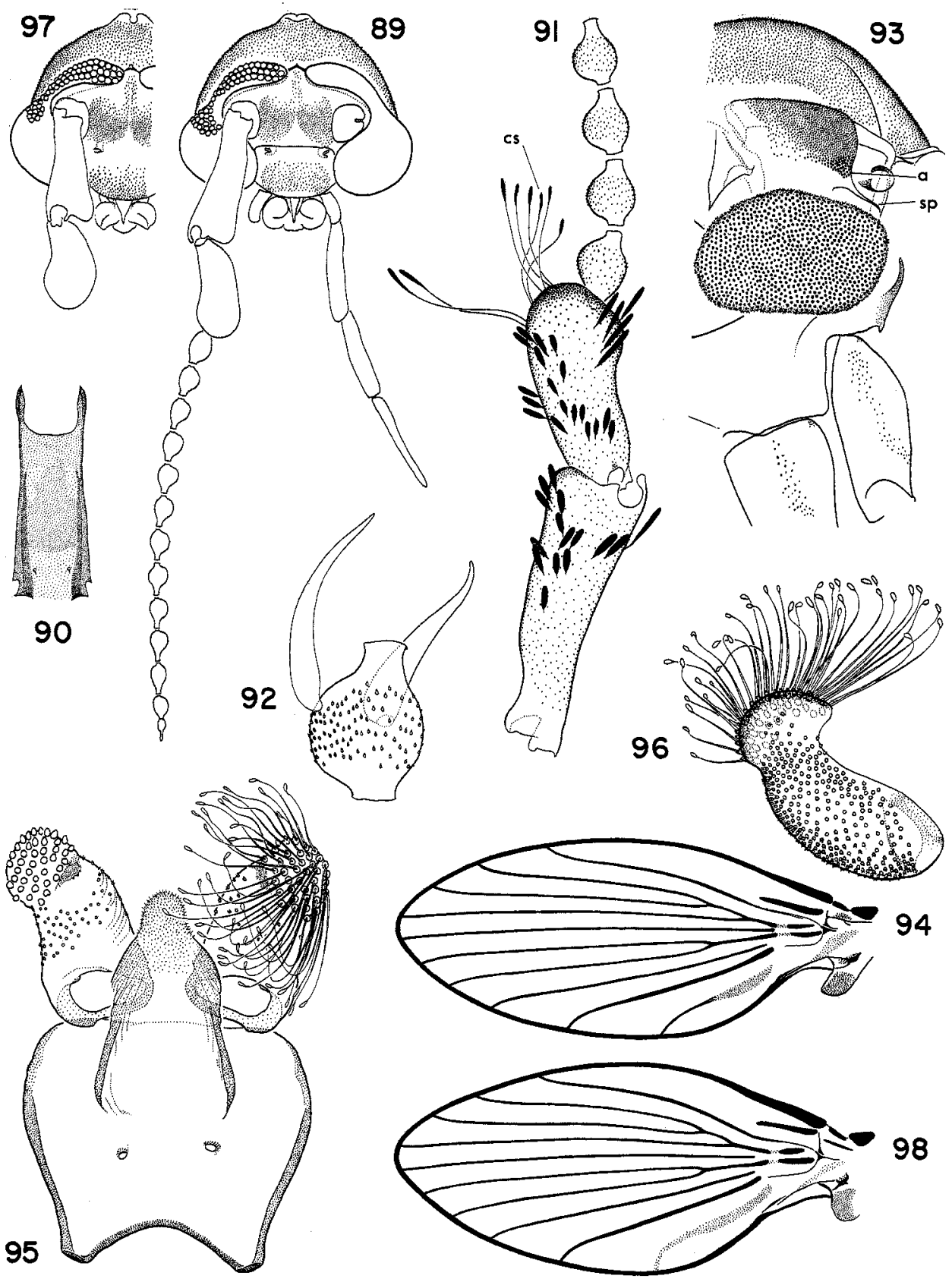

Figs 89-98. 89-96, Brunettia (Maurobrunettia) impudica, sp. nov., male: 89, head; 90, cibarium; 91, base of antenna ( $c s$, clavate scales); 92, flagellomere 3; 93, anterior thorax, lateral ( $s p$, spiniform process; $a$, enlarged antero-ventral scars); 94, wing; 95, epandrium, tenth tergite and cercopods, dorsal; 96 , cercopod, lateral. 97,98 , Form from Mossman Gorge related to impudica, male: 97 , head; 98 , wing. 


\section{Description}

Male with enormous mesothoracic allurement organs, narrowed to thick stalks beneath.

Male. Vestiture bushy, mainly black, legs banded with white.

Head (Fig. 89) $0.79 \times$ as long as broad; narrower than in some related species and frons accordingly less wide and antennae less widely separated. Vertex high, scars not separated medially; occipital lobe prominent. Eyebridges separated by $2 \cdot 6$ facet diameters, connected by obtuse V-shaped suture, sometimes with faint posterior arm. Frontal scar patch with deep triangular cleft anteriorly, otherwise undivided or very narrowly divided; long median extension, contiguous with main patch, extending to between eyebridges. Anterior tentorial pit with complex sclerotised lips, linked to medial edge of eye by incomplete line of sclerotisation. Cibarium (Fig. 90) with lateral walls complex anteriorly, posterior margin a straight line flanked by stout, roughly parallel posterior arms. Palpi $(1 \cdot 0-3 \cdot 1-2 \cdot 5-3 \cdot 1)$ $1.7 \times$ length of head; about 5 sensory rods on dorsal side of palpomere 1 . Antenna $1.9 \times$ length of palp and $0.6 \times$ length of wing; scape and pedicel very enlarged, mostly clothed in short black scales. Base of antenna, Fig. 91; scape $1.3 \times$ length of pedicel, medial side of scape enlarged distally, strongly constricted in basal third; pedicel almost reniform; medial side with massive distal enlargement, medial side and distal enlargement bearing numerous long clavate scales (Fig. 91 cs); flagellomeres showing gradual transformation from basal to distal members; ascoids digitate, inflated basally (Fig. 92).

Thorax (Fig. 93). Enormous mushroom-shaped mesothoracic allurement organs, oval in outline, membranous beneath, attached by thick stalk to anepisternite below spiracle, outer surface bearing dome-shaped papillae amongst short thorn-shaped microsetae. Anepisternite forming abnormally well-developed wing dorsally, bearing very dense scars; scars enlarged adjacent to spiracle. Wing (Fig. 94, jugal tuft removed) $2 \cdot 3 \times$ as long as broad, very slightly enlarged in anal region. Hair scars extending onto membrane from costa, progressively sparser at greater distances from costa; forks very basal, at almost same level, $\mathrm{R}_{2} 6.7 \times$ length of $\mathrm{R}_{2+3}$. Wing length $2 \cdot 6-2 \cdot 85 \mathrm{~mm}$.

Terminalia (Figs $95,96,99$ ). Style $0 \cdot 96 \times$ length of coxite, slender, evenly curved, acutely pointed; one distal seta exceptionally long and one short. Coxite constricted in basal half, no lateral groove. Aedeagus with lateral margins rather straight, forming shoulders posteriorly; distal blades parallel, meeting like blades of forceps; apodeme with strong keel, lateral wings broad posteriorly, sharply tapered to shortly before apex of keel. Parameres usually stout and blunt, $0.61 \times$ length of aedeagus. Epandrium, 10th tergite and cercopods (Figs 95, 96). Cercopod with enlarged head and very numerous retinacula.

\section{Remarks}

A single male from Mossman Gorge, N. Queensland, D. H. Colless, 23.iv.67 (ANIC, Duckhouse No. 2285) is close to B. impudica but distinctive in its shorter, stouter scape and pedicel (Fig. 97) and broader wing (Fig. 98). This is apparently a separate species but the specimen is too damaged to warrant naming.

Brunettia (Maurobrunettia) concubinalis, sp. nov.

\section{Material Examined}

Holotype. $O^{*}$, Queensland: Babinda, lowland rainf., 12.iv.71, D. and S. Duckhouse (ANIC, type No. 6089).

Paratypes. $40^{\circ}$, with holotype (ANIC, BMNH, BPB); $20^{\circ}$, Lake Eacham Natl Pk, rainf., $730 \mathrm{~m}$, 15.iv.71, Duckhouse (ANIC); 20', Palmerston Natl Pk, rainf., 370 m, 18.iv.71, Duckhouse (ANIC); $20^{\circ}$, Palmerston Nat1 Pk, rainf., 520 m, 30.iv.71, Duckhouse (ANIC); $10^{\circ}, 14 \cdot 5 \mathrm{~km}$ SSE. of Ravenshoe, 840 m, 21.iv.69, I. F. B. Common and M. Upton (ANIC).

Other material. All Queensland: $20^{\circ}$, Upper Mulgrave R, $16 \mathrm{~km}$ Goldsborough Rd, 9.v.67, D. H. Colless (ANIC); 50*, Mt Edith Forest Rd, $1.6 \mathrm{~km}$ off Danbulla Rd, 6.v.67, Colless (ANIC); $20^{\circ}$, Wongabel St. For., 5.v.67, Colless (ANIC).

\section{Description}

Close to $B$. impudica. Distinguished by the more enlarged anal region of the wing, much smaller mesothoracic allurement organs and differently shaped scape. 
Male. Head (Fig. 100) $0 \cdot 77 \times$ as long as broad; frons and clypeus wider and antennae more widely separated than $B$. impudica. Eyebridges separated by $2 \cdot 6$ facet diameters. Frontal scar patch larger than $B$. impudica. Anterior tentorial pit with fluting extending inward from lips; pit not linked to median edge of eye-line of sclerotisation starting from eye more anteriorly and hence ending blindly. Cibarium thick-walled anteriorly, tapered

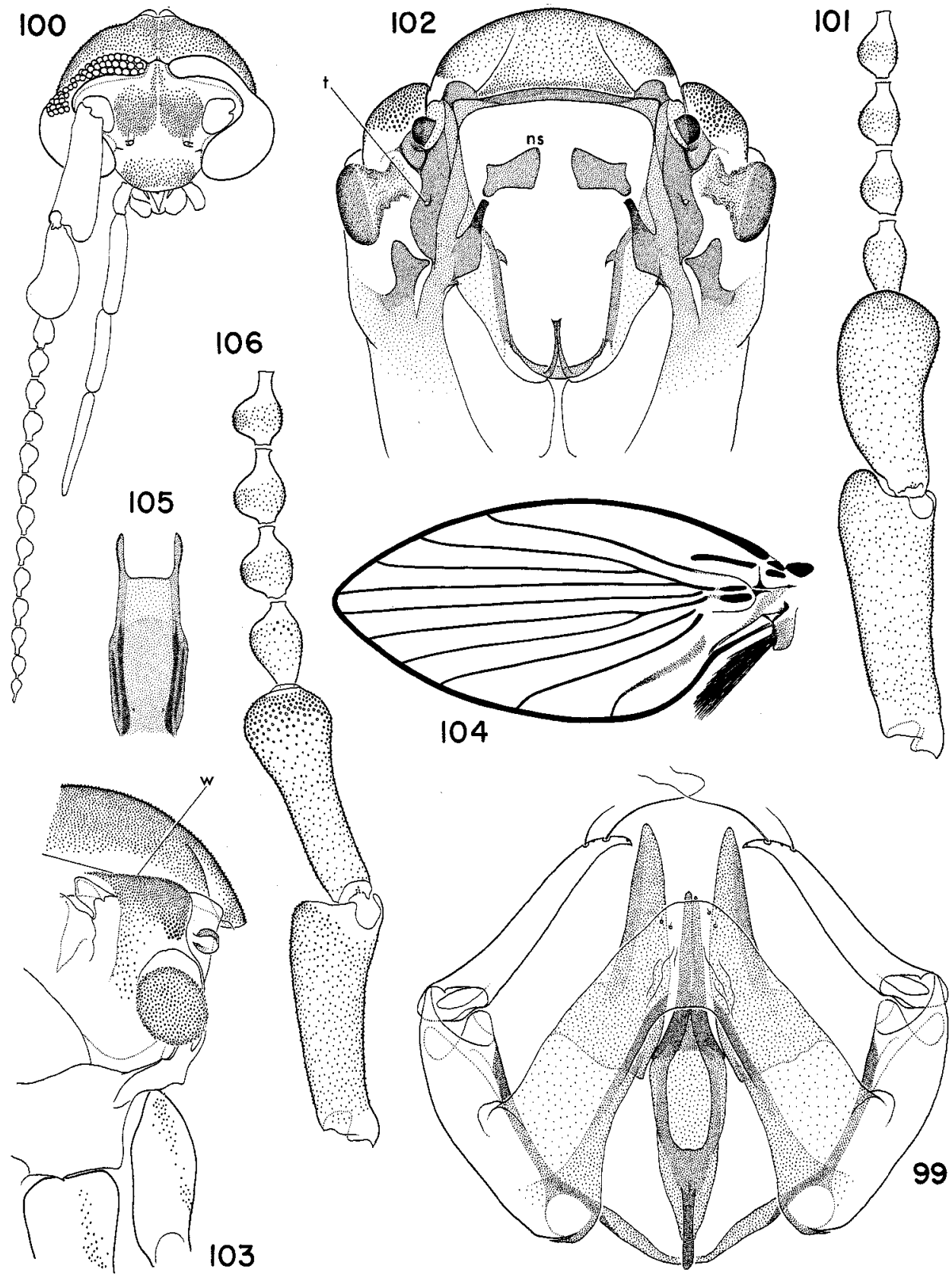

Figs 99-106. 99, Brunettia (Maurobrunettia) impudica, sp. nov., male: gonopods and aedeagus, dorsal. 100-104, Brunettia (Maurobrunettia) concubinalis, sp. nov., male: 100, head; 101, base of antenna; 102, anterior thorax, frontal view ( $t$, thoracic pore; $n s$, neck sclerite); 103 , anterior thorax, lateral ( $w$, wing of anepisternite); 104, wing. 105, 106, Brunettia (Maurobrunettia) immodesta, sp. nov., male: 105 , cibarium; 106 , base of antenna. 
posteriorly, arms stout, short. Palpi $(1 \cdot 0-3 \cdot 2-2 \cdot 5-3 \cdot 2) 1 \cdot 7 \times$ length of head; about 5 sensory rods on dorsal side of palpomere 1 . Antenna similar to $B$. impudica; $2.0 \times$ length of palp and $0.67 \times$ length of wing. Base of antenna, Fig. 101; scape $1.47 \times$ length of pedicel; medial side of scape more enlarged distally, base stout and unconstricted. Ascoids long, curled, slightly inflated at base.

Thorax (Figs 102, 103). Mesothoracic allurement organs similar to B. impudica but rounded in outline and far smaller. Anepisternite essentially as in $B$. impudica but shorter antero-posteriorly. Wing (Fig. 104) $2 \cdot 15 \times$ as long as broad, enlarged in anal region, costa exceptionally convex between costal node and tip of $R_{1} ; R_{2} 5 \cdot 3 \times$ length of $R_{2+3}$. Wing length $2 \cdot 05-2 \cdot 4 \mathrm{~mm}$.

Terminalia very similar to $B$. impudica. Style $0.97 \times$ length of coxite; aedeagal apodeme without lateral wings; parameres slender, uncinate at tips, $0.65 \times$ length of aedeagus. Cercopod shorter than B. impudica.

\section{Brunettia (Maurobrunettia) immodesta, sp. nov.}

Material Examined

Holotype. O O Queensland: Mt Hypipamee St. For., rainf., $1050 \mathrm{~m}, 14 . \mathrm{iv} .71$, D. and S. Duckhouse (ANIC, type No. 6091).

Paratypes. $30^{\circ}$, with holotype (ANIC, BMNH, BPB); $110^{\circ}$, same loc., 29.iv.71, Duckhouse (ANIC, BMNH, BPB).

\section{Description}

Similar to $B$. concubinalis, but pedicel elongate pyriform instead of reniform. Sister species of $B$. cinaeda sp. nov.

Male. Head (Fig. 107) $0.69 \times$ as long as broad; frons wide and antennae widely separated. Vertex low and rounded, occipital lobe very small. Eyebridges separated by 3.6 facet diameters. Frontal scar patch with deep triangular cleft anteriorly, and median scar-free line running back to posterior edge; broad posterior extension to between eyebridges. Anterior tentorial pit with lips not especially complex, no fluting; line of sclerotisation from median edge of eye prominent, ending blindly anterior to pit. Cibarium (Fig. 105) thickwalled anteriorly, tapered posteriorly, arms stout, in line with lateral walls or slightly divergent. Palpi $(1 \cdot 0-2 \cdot 6-2 \cdot 3-2 \cdot 8) 1 \cdot 9 \times$ length of head; about 5 sensory rods on dorsal side of palpomere 1 . Antenna $2.25 \times$ length of palp and $0.6 \times$ length of wing. Base of antenna, Fig. 106; scape $1.15 \times$ length of pedicel; similar to $B$. concubinalis but shorter and distally with angular projection in place of rounded medial enlargement; pedicel elongate pyriform. Ascoids (Fig. 108) long, curled, not inflated.

Thorax and allurement organs similar to B. concubinalis. Wing (Fig. 109) $2 \cdot 22 \times$ as long as broad, similar to $B$. concubinalis but less enlarged in humeral region and more enlarged in anal region; $R_{2} 5 \cdot 3 \times$ length of $R_{2+3}$. Wing length $2 \cdot 45-2 \cdot 65 \mathrm{~mm}$.

Terminalia (Figs 110,111 ) very similar to $B$. impudica and $B$. concubinalis, but coxites stouter, styles less pointed at tips and parameres and styles more slender; style $1.03 \times$ length of coxite. Cercopod (Fig. 111) with small head and fewer retinacula.

Material Examined

Brunettia (Maurobrunettia) cinaeda, sp. nov.

Holotype. $\quad$ O $^{\circ}$ Queensland: Babinda, lowland rainf., 12.iv.71, D. and S. Duckhouse (ANIC, type No. 6090).

Paratypes. 10, with holotype (ANIC); 1\%, Ingham-Wallaman Falls Rd, $245 \mathrm{~m}$, rainf., 3.iv.71, Duckhouse (BPB).

Other material. All Queensland: 20, Dunk I. Natl Pk, rainf. on hill slopes, 6.iv.71, Duckhouse (ANIC); $1 \sigma^{\circ}$, Mt Spec Natl Pk, Maidenhair Fern Gully, rainf. along ck, light trap, 31.iii.71, Duckhouse (ANIC); 10, Bramston Beach nr Innisfail, open savannah, 30.iv.67, D. H. Colless (ANIC). 


\section{Description}

Sister species of $B$. immodesta, as shown by terminalia, shape of wing and general form of antenna, but scape and pedicel short and ascoids very inflated basally.

Male. Head (Fig. 112) $0.68 \times$ as long as broad; vertex less high, frons and clypeus wider and antennae more widely separated than $B$. impudica and $B$. concubinalis. Eyebridges

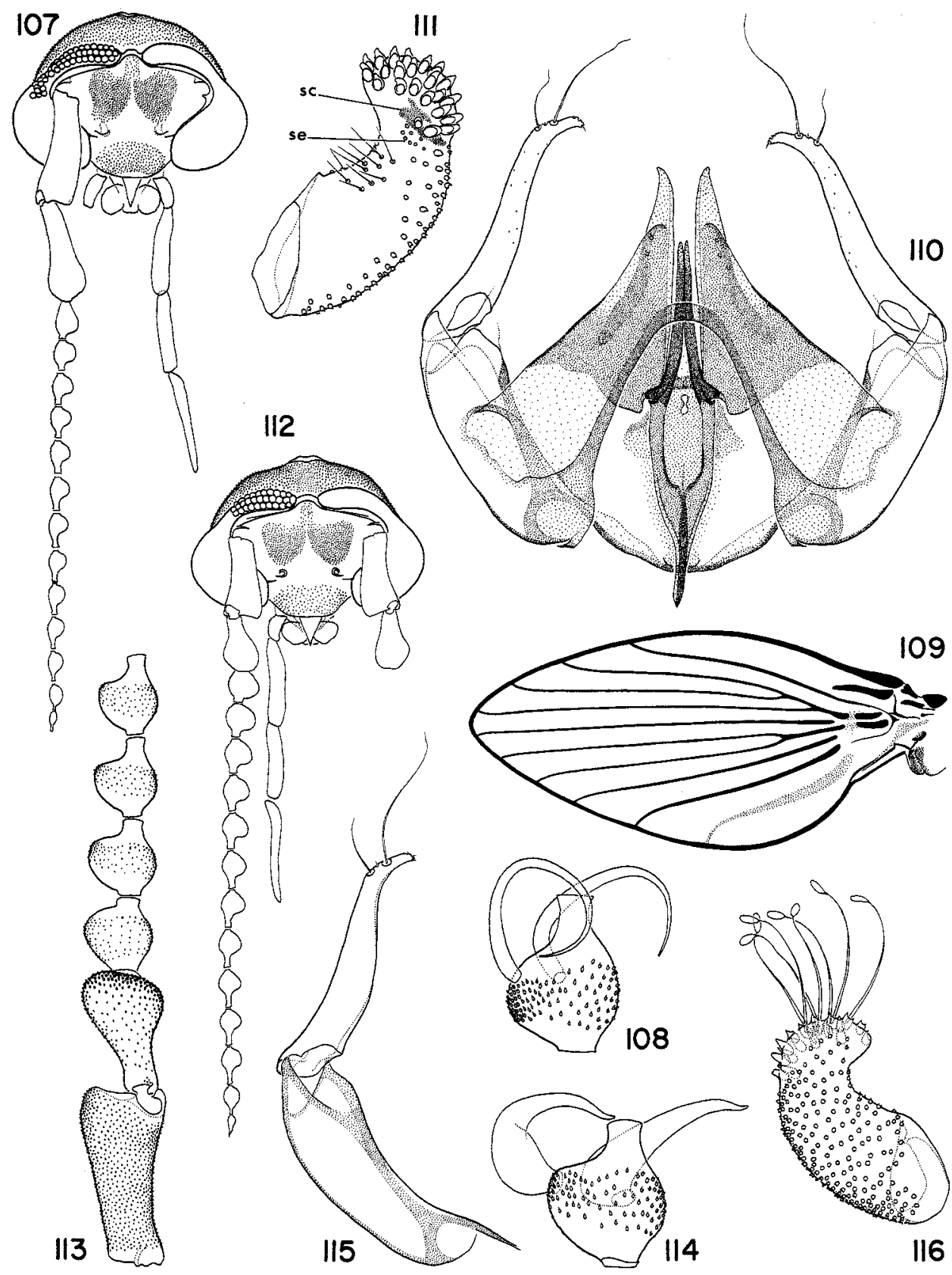

Figs 107-116. 107-111, Brunettia (Maurobrunettia) immodesta, sp. nov., male: 107, head; 108, flagellomere 3, with ascoids; 109, wing; 110, gonopods and aedeagus, dorsal; 111 , cercopod, inner face ( $5 c$, area of sclerotisation; se, shaftless sensilla). 112-116, Brunettia (Maurobrunettia) cinaeda, sp. nov., male: 112 , head; 113 , base of antenna; 114 , flagellomere 3 , with ascoids; 115 , gonopod, dorsal; 116 , cercopod, lateral. 
separated by 2.8 facet diameters, connected by broad sclerotised arch. Frontal scar patch very large. Anterior tentorial pit without fluting; not linked to median edge of eye; line of sclerotisation more anterior in position and hence ending blindly. Cibarium constricted posteriorly, posterior arms parallel. Palpi $(1 \cdot 0-3 \cdot 5-3 \cdot 0-3 \cdot 9) 2 \cdot 3 \times$ length of head; specimens pallid and sensory rods not visible. Antenna $2.1 \times$ length of palp and $0.75 \times$ length of wing. Base of antenna, Fig. 113; scape and pedicel short for Maurobrunettia; scape 1.3× length of pedicel, only just reaching beyond anterior edge of eye, medial side not especially enlarged distally, stout and unconstricted basally; pedicel pyriform; no clavate scales. First few flagellomeres with bulbs abnormally enlarged on inner sides. Ascoids (Fig. 114) curled, very inflated basally.

Thorax with mesothoracic allurement organs similar to $B$. concubinalis but larger, rounded in outline. Anepisternite similar to $B$. impudica; anterior process shorter and stouter, with stalk of allurement organ arising immediately under it. Wing almost identical to $B$. immodesta; $2 \cdot 36 \times$ as long as broad, anal region conspicuously enlarged, apical region narrowed; length of pencil of hair on jugum equal to distance from base of antenna to tip of $2 \mathrm{nd}$ flagellomere; $R_{2} 6.5 \times$ length of $R_{2+3}$. Wing length $2.0 \mathrm{~mm}$.

Terminalia very similar to $B$. immodesta and most other Maurobrunettia species. Gonopod, Fig. 115; style $0.96 \times$ length of coxite, more sinuous on medial margin; parameres $0.63 \times$ length of aedeagus, tapered to straight pointed tips. Cercopod (Fig. 116) short with small head; few retinacula with relatively large heads.

\section{Remarks}

The 'other material' differs from typical $B$. cinaeda in structural details, mainly of the antenna, perhaps indicating the presence of more than one species. Further material is required to evaluate this.

\section{Material Examined}

\section{Brunettia (Maurobrunettia) salax, sp. nov.}

Holotype. Or, Queensland: Eungella Natl Pk, $20^{\circ} 55^{\prime} \mathrm{S} ., 148^{\circ} 30^{\prime} \mathrm{E} ., 460-610 \mathrm{~m}$, open shade, 5.v.71, D. and S. Duckhouse (ANIC, type No. 6092).

Paratypes. $100^{\circ}$, with holotype (ANIC, BMNH, BPB); $10^{\circ}$, Eungella Natl Pk, $460-520 \mathrm{~m}$, streams and trickles, 27.iii.71, Duckhouse (ANIC); 20, Conway Natl Pk, cyclone devastated coastal for., $15 \mathrm{~m}$, dancing on upper leaf surfaces, 30.iii.71, Duckhouse (ANIC).

\section{Description}

Similar to preceding species but antenna with dense dark spines on outer sides of flagellomeres 3-5, and scape with massive medial enlargement distally.

Male. Vestiture dark, but in general much less dense and bushy than $B$. impudica. Head (Fig. 117) $0.73 \times$ as long as broad. Eyebridges separated by 3.6 facet diameters; internal cuticular ledge between eyebridges immediately anterior to interocular suture, very broad and bilobed (Fig. 118). Frontal scar patch divided by broad median scar-free band, also separated from its posterior prolongation by distinct gap. Anterior tentorial pit with small opening, lips conspicuously fluted. Line of sclerotisation from median edge of eye usually indistinct; where distinct, ending blindly anterior to pit. Cibarium similar to $B$. immodesta, posterior arms very stout. Palpi $(1 \cdot 0-3 \cdot 0-2 \cdot 6-3 \cdot 7) 1 \cdot 8 \times$ length of head; group of 3 sensory rods on dorsal side of palpomere 1 . Antenna $1.9 \times$ length of palp and $0.69 \times$ length of wing; very large dark fans of vestiture on inner sides of scapes, meeting in midline. Base of antenna, Fig. 119; scape $2.3 \times$ length of pedicel; massive medial enlargement distally; pedicel pyriform; necks of flagellomeres $1-4$ vestigial; bulbs of flags 3-5 enlarged, rounded, bearing dense lateral brushes of dark longitudinally fluted and ciliate spines. Ascoids (Fig. 120) very inflated.

Thorax with anepisternite tall, its anterior margin weakly concave; allurement organ about same size as $B$. concubinalis and $B$. immodesta, rounded in outline. Wing (Fig. 121) similar to $B$. impudica: $2 \cdot 5 \times$ as long as broad; little enlarged in anal and humeral regions; narrow scales on underside in basal half; length of pencil of hair on jugum equal to distance from base of antenna to beyond tip of 4 th flagellomere. $R_{2} 6 \cdot 9 \times$ length of $R_{2+3}$. Wing length $1 \cdot 75-2 \cdot 25 \mathrm{~mm}$. 
Terminalia (Fig. 128) similar to B. impudica but aedeagus shorter, aedeagal apodeme with smaller lateral wings and parameres slender. Style $0.91 \times$ length of coxite; apical region stouter than $B$. impudica.

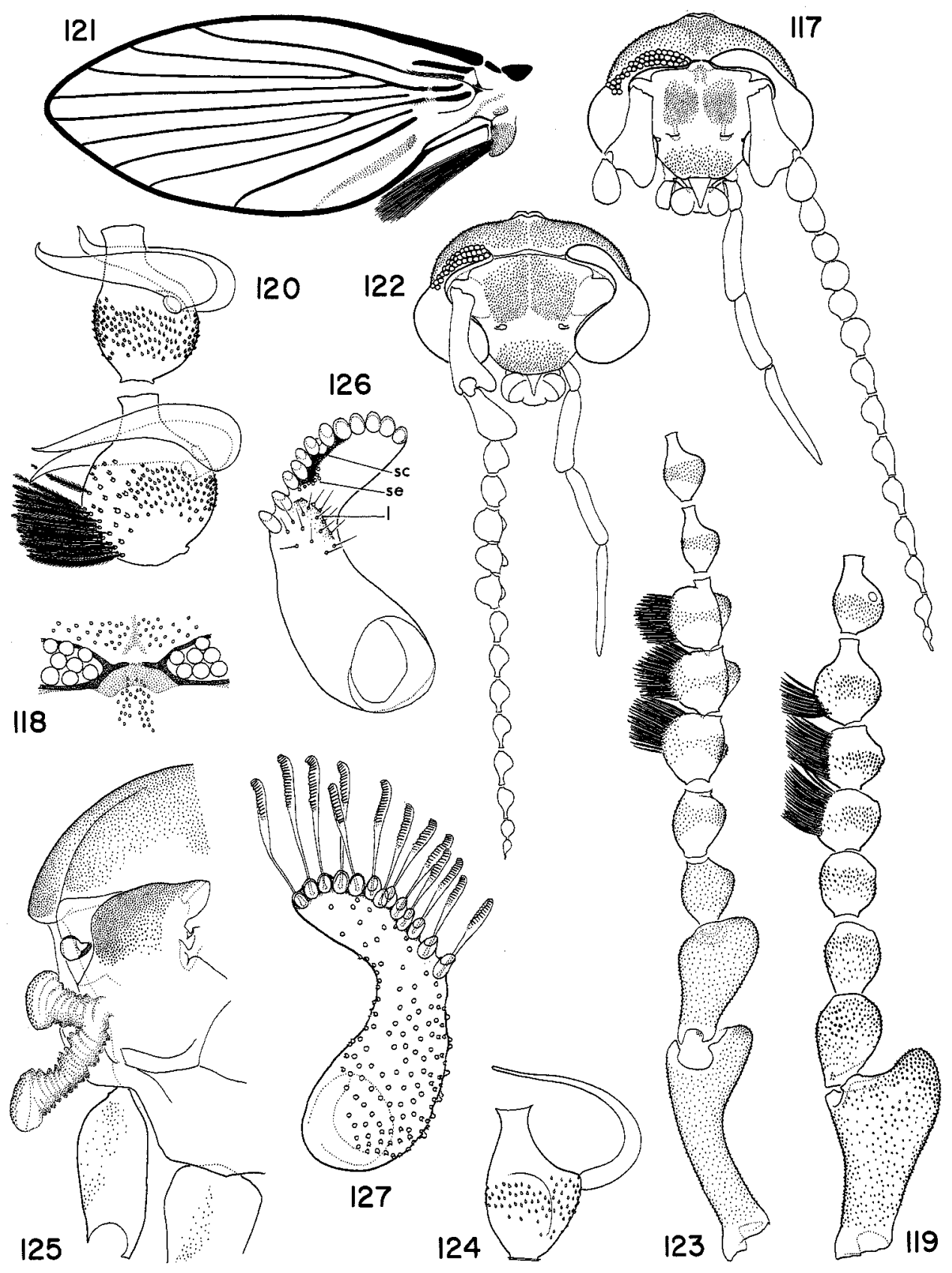

Figs 117-127. 117-121, Brunettia (Maurobrunettia) salax, sp. nov., male: 117, head; 118, area between eyebridges; 119 , base of antenna; 120, flagellomeres 5 and $6 ; 121$, wing. 122-127, Brunettia (Maurobrunettia) eximia, sp. nov., male: 122 , head; 123 , base of antenna; 124 , flagellomere $6 ; 125$, anterior thorax, lateral; 126, cercopod, inner face ( $s c$, area of sclerotisation; se, shaftless sensilla; $l$, spinous lobe); 127 , cercopod, outer face. 
Material Examined

Brunettia (Maurobrunettia) eximia, sp. nov.

Holotype. o , Queensland: Eungella Natl Pk, 460-520 m, streams and trickles, 27.iii.71, D. and S. Duckhouse (ANIC, type No. 6093).

\section{Description}

An anomalous species, linked with $B$. salax by antennal features, including the presence of dense dark spines on the outer sides of flagellomeres 3-5, but lacking the features of the cercopods that especially characterise Maurobrunettia: retinacula not clavate but with spore capsule tips; not clustered but uniseriate on upper side of cercopod, as in Atrichobrunettia. See discussion at end of section on Maurobrunettia.

Male. Head (Fig. 122) $0.69 \times$ as long as broad. Frons very broad and antennae widely separated; frontal scar patch clearly divided by median scar-free band, no posterior prolongation. Vertex broad, low, with large rounded shoulders; scars divided by median scar-free band. Eyebridges separated by 11.7 facet diameters or $0.32 \times$ width of head. Anterior tentorial pit with lips complex but not fluted. No line of sclerotisation from median edge of eye. Palpi (1.0-2.9-2.4-3.3) 1.9 $\times$ length of head. Antenna $1.8 \times$ length of palp and $0.7 \times$ length of wing; large dark fans of vestiture on inner sides of scapes, meeting in midline. Base of antenna, Fig. 123; scape conspicuously curved, medial enlargement distally, $1.66 \times$ length of pedicel; pedicel pyriform, proportionately longer than $B$. salax, similar shape to $B$. cinaeda. As in $B$. salax, necks of flagellomeres 1-4 vestigial, and bulbs of flags 3-5 enlarged, bearing dense brushes of dark spines on outer sides; spines longitudinally fluted and ciliate as in $B$. salax. Ascoids (Fig. 124) digitate, much less inflated than $B$. salax.

Thorax (Fig. 125). Anepisternite with scars concentrated anteriorly, but none enlarged as in typical Maurobrunettia species. Allurement organs stalked, furcate, each ramus with long corrugated stem and small rounded head bearing pits. Wing $2.55 \times$ as long as broad; very similar to $B$. salax (Fig. 121); more pointed than $B$. impudica, and posterior margin conspicuously more convex than anterior; little enlarged in anal and humeral regions; long hair pencil on jugum; denuded jugum subdivided into proximal region bearing large scars and distal region bearing fine scars left by hairs of pencil, and with cuticular supports; $R_{2} 7 \cdot 5 \times$ length of $R_{2+3}$. Wing length $2 \cdot 13 \mathrm{~mm}$.

Terminalia (Figs 126, 127, 129). Gonopods and aedeagus similar to B. salax. Gonopod, especially coxite, stouter; style only $0.89 \times$ length of coxite, tip more evenly curved and paired setae displaced further from tip. Aedeagus with lateral margins forming rounded 'racquet' region; apodeme very broad at base, tapered to narrow tail without wings. Parameres stout and blunt, $0.66 \times$ length of aedeagus. Epandrium shorter than broad, pair of small rounded apertures. Cercopod (Fig. 127) strongly curved; about 13 retinacula, uniseriate on outer side, tips apparently as in Atrichobrunettia but only visible in lateral view. On inner side of cercopod (Fig. 126) line of sclerotisation (sc) running along middle region of line of retinacula, and cluster of shaftless sensilla (se) abutting sclerotisation; spinous lobe $(l)$ at elbow.

\section{Brunettia (Maurobrunettia) consobrina, sp. nov.}

\section{Material Examined}

Holotype. $\sigma^{\circ}$, Queensland: Mt Spec Natl Pk, rocky foothills, Maidenhair Fern Gully, 275 m, rainf. along ck. in dry sclerophyll for., light trap, 31.iii.71, D. and S. Duckhouse (ANIC, type No. 6094).

\section{Description}

Recognised amongst Maurobrunettia species by its small scape and pedicel; wing without enlargements in anal and humeral regions, and eyebridges not constricted basally. Cercopod bearing only about 15 clavate retinacula and without the usual sclerotisation adjacent to them. 
Male. Head (Fig. 130) $0.7 \times$ as long as broad. Eyebridges not constricted basally, separated by $2 \cdot 3$ facet diameters, connected by very low arch. Frontal scar patch large with median extension to between eyebridges, deep triangular emargination anteriorly, contiguous with median scar-free band which reaches tip of median extension. Anterior tentorial pit with complex sclerotisations running towards margin of eye. Cibarium thickwalled anteriorly, constricted posteriorly, arms slender. Palpi $(1 \cdot 0-3 \cdot 1-2 \cdot 7-3 \cdot 1) 1 \cdot 65 \times$ length

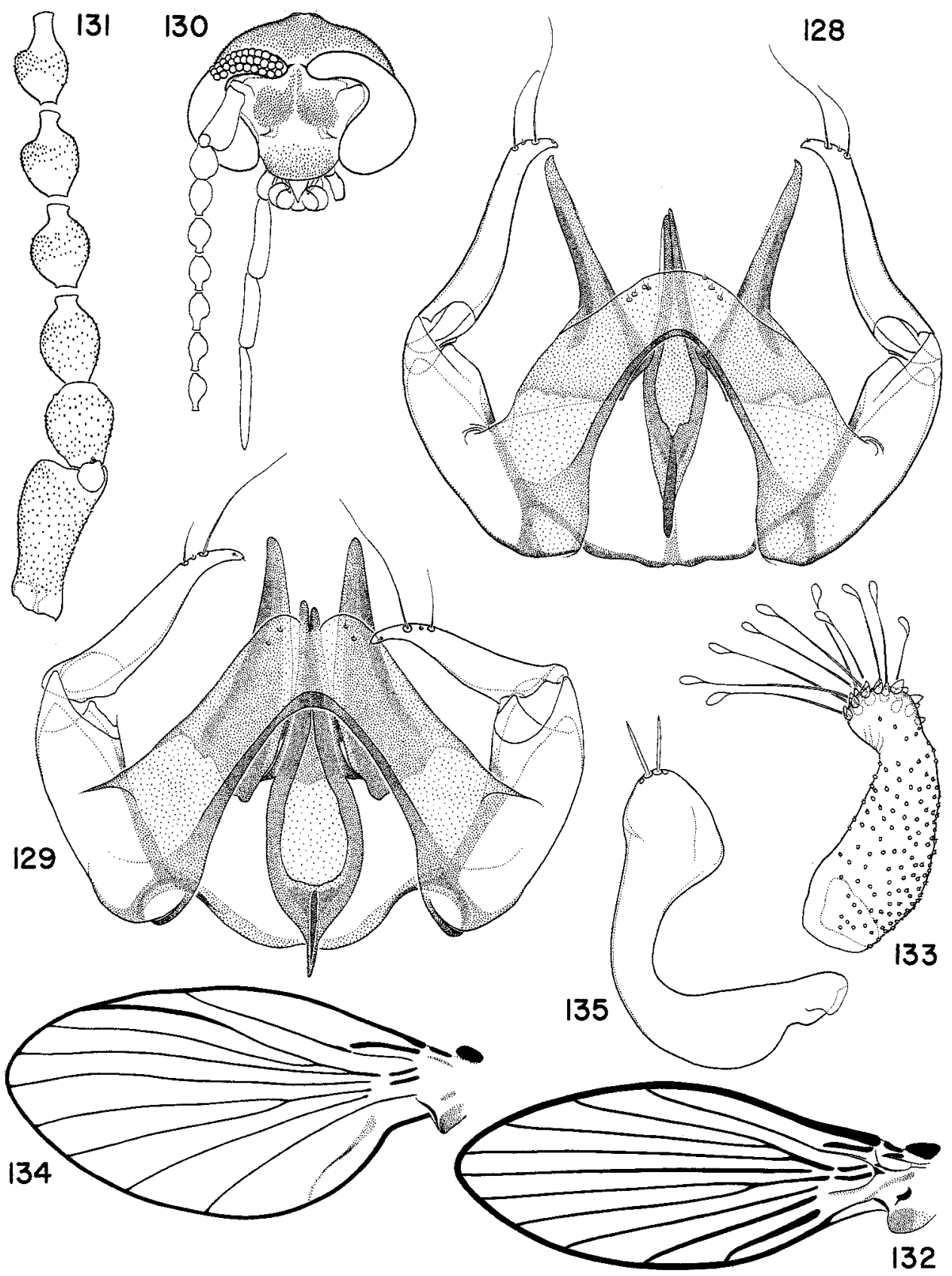

Figs 128-135. 128, Brunettia (Maurobrunettia) salax, sp. nov., male: gonopods and aedeagus, dorsal. 129, Brunettia (Maurobrunettia) eximia, sp. nov., male: gonopods and aedeagus, dorsal. 130-133, Brunettia (Maurobrunettia) consobrina, sp. nov., male: 130, head; 131, base of antenna; 132, wing; 133, cercopod. 134,135, Brunettia (Campanulobrunettia) sinuosa Quate and Quate, male: 134, wing; 135 , style. 
of head; small cluster of sensory rods on dorsal side of palpomere 1 . Antenna $2 \cdot 2 \times$ length of palp and $0.8 \times$ length of wing. Base of antenna, Fig. 131; scape and pedicel little larger than in typical Atrichobrunettia species, but pedicel distinctly pyriform; scape $1.8 \times$ length of pedicel; ascoids long, digitate, curled.

Thorax: anepisternite typical for Maurobrunettia, anterior margin rising steeply into large 'wing'; allurement organ small, mushroom-shaped. Wing (Fig. 132) not enlarged in anal and humeral regions, $2 \cdot 5 \times$ as long as broad; $R$ fork basal to $M$ fork; $R_{2} 6 \cdot 8 \times$ length of $R_{2+3}$. Wing length $1.67 \mathrm{~mm}$.

Terminalia (Figs 133, 136). Gonopods close-set. Style $0.9 \times$ length of coxite, stout, rapidly constricted just beyond halfway from base to tip. Aedeagus very short; distal blades exceedingly short, stout, very unequal in length, strongly convergent, rounded tips partially crossing; apodeme with narrow lateral wings. Parameres slender, $0.6 \times$ length of aedeagus. Epandrium shorter than broad, apertures not clearly visible but apparently paired. Cercopod (Fig. 133) of Maurobrunettia type, but only about 13-14 retinacula on abnormally small head, tips large and clavate; no sclerotisation adjacent to retinacula.

\section{Remarks}

On first acquaintance, Maurobrunettia is separated from Atrichobrunettia by clear discontinuities. However, as is so often found, there are some rare species in which the discontinuities are not maintained. In $B$. eximia, the cercopods and retinacula are as in Atrichobrunettia, and in $B$. consobrina there is an all-round weakening of subgeneric characters, to the extent that if this had been the only Maurobrunettia discovered it would, doubtless, have been regarded as an aberrant Atrichobrunettia. But in both forms the thoracic allurement organs are protuberant and stalked as in Maurobrunettia. Such organs do not occur in Atrichobrunettia. What is the phylogenetic status of these species?

I suggest that $B$. consobrina is a Maurobrunettia exhibiting partial secondary loss of the specialisations of Maurobrunettia.

$B$. eximia is more difficult because it shows a combination of features shared with B. (Maurobrunettia) salax (flagellomeres 3-5 enlarged, with brushes of short, dark, fluted and ciliate spines on outer sides; form of wing) and Atrichobrunettia (cercopod of typical shape for this subgenus, bearing uniseriate retinacula with fringed heads). The features shared with $B$. salax are not known in any other psychodids, even in Maurobrunettia, and are therefore synapomorphisms, indicating that $B$. eximia and $B$. salax are sister species. Those that are shared with Atrichobrunettia are features of that entire subgenus, and both uniseriate retinacula and retinacula with heads resembling those in $B$. eximia also occur in the outgroup, Setomima (Fig. 1). They are therefore more probably plesiomorphic. I conclude that $B$. eximia is either the true sister species of $B$. salax, with cercopods and retinacula showing reversion towards the ancestral condition, or a hybrid between $B$. salax and a species of Atrichobrunettia, possibly close to $B$. albifrons, sp. nov. The latter hypothesis is supported by the fact that $B$. eximia was collected in the same locality as $B$. salax, but nowhere else, and by the degree of detail with which its wing and antenna agree with $B$. salax, and its cercopod with Atrichobrunettia. Hybridisation with $B$. albifrons, or a related species, would help to explain a number of features, including the wide separation between the eyebridges, the frontal scar patch without posterior prolongation, the slender scape, the broad-based and more nearly triangular form of the styles, and the aedeagus, which is very broad and rounded anteriorly.

Subgenus Campanulobrunettia, subg. nov.

Type species: Brunettia uncinata, sp. nov., by present designation.

Probable plesiomorph sister group of subg. Brunettia.

\section{Definition}

Male. Head generally broad. Eyebridges of 3 facet rows, not especially arched, rarely contiguous. Scape usually short, not reaching level of anterior margin of eye except in B. longiscapa Quate and Quate gp.; pedicel subspherical. Bulbs of flagellomeres often very enlarged where ascoids are inserted-forming shoulders, or in extreme cases wing-like projections (e.g. B. goliath Quate and Quate, B. heterostylis, sp. nov.); but in dorsal view 
the projections and their attached ascoids tend to be placed one above the other, thus in outline the flagellomeres look deceptively like those of other subgenera. Ascoids palmate, with many branches.

No thoracic allurement organs. Anepisternite with scars uniform; protuberant, but anterior margin not especially excavated and not tending to form spine-shaped projection below spiracle as in Maurobrunettia.

Wing tending to enlarge in anal and humeral regions, generally broad, sometimes very broad as in more specialised species of subg. Brunettia; veins and membrane covered in prostrate overlapping scales; veins sclerotised, but precise limits indistinct; denuded wing with scars on veins mostly no larger or denser than on membrane between, except at bases and to a lesser extent tips of veins. $\mathbf{R}$ fork above or basal to $\mathbf{M}$ fork; wing apex rounded and above tip of $\mathrm{R}_{5}$. CuA $\mathrm{A}_{2}$ tends to be poorly defined, unsclerotised, but not especially broad; in B. onerata Quate and Quate, secondarily lost except for extreme base. Jugum usually with thick tuft of glutinous-looking scales anteriorly, supplied by enlarged trachea, supported by sclerotised struts (e.g. B. uncinata, Fig. 140).

Style with apical setae short, straight, subequal; paired in all species except $B$. tenuistyla Quate and Quate; aedeagal apodeme generally broad and winged; parameres usually strongly convergent and pressed together in midline. Otherwise, terminalia variable but tending to show several characteristic features, overlapping in various combinations: (i) segregation of retinacula into separate terminal and ventral groups; (ii) presence of hooded or bell-shaped tips on terminal retinacula; (iii) styles flattened and enlarged, forming paddle shape; (iv) apical region of style etiolated, leaving paired apical setae abnormally remote from tip*. Retinacula never clavate or uniseriate; cercopod without sclerotisation adjacent to retinacula as seen in most Maurobrunettia and Atrichobrunettia species.

\section{Remarks}

Quate \& Quate (1967) state that $\mathrm{CuA}_{2}$ is 'completely absent' in $B$. anfracta Quate and Quate, but show it clearly in their figure. Examination of the holotype confirms that it is absent.

\section{Distribution}

Campanulobrunettia is restricted to Australia and Papua-New Guinea. It appears to reach its greatest diversity in Papua-New Guinea, and in Australia it is only known from the tropics, south to $17^{\circ} \mathrm{S}$.

\section{Key to Males of Species of subg. Campanulobrunettia}

1. Veins $R_{2}-R_{5}$ sinuous and $R_{2}$ thickened in distal half (Fig. 134); style strongly uncinate and capitate (Fig. 135) (New Guinea) .......................... B. sinuosa Quate and Quate

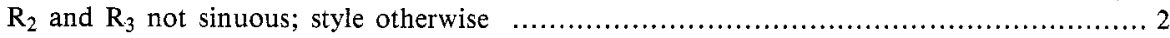

2. Style distinctly paddle-shaped, as broad as coxite in distal quarter (e.g. Fig. 168) .......... 3

Style not paddle-shaped, less than half as broad as coxite in distal quarter $\ldots \ldots \ldots \ldots \ldots \ldots \ldots 6$

3 Post-hypandrial plate strongly shouldered (e.g. Fig. 159); style with 2 enlarged setae distally Place of the usual place of the usual pair (New Guinea) B. adunata, sp. nov.

4. Aedeagal apodeme truncated; scars on vertex divided by median scar-free band ............. 5 Aedeagal apodeme drawn out into tail; scars on vertex not divided medially (New Guinea) B. remostyla Quate and Quate

5. Wing broad, anal region very enlarged (Fig. 158) (New Guinea) ... B. heterostylis, sp. nov. Wing narrow, anal region no more enlarged than humeral region (New Guinea)

B. palmata Quate and Quate

6. Apical region of style etiolated, leaving paired apical setae abnormally remote from tip, and region beyond setae narrow and tapered (e.g. Fig. 151) $\ldots \ldots \ldots \ldots \ldots \ldots \ldots \ldots \ldots \ldots \ldots \ldots$

Apical region of style not etiolated and apical setae not remote from tip .................. 10

*(i)-(iii) also occur in some Psychodinae that are more basal cladistically (Fig. 1), notably the maruinine genera Alepia (a probable member of line b), and Setomima; and if these taxa are used as outgroups, the characters in question are identified as plesiomorphisms. 
7. Parameres strongly capitate (Papua, Murua; New Guinea) ... B. longiscapa Quate and Quate

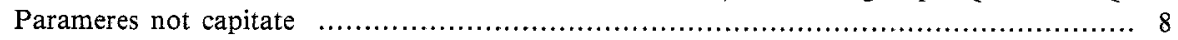

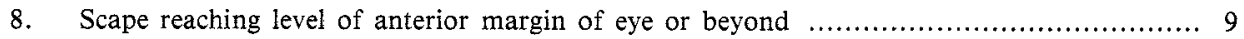
Scape not reaching level of anterior margin of eye (Northern Territory)

B. ultima, sp. nov.

9. Parameres slender, tapered and uncinate (Queensland) Parameres apically enlarged and coiled (New Guinea) B. uncinata, sp. nov.

10. Style bifurcated apically (New Guinea) B. anfracta Quate and Quate

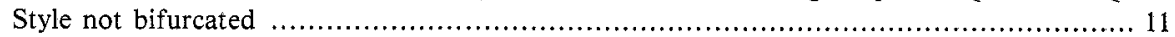

11. Eyebridges contiguous; retinacula segregated into terminal and ventral groups (New Guinea) B. cyclops Quate and Quate

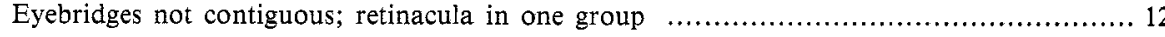

12. Wing far longer than broad, slender; flagellomeres without wing-like projections (Papua, Murua) ................................................ B. tenuistyla Quate and Quate Wing broader than long; flagellomeres with large wing-like projections (New Guinea)

B. goliath Quate and Quate

Brunettia (Campanulobrunettia) uncinata, sp. nov.

Material Examined

Holotype. $\sigma^{\circ}$, Queensland: Mossman Gorge, rainf., $80 \mathrm{~m}, 9 . \mathrm{iv} .71$, D. and S. Duckhouse (ANIC, type No. 6095).

Paratype. 10 , with holotype (ANIC).

\section{Description}

Similar to B. anfracta Quate and Quate, but male distinguished by the exceptionally enlarged humeral region of the wing, and by parameres that are slender, spiniform and strongly uncinate, instead of enlarged and coiled.

Male. Vestiture of specimens in alcohol dark brown, no visible banding on legs; wing scales greenish iridescent by reflected light.

Head (Fig. 137) $0.8 \times$ as long as broad, broader than B. anfracta; vertex low, scars not separated medially; occipital lobes prominent. Eyebridges very narrowly separated. Frontal scar patch sharply divided, longer antero-posteriorly than $B$. anfracta, no median extension. Anterior tentorial pit very small and thick-lipped, linked to medial edge of eye by stout band of sclerotisation. Cibarium (Fig. 138) strongly tapered in posterior half, arms slender, parallel. Labrum epipharynx conspicuously ciliate laterally as in B. ciliaris. Palpi $(1 \cdot 0-$ $4 \cdot 0-3 \cdot 2-4 \cdot 3) 1 \cdot 98 \times$ length of head; sensory rods on dorsal side of palpomere 1 . Verticils dark, rather shallowly cupuliform to spreading. Antenna $1.65 \times$ length of palp and $0.6 \times$ length of wing. Base of antenna, Fig. 139; scape long, $3.9 \times$ length of pedicel, extending to beyond level of eye by distance equal to length of pedicel, basal half precisely cylindrical, 'apicomedian' region of Quate and Quate enlarged and bearing dense patch of vestiture as in $B$. longiscapa Quate and Quate, but rounded, not sharply angular; pedicel rounded, with collar-like basal constriction; basal bulbs of flagellomeres roughly cordate, as in $B$. longiscapa, but shoulders unequally developed; necks up to $0.66 \times$ length of bulbs (flag. 9)

Thorax: wing of anepisternite produced strongly backwards. Wing (Fig. 140) broad; costal node triangular; jugal lobe with brush very large and thick, formed of firmly attached scales, supplied by enlarged trachea. Humeral region exaggerated. Forks at same level, $\mathrm{R}_{2}$ $5.4 \times$ length of $R_{2+3}$. Scales on wing broad, about $2 \times$ as long as broad. Wing length $2.5 \mathrm{~mm}$.

Terminalia (Figs 141-143). Style $0.96 \times$ length of coxite, slender, apical region etiolated [(iv), above], hooked inwards; coxite showing lateral groove. Hypandrium curved less strongly backwards than in most Brunettia species. Aedeagus: basal apodeme broad, with prominent keel; distal blades coarse, triangular, and tips widely separated; sides of aedeagus forming prominent, laterally directed points at level of bases of parameres. Gonocoxal apodemes forming pair of rounded lobes anteriorly, flanking aedeagal apodeme. Parameres long, slender, spiniform, strongly uncinate: in lateral view a pair of hooks curved upward 
then forwards. Cercopod (Fig. 142) with retinacula segregated into separate terminal and ventral groups [(i), above]; terminal retinacula having long slender stems, angled as shown, tips essentially as in Setomima gloriosa (Tonnoir): distal region of stem with lateral serrations, lengthening towards tip, then curved over to form large apical hood, appearing in frontal view as bell tip [(ii), above]; ventral retinacula with short, stout stems and abbreviated tips. Tenth tergite, Fig. 143.

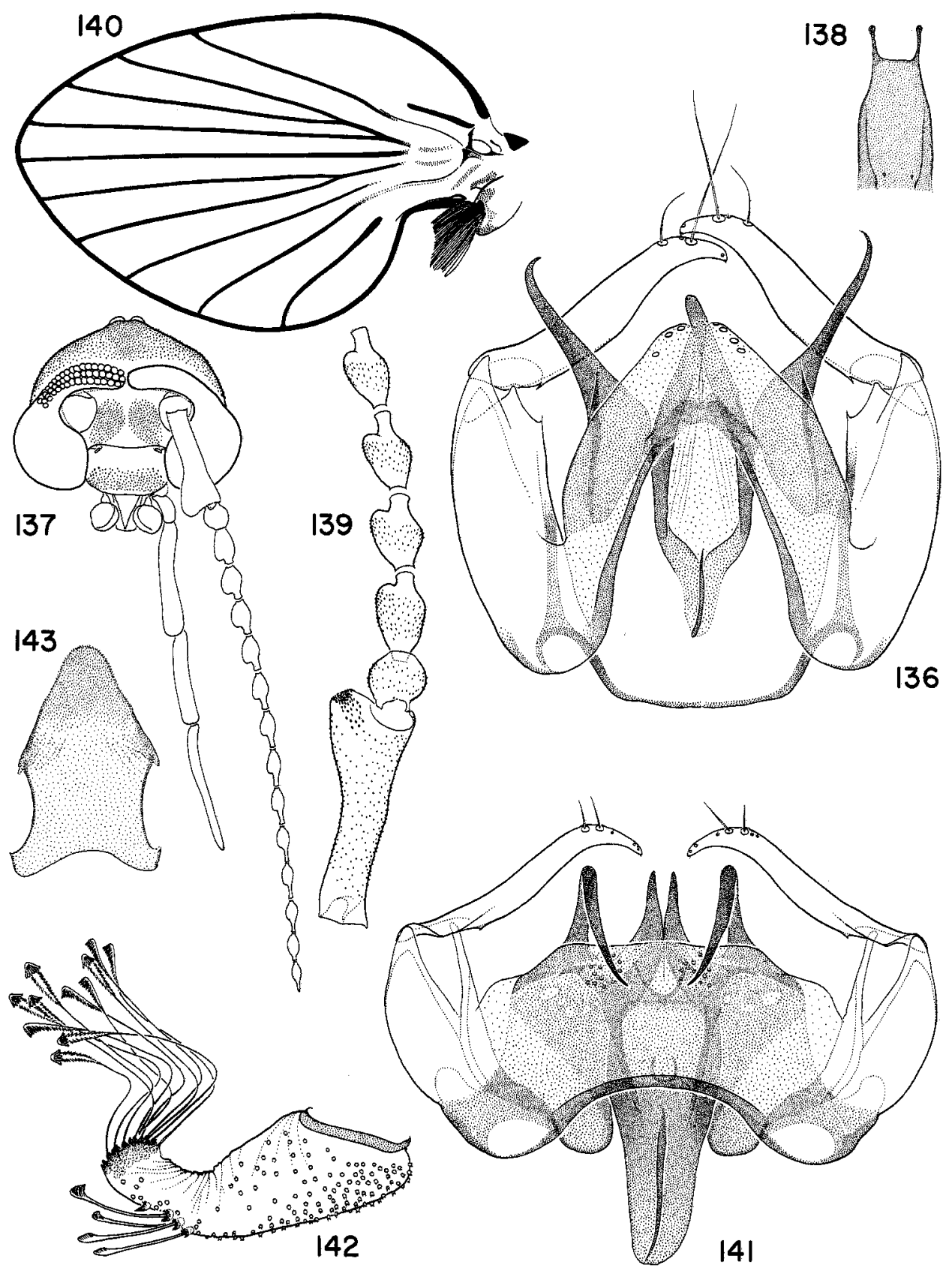

Figs 136-143. 136, Brunettia (Maurobrunettia) consobrina, sp. nov., male: gonopods and aedeagus, dorsal. 137-143, Brunettia (Campanulobrunettia) uncinata, sp. nov., male: 137, head; 138 , cibarium; 139 , base of antenna; 140, wing; 141 , gonopods and aedeagus, dorsal; 142, cercopod; 143 , tenth tergite. 
Brunettia (Campanulobrunettia) ultima, sp. nov.

Material Examined

Holotype. $\sigma$, Northern Territory: Coburg Peninsula, Black Point, $11^{\circ} 09^{\prime}$ S., $132^{\circ} 09^{\prime}$ E., 24.i.77, E. D. Edwards (ANIC, type No. 6096).

Paratypes. $10^{\circ}$, Wessel Is, Rimbija I., $11^{\circ} 01^{\prime}$ S., $136^{\circ} 45^{\prime}$ E., malaise trap, 13-14.ii.77, T. A. Weir (ANIC); 1o, same locality, 21.i.77, E. D. Edwards (ANIC).

\section{Description}

Similar to $B$. anfracta, $B$. uncinata and $B$. longiscapa, but male distinguished by its narrow wing and simple tapered parameres.

Male. Vestiture unknown. Head (Fig. 144) similar to $B$. anfracta, $0.8 \times$ as long as broad; scars on vertex not separated medially. Eyebridges separated by $2 \cdot 2$ facet diameters, interocular suture as in $B$. anfracta. Frontal scar patch divided anteriorly, united posteriorly and with prominent median extension to between eyebridges. Anterior tentorial pit neither small nor thick-lipped; faintly linked to median edge of eye. Cibarium slightly tapered in distal half; arms slender, weakly divergent. Labrum epipharynx ciliate laterally, as in B. ciliaris. Palpi $(1 \cdot 0-3 \cdot 4-3 \cdot 2-3 \cdot 9) 1 \cdot 68 \times$ length of head; sensory rods on dorsal side of palpomere 1 . Antenna $1.8 \times$ length of palp and $0.7 \times$ length of wing. Base of antenna, Fig. 145; scape short-scape and pedicel not reaching level of anterior edge of eye; pedicel rounded; basal bulbs of flagellomeres with ascoids on well-developed shoulders, but proximal region of bulb also more enlarged than $B$. uncinata. Basal flagellomeres and ascoids, Fig. 146.

Thorax (Fig. 147). Anepisternite swollen, projecting beyond anterior rim of mesothorax, only very slightly excavated adjacent to spiracle. Wing (Fig. 148) rather narrow, $2 \cdot 4 \times$ as long as broad; anal and humeral regions little enlarged; jugal lobe with brush large and thick, apparently as in $B$. uncinata, but tracheal enlargement less evident. Forks incomplete (bases of $R_{3}$ and $M_{1}$ lacking); $R$ fork very basal to $M$ fork, $R_{2} 7 \cdot 0 \times$ length of $R_{2+3}$. Scales on wing narrow, about $7 \times$ as long as broad. Wing length $1.65-1.75 \mathrm{~mm}$.

Terminalia (Figs 149-151). Style as long as coxite, similar to B. uncinata, broader at base, apical third more slender and less hooked; coxite without lateral groove. Hypandrium as in $B$. uncinata. Aedeagus: basal apodeme broader than $B$. uncinata-widened laterally at level of bases of coxites, keel faint; distal blades finely tapered, tips closely adpressed; sides of aedeagus forming laterally directed points at level of bases of parameres. Gonocoxal apodemes forming pair of triangular lobes anteriorly, beneath sides of aedeagal apodeme. Parameres curved backwards, distal halves uniform in width, tips broad and rounded. Epandrium (Fig. 149) with large unsclerotised area adjacent to basal thickening, partly overlaid by microsetose membrane as shown; posterior corners sharply angled. Cercopod (Fig. 150) shorter and stouter than B. uncinata, apical lobe smaller; retinacula similar to B. uncinata.

\section{Brunettia (Campanulobrunettia) heterostylis, sp. nov.}

\section{Material Examined}

Holotype. o, New Guinea: Central Province, Rouna Falls, wet mossy cliffs, 24.v.86, J. W. Ismay (ANIC, type No. 6097).

\section{Description}

Large species showing combination of flagellomeres with lateral wings, as in $B$. goliath Quate and Quate, and paddle-shaped styles as in B. remostyla Quate and Quate.

Male. Vestiture unknown. Head (Fig. 153) $0.77 \times$ as long as broad; vertex more conical than dome-shaped, its scars weakly divided by median scar-free band. Eyebridges widely separated by $7 \cdot 4$ facet diameters, cuticle wrinkled between eyebridge and antennal insertion area; interocular suture a pair of indistinct tapered spurs. Frontal and clypeal region broad, and antennae widely separated. Frontal scar patch divided medially, no median extension. 
Fronto-clypeal suture prominent. Anterior tentorial pit fairly large, lips normal, tubes with complex fluting, linked to median edges of eyes. Cibarium (Fig. 154) stout, very thick-walled anteriorly, arms short and divergent. Labellum (Fig. 155) with transverse row of short, stout spines on band of darkly sclerotised cuticle. Palpi $(1 \cdot 0-3 \cdot 8-3 \cdot 9-4 \cdot 8) 2 \cdot 28 \times$ length of head; palpomere 2 inflated, sensory rods on dorsal side of 1 st. Antenna $1.4 \times$ length of palp and $0.55 \times$ length of wing. Scape short, $2 \cdot 1 \times$ length of pedicel, reaching just over half way to level of anterior edge of eye; flagellomeres with ascoids on prominent lateral wings

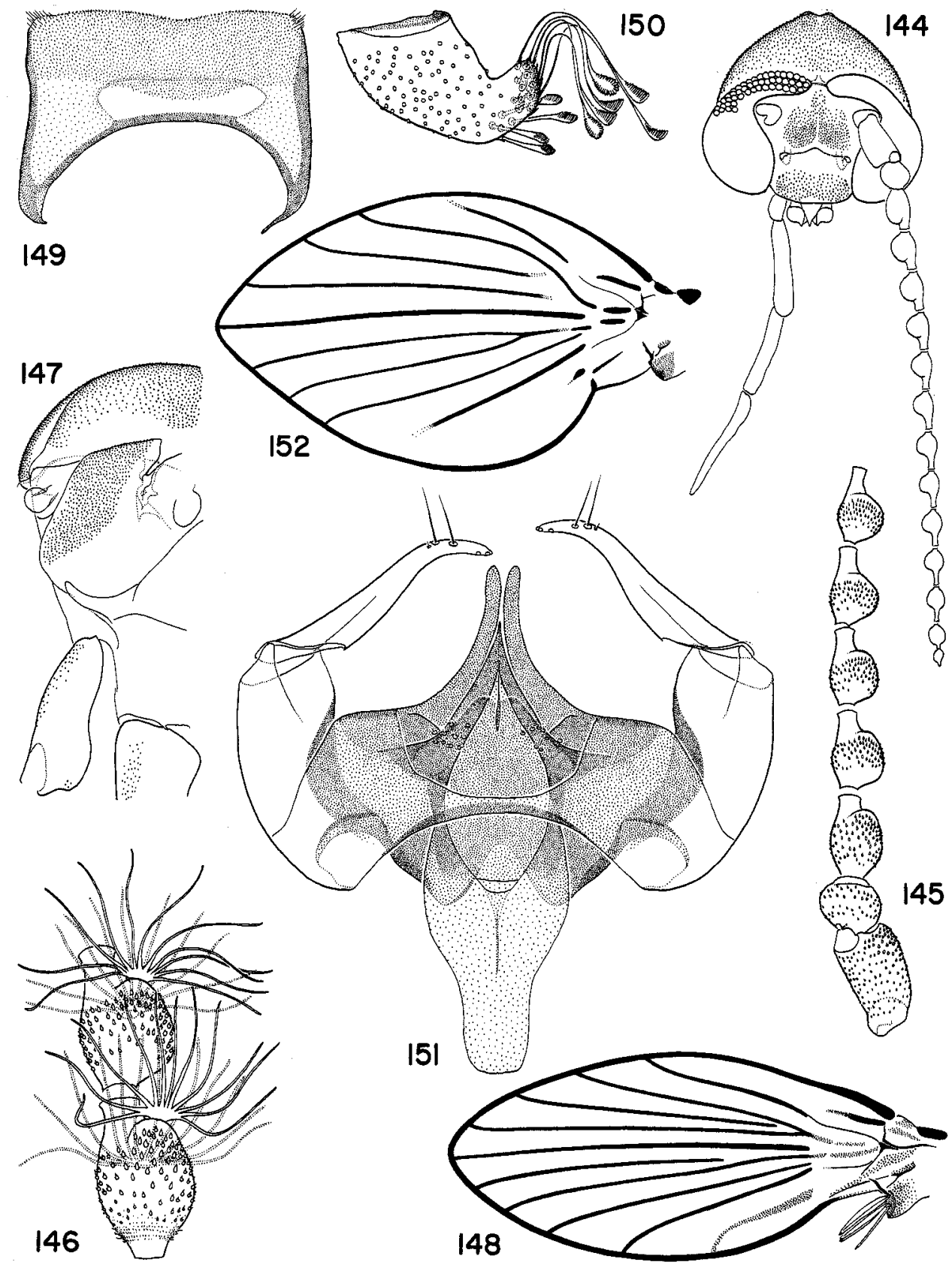

Figs 144-152. 144-151, Brunettia (Campanulobrunettia) ultima, sp. nov., male: 144, head; 145 , base of antenna; 146, flagellomeres 1 and 2; 147, anterior thorax, lateral; 148, wing; 149, epandrium; 150, cercopod; 151, gonopods and aedeagus, dorsal. 152, Brunettia (Brunettia) onerata Quate and Quate, male: wing. 
(Fig. 156), not clearly visible on distal flagellomeres because on the only specimen antenna is twisted distally, giving view in profile (Fig. 157); last flagellomere continuously tapered from bulb to tip of apiculus, as in Setomima species; apiculus with single lateral seta on dome-shaped base and 2 short sensory setae at tip.

Thorax with anepisternite swollen, but less so than $B$. ultima; anterior margin with thoracic pore on nipple. Wing (Fig. 158) $1.5 \times$ as long as broad, great breadth due especially to enlargement in anal region; margin slightly scalloped between tips of veins.

Jugal lobe smaller than in two previous species; wing denuded but morphology of lobe indicates that brush is relatively weakly developed: no tracheal enlargement. $R$ fork well basal to $M$ fork, $R_{2} 7 \cdot 8 \times$ length of $R_{2+3}$. Wing membrane densely covered in very narrow scales. Wing length $3.0 \mathrm{~mm}$.

Terminalia (Figs 159-163) similar to B. remostyla. Style $1.95 \times$ length of coxite, paddleshaped, longer and narrower than $B$. remostyla; surface layer on inner side translucent, contrasting with remainder which is well-sclerotised; coxites splayed sideways, without lateral groove. Hypandrium arched strongly backwards as in subg. Maurobrunettia, thus contrasting with two preceding species. Post-hypandrial plate strongly shouldered, emarginate posteriorly between shoulders. Aedeagus: basal apodeme truncated, exceedingly short and broad; keel moderately developed; distal blades adpressed in distal halves, tips small, pointed, triangular; unique translucent digitate structure with ventral groove (Fig. 159d) arising at base of apodeme, extending backwards above distal blades but beneath post-hypandrial plate to the point where blades meet in midline; aedeagus not forming points laterally. Gonocoxal apodemes forming pair of rounded lobes anteriorly, flanking apex of aedeagal apodeme. Parameres curved backwards, tapered to narrow rounded tips. Epandrium (Fig. 160) with broad slit-shaped aperture (ea); lateral margins recurved to form strong rim; sclerotisation emarginated posteriorly in midline beneath tenth tergite. Tenth tergite with microsetose acuminate tip and curved divergent arms (a) anteriorly, showing more exaggerated expression of features seen in two preceding species. Cercopod (Figs 161, 162) very short and rounded; single dense cluster of retinacula on inner side, reminiscent of distribution in Maurobrunettia; retinacula with short, slender, flexible stems and 'bell-shaped' to hooded tips (Fig. 163); tips grading from fully expanded on one side of cluster to unexpanded on other.

Brunettia (Campanulobrunettia) adunata, sp. nov.

Material Examined

Holotype. $\sigma^{*}$, New Guinea: Maprik-Sepic area, light trap, iv.58 (Malaria Control Pilot Project, Sydney School of Public Health and Tropical Medicine) (ANIC, type No. 6098).

\section{Description}

Similar to B. palmata Quate and Quate; distinguished by lack of a median scar-free band on the vertex, rounded wing tip, and structure of the terminalia.

Male. Head (Fig. 165) resembling that of Horobrunettia species; $0.85 \times$ as long as broad; capsule wrinkled ventrally around occipital opening; vertex expanded posteriorly on either side of occipital region; scars on vertex rather sparse, not separated medially. Eyebridges separated by $5 \cdot 3$ facet diameters, connected by $Y$-shaped sclerotisation, arms dark adjacent to eyes, faint towards midline. Frontal scar patch narrowly divided, no median extension. Anterior tentorial pit very close to medial edge of eye, adjacent to fronto-clypeal suture; tentorial tube fluted, running diagonally forward then elbowed backwards. Cibarium slightly tapered and very thin-walled posteriorly, arms long, slender, widely spaced, posterior margin a straight line between. Labrum epipharynx ciliate laterally as in $B$. uncinata. Labellum with posterior line of setae and lateral sclerotisation strongly developed as in other Campanulobrunettia species. Palpi $(1 \cdot 0-3 \cdot 6-3 \cdot 3-4 \cdot 1) 1 \cdot 69 \times$ length of head; no sensory rods visible. Antenna incomplete; scape short, $1.7 \times$ length of pedicel, reaching just over half way to level of anterior edge of eye; flagellomeres with prominent lateral shoulders, only visible in lateral view (Fig. 164); ascoids palmate (Fig. 166). 
Thorax with anepisternite projecting beyond anterior rim of mesothorax. Wing (Fig. 167) narrow, $2 \cdot 8 \times$ as long as broad, not enlarged in anal or humeral region; forks at almost same level, slightly basal to tip of $\mathrm{CuA}_{2} ; \mathrm{R}_{2} 5 \cdot 0 \times$ length of $\mathrm{R}_{2+3}$. Wing length $1.53 \mathrm{~mm}$.

Terminalia (Figs 168, 169) very similar to $B$. palmata. Style $1.6 \times$ as long as coxite, surface layer on inner side not translucent, 3 large distal spines in place of usual pair. Coxite

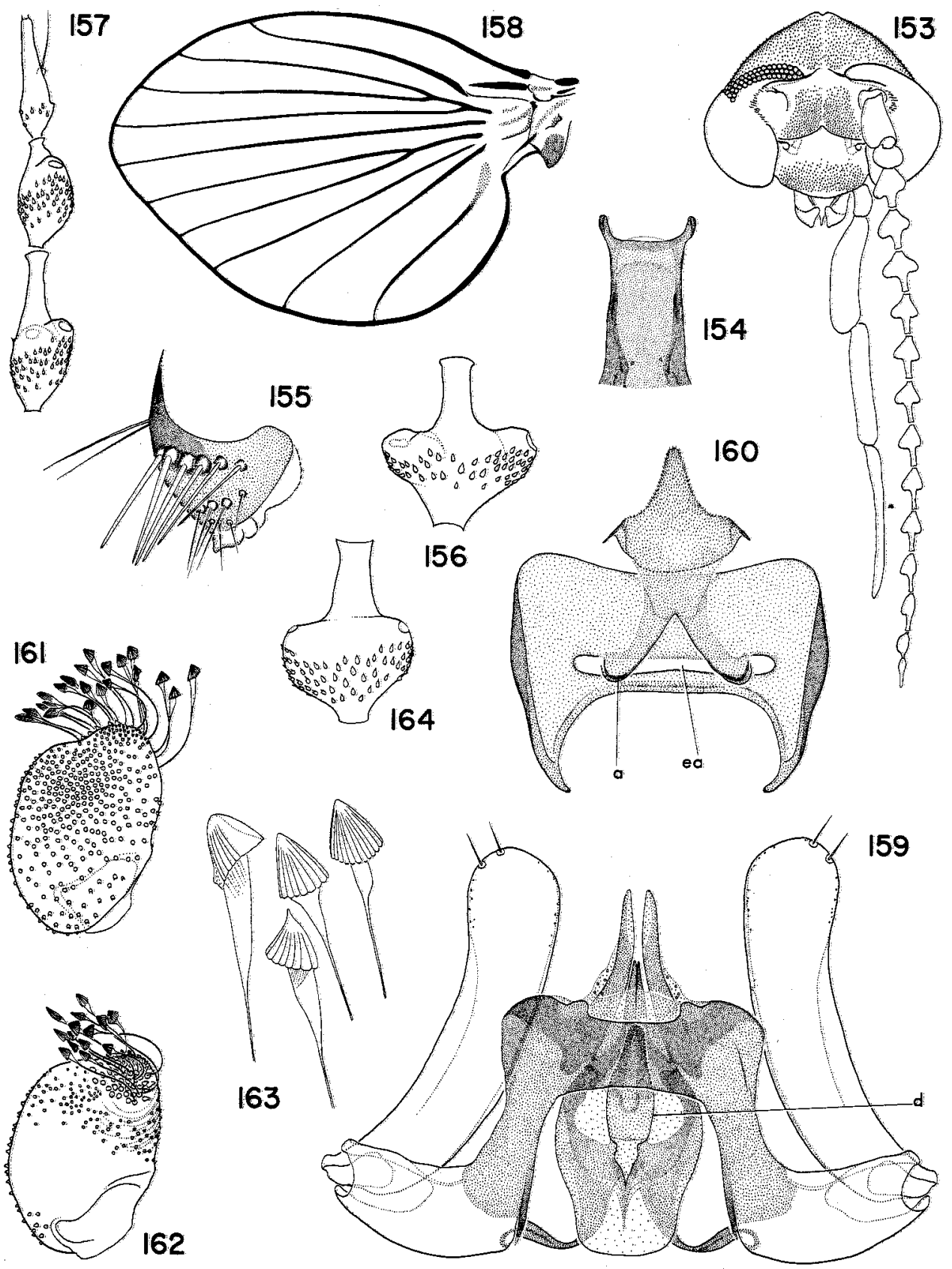

Figs 153-164. 153-163, Brtnettia (Campanulobrunettia) heterostylis, sp. nov., male: 153, head; 154, cibarium; 155, labellum, RH lobe; 156 , flagellomere $3 ; 157$, tip of antenna; 158 , wing; 159, gonopods and aedeagus, dorsal ( $d$, digitate structure arising at base of aedeagal apodeme); 160 , epandrium and tenth tergite, dorsal (ea, epandrial aperture; $a$, anterior arm of tenth tergite); 161 , cercopod, outer face; 162, cercopod, inner face; 163, tips of retinacula. 164, Brunettia (Campanulobrunettia) adunata, sp. nov., male: flagellomere 4. 
slender, splayed sideways, not grooved. Hypandrium arched strongly backwards, clearly split at base, with outer part running into parabasal region of coxite, and inner part expanding distally into broad process, probably articulating with epandrium. Post-hypandrial plate not especially shouldered. Aedeagus: basal apodeme well-developed, moderately long and broad, not truncated as in $B$. palmata and $B$. heterostylis; keel present; distal blades adpressed in distal halves, about as long as 'racquet', far shorter than parameres; no digitate structure as in B. heterostylis; aedeagus not forming points laterally. Epandrium, Fig. 169; apertures moderately large, very widely separated; lateral margins recurved to form rim, broadest at level of apertures. Tenth tergite very large, acuminate distally, basal region divided medially, each half with slender lateral arm (Fig. 169a) running posteriorly to articulation with cercopod. Cercopod with about 14 short retinacula on slender apex.

Subgenus Horobrunettia, subg. nov.

Type species: Brunettia arnhemae, sp. nov., by present designation.

\section{Remarks}

Horobrunettia is in many ways a peculiar subgenus, lacking some of the most conservative features of Brunettia, and generally to be regarded as lying at its limits. Some features are plesiomorphisms-e.g. the presence of vestiture on the epandrium, and the separate epandrial apertures. Others, including the structure of the aedeagal complex, could be basically plesiomorphic, or apomorphic. Quate \& Quate (1967) classified the species known to them in Atrichobrunettia. Nonetheless, they differ greatly from Atrichobrunettia and require a separate subgenus.

There are similarities between Horobrunettia and Mirousiella, raising the possibility that they are the same subgenus. However, I feel they are not the same and, since the overall distribution is highly peculiar, sound reasons should be provided to support any attempt at combining them. The similarities are probably due partly to symplesiomorphy, and partly to convergence.

Initially, I considered that $B$. arnhemae and $B$. ancora should be in separate subgenera, but they are linked by the Papua-New Guinean B. lyrata (Quate and Quate), B. microps (Quate and Quate) and $B$. tribulosa (Quate and Quate). These are described as showing 'genitalic characters which are markedly dissimilar although non-sexual characters show few differences'. The same comment applies to all species here included in Horobrunettia.

\section{Definition}

Male and Female. Small species with slender wings.

Head with vertex usually enlarged posteriorly on either side of occipital region; eyebridges of 3 facet rows, often very short; antennal scape short, but pedicel usually reaching beyond anterior margin of eye; last 2 flagellomeres separate; paired digitate ascoids on all but last 3 flagellomeres.

Wing not enlarged in anal or humeral region; veins strong, sclerotised, with numerous scars throughout; membrane naked; tendency towards loss of hair lines and associated triangular sclerotisation; $\mathrm{CuA}_{2}$ usually short, ending before level of medial fork and not reaching wing margin; $R$ fork usually well beyond $M$ fork; $R_{5}$ ending at, or posterior to, wing tip.

Male. Usually no thoracic allurement organs; mesothoracic spiracle set low; anepisternite with scars uniform in size; anterior margin not especially excavated, not tending to form spiniform projection below spiracle as in Maurobrunettia.

Distal blades of aedeagus tending to curve strongly inwards from lateral arms; aedeagal apodeme narrow, without lateral wings; parameres widely separated. Styles tending to become strongly uncinate; enlarged distal setae variously multiplied or enlarged. Sparse hair on ventral surface of epandrium. Cercopod short, about twice as long as broad; 2-4 short, straight retinacula, tips capitate and of 'spore capsule' type (Figs 175, 179), not hooded; no sclerotisation or shaftless sensilla adjacent to retinacula. 
Female. Subgenital plate, especially distal lobes, not of typical form as seen in other subgenera, but spermathecae with characteristic saw-tooth sclerotisations on ventral side.

\section{Distribution}

Except for a single Philippine species, Brunettia amoena (Quate), Horobrunettia is restricted to Papua-New Guinea and northern Australia.

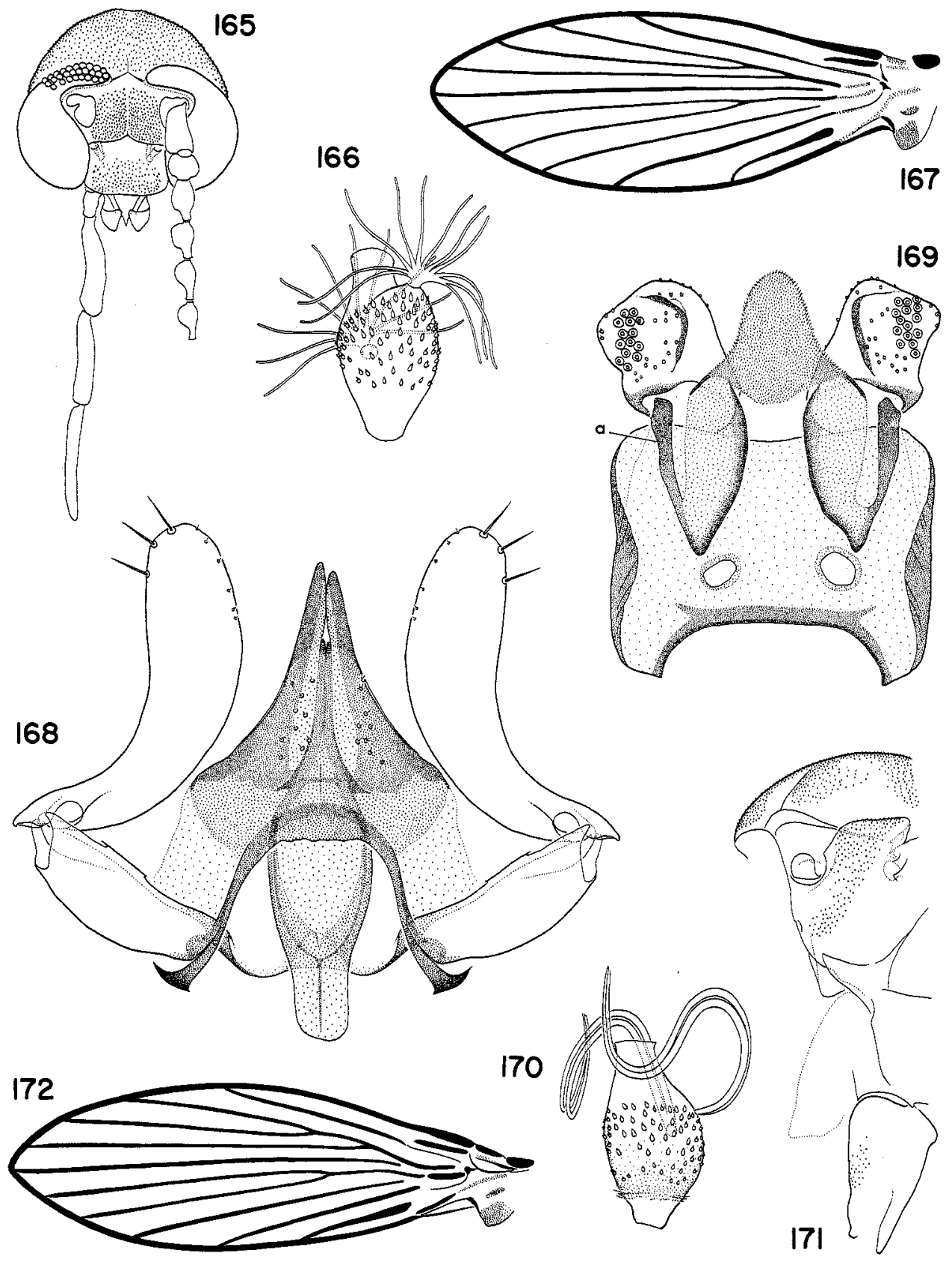

Figs 165-172. 165-169, Brunettia (Campanulobrunettia) adunata, sp. nov., male: 165, head; 166, flagellomere 1; 167, wing; 168, gonopods and aedeagus, dorsal; 169 , epandrium, tenth tergite and cercopods (a, lateral arm of tenth tergite). 170-172, Brunettia (Horobrunettia) arnhemae, sp. nov., male: 170 , flagellomere $1 ; 171$, anterior thorax, lateral; 172 , wing. 


\section{Key to Males of Australopapuan Species of subg. Horobrunettia}

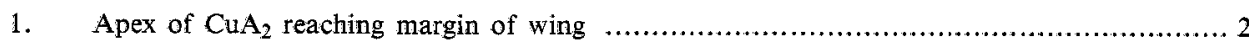

$\mathrm{CuA}_{2}$ short, apex straight and not reaching margin of wing . .................................. 3

2. $\mathbf{R}_{\mathbf{5}}$ attached to $\mathbf{R}_{\mathrm{S}}$ at base; aedeagus asymmetrical, one distal blade about as long as style (New Guinea) .......................................... lyrata (Quate and Quate), comb. nov.

$R_{5}$ not attached to $R_{s}$; aedeagus symmetrical, distal blades less than half as long as style (Northern Territory) ............................................... arnhemae, sp. nov

3. Aedeagus with distal blades triangular, tips divergent (Queensland and Northern Territory) ...

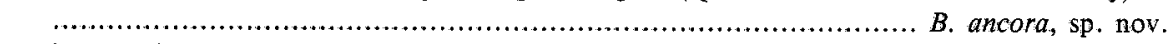

Aedeagus with distal blades not triangular, tips convergent

B. ancora, sp. nov

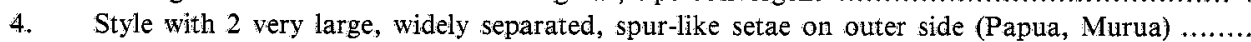

B. tribulosa (Quate and Quate), comb. nov.

Style with 2 small, close-set setae on outer side (New Guinea)

B. microps (Quate and Quate), comb. nov.

Material Examined

Brunettia (Horobrunettia) arnhemae, sp. nov.

Holotype. $\sigma^{*}$, Northern Territory: Batten Point, $15^{\circ} 54^{\prime} \mathrm{S} ., 136^{\circ} 32^{\prime} \mathrm{E} ., 30 \mathrm{~km} \mathrm{NE}$. by E. of Borroloola, 30.x.75, McArthur R Survey, M. S. Upton (ANIC, type No. 6099).

Paratype (allotype). $1 \%$, with holotype (ANIC).

Other material. 2\%,3\%, Berrimah, Quarantine Stn, light trap, 29.x-15.xi.57, E. J. Reye (ANIC); 10 , same loc., 7.iii.69, M. D. Murray (ANIC).

\section{Description}

Aedeagus resembling that of many Mormia species: distal blades converging like arms of calipers and meeting tip to tip. Female subgenital plate with distal lobes strongly constricted basally. Closest to B. microps (Quate and Quate).

Male. Head (Fig. 173) about $0.75 \times$ as long as broad (in holotype, not displayed in true frontal view). Capsule wrinkled ventrally around occipital opening. Vertex with scars less dense medially, but not separated. Eyebridges arched, rounded medially, separated by about 1.0 facet diameters, connected by curved interocular sclerotisation, facets large. Frontal scar patch divided medially, small posterior prolongation to between eyebridges. Anterior tentorial pit very close to inner margin of eye; first section of tube unsclerotised, running diagonally forward then elbowed sharply backwards as sclerotised section. Cibarium unsclerotised in posterior half; arms well separated, long and very slender, slightly convergent, posterior margin a straight line between arms. Mouthparts very short, clypeus not projecting beyond anterior ends of eyes. Palpi $(1 \cdot 0-4 \cdot 3-3 \cdot 9-5 \cdot 7) 1 \cdot 8 \times$ length of head. Antenna $2 \cdot 2 \times$ length of palp and $0.73 \times$ length of wing. Scape very short, $1.5 \times$ length of pedicel; pedicel not nearly reaching level of anterior margin of eye. Flagellomeres with necks up to about $0.6 \times$ lengths of bulbs (flag. 7); necks of last 3 not noticeably diminished, but bulb of last (13th) reduced; 2 ascoids on flags $1-14$, each with 2 closely paired very sinuous arms (Fig. 170).

Thorax (Fig. 171). Wing of anepisternite strongly developed, broadly overlapping rim of mesonotum; no allurement organs; spiracle set low. Wing (Fig. 172); $\mathrm{CuA}_{2}$ running into margin (its apex complete), $R$ fork at level of tip of $\mathrm{CuA}_{2}, R_{2} 3 \cdot 1 \times$ length of $R_{2+3} ; R_{5}$ reaching margin slightly posterior to wing tip. Wing length $1.6 \mathrm{~mm}$.

Terminalia (Figs 174, 175). Coxite very short, saccate anteriorly, splayed strongly sideways. Style $2 \cdot 1 \times$ length of coxite, produced laterally at base; blade with projecting ridge medioventrally (Fig. 174r), apex broad and rounded. Aedeagus $1.9 \times$ length of parameres; distal blades slender, converging like arms of calipers, rounded tips meeting in midline; bases of distal blades projecting anteriorly as pair of long wing-like processes (Fig. 174w) above aedeagal apodeme; apodeme long, slender, apparently almost cylindrical. Parameres thorn-shaped, divergent. Hypandrium arched weakly backwards. Cercopod (Fig. 175) with 2 terminal retinacula. 
Female. Head (Fig. 176) $0.83 \times$ as long as broad. Capsule wrinkled around occipital opening as in $\sigma$. Eyebridges separated by $2 \cdot 3$ facet diameters, connected by low sclerotised arch, very thin in middle. Anterior tentorial pit and tube as $\sigma^{\circ}$, but first section faintly sclerotised. Cibarium similar to $\sigma^{\circ}$, but slightly sclerotised in posterior half. Antenna incomplete, but flagellomeres smaller and shorter than $\sigma$.

Wing length $1.65 \mathrm{~mm}$.

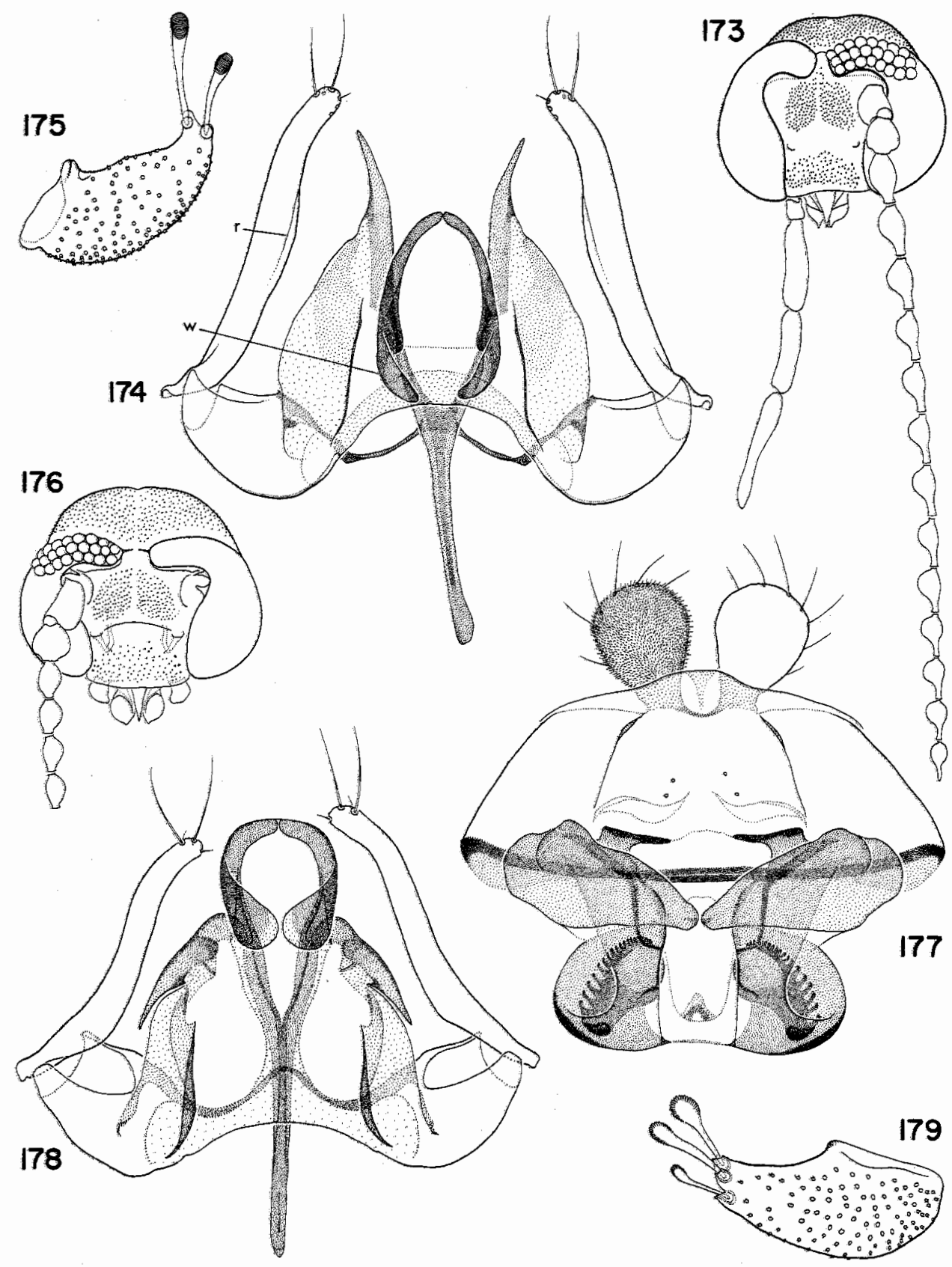

Figs 173-179. 173-175, Brunettia (Horobrunettia) arnhemae, sp. nov., male, and 176, 177, female: 173, head; 174, gonopods and aedeagus, dorsal ( $r$, projecting ridge; $w$, wing-like process); 175 , cercopod; 176 , head; 177 , subgenital plate and associated structures. 178, Male from Berrimah listed as arnhemae, 'other material': gonopods and aedeagus, dorsal. 179, Brunettia (Horobrunettia) ancora, sp. nov. male: cercopod. 
Subgenital plate and spermathecae, Fig. 177. Distal lobes constricted basally to less than half their greatest width; plate squat, $0 \cdot 56 \times$ as long as broad, basal thickening without median keel. Dorsal flap as in typical species of subgenera Brunettia and Atrichobrunettia. Spermathecae with strong saw-tooth sclerotisations. Ovipositor $2 \cdot 1 \times$ length of subgenital plate.

\section{Remarks}

Males listed as 'other material' differ from the holotype in some details and probably represent a second species. Unfortunately, they are battered. The head shows differences in the tentorial tubes and clypeus. In all three the aedeagus is more or less protracted and the parameres rotated (e.g. Fig. 178), so the terminalia cannot be properly compared with the holotype. The different appearance of the aedeagus and other structures may be partly due to deformation of the elastic cuticular structures produced by protraction, but is, I think, also partly due to actual differences in shape.

\section{Material Examined}

\section{Brunettia (Horobrunettia) ancora, sp. nov.}

Holotype. $\sigma$ Queensland: Goondi, $\mathrm{nr}$ Innisfail, open cane country, light trap, 12.vi.63, Standfast (ANIC, type No. 6100).

Paratypes. $10^{\circ}$, with holotype (DD); $50^{\circ}, 4 \%$, and $1 \%$ (allotype), Innisfail, Webbs Farm, light trap, 9.iv.64, Standfast (ANIC, BMNH, BPB); 1\%, Innisfail, Eubenangee Swamp, light trap, 13.vi.63, Standfast (ANIC); 10, same data, 12.xi.63 (ANIC); 10, same data, 8.iv.64 (ANIC); 10, Innisfail, Moran $\mathrm{Ck}$, light trap, 13.vi.63, Standfast (ANIC); 20, same data, 1.xii.63 (ANIC); 10, Northern Territory: Darwin, East Arm Convent, light trap, 26-7.xi.57, J. Dyer (ANIC); 10 , Darwin, light trap, 5-6.i.58, Dyer (ANIC).

\section{Description}

Distal blades of aedeagus a pair of short, triangular structures, fused at base and with divergent points; female subgenital plate with distal lobes parallel, spinous in U-shaped emargination between.

Male. Head (Fig. 180) $0.9 \times$ as long as broad. Capsule wrinkled ventrally around occipital opening, on dorsal surface of occipital lobe and on adjacent region of vertex. Vertex rather high, angular posteriorly on either side of occipital region; scars sparse towards occipital lobe but not separated medially. Eyebridges short, tapered medially, separated by $3 \cdot 5$ facet diameters; connecting sclerotisation weakened medially, with 2 arms extending diagonally backwards to midline, joining median hairline that extends to wrinkled region of posterior vertex. Frontal scar patch narrowly divided medially. Fronto-clypeal suture strongly marked on either side; anterior tentorial pit sclerotised very close to inner margin of eye, and joined to suture by which it is linked to eye; tentorial tube running downward and slightly forward from opening, not noticeably elbowed as in B. arnhemae. Cibarium slightly sclerotised in posterior half. Clypeus projecting beyond anterior margins of eyes as rounded lobe, overhanging bases of palpi. Palpi $(1 \cdot 0-3 \cdot 3-3 \cdot 1-3 \cdot 6) 1 \cdot 5 \times$ length of head. Antenna incomplete on all specimens; scape $1.9 \times$ length of pedicel; pedicel reaching beyond level of anterior margin of eye. Flagellomeres with necks poorly delimited from bulbs; neck of 3 rd flagellomere $0.43 \times$ length of bulb; verticillar scars extending further distally on outer side; ascoids long, digitate, sinuous (Fig. 181).

Thorax (Fig. 182). Wing of anepisternite less strongly developed than $B$. arnhemae, in both species upper margin parallel with rim of mesonotum; anepisternite swelling anteriorly below spiracle; no allurement organs. Wing (Fig. 183) rather broad for this subgenus; $\mathrm{CuA}_{2}$ straight and not running into margin (apex incomplete); $M$ fork just beyond level of tip of $\mathrm{CuA}_{2}$, R fork well beyond $M ; R_{2} 2.05 \times$ length of $R_{2+3} ; R_{5}$ reaching margin well posterior to wing tip-tip situated almost midway between $R_{4}$ and $R_{5}$; hair lines and triangular sclerotisation characteristic of Brunettia, absent. Wing length $1.35-1.65 \mathrm{~mm}$.

Terminalia (Figs 179, 184-186). Coxite short and stout, normal in position. Style elongate, strongly uncinate, angular at base, tapered in basal third then slender, cylindrical to rounded tip; 3-4 equally developed apical setae (no separate pair as in other species). 
Aedeagus $1.61 \times$ length of parameres; distal blades short, triangular, fused at base and with divergent points; apodeme long, laterally flattened at apex, in dorsal view widening progressively from anterior to posterior, margins forming continuous line with lateral arms of 'racquet' region. Parameres very long, articulating with aedeagus far anteriorly at point marked $a$ on Fig. 184, sinuous distally. In protraction, parameres rotate sideways and backward, their bases compressing aedeagus, greatly diminishing distance between its lateral arms (Fig. 185). Hypandrium forming almost straight line between bases of coxites.

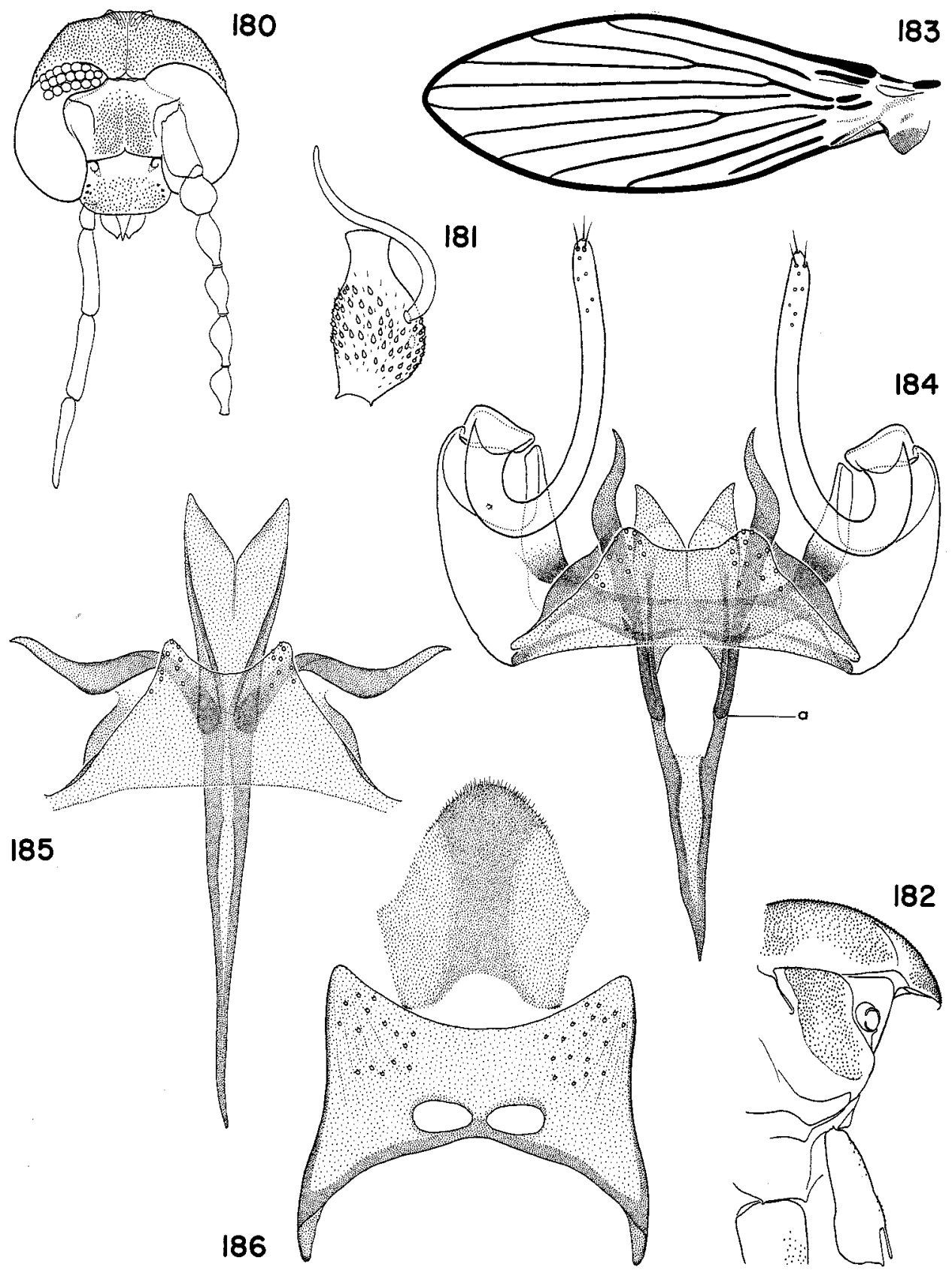

Figs 180-186. Brunettia (Horobrunettia) ancora, sp. nov., male: 180, head; 181 , median flagellomere; 182 , anterior thorax, lateral; 183, wing; 184, gonopods and aedeagus, dorsal (aedeagus retracted) ( $a$, point of articulation between paramere and aedeagus); 185 , aedeagal complex (aedeagus protracted); 186 , epandrium and tenth tergite, ventral. 
Post-hypandrial plate bilobed with shallow median concavity. Epandrium, Fig. 186; scars more numerous than $B$. arnhemae; paired apertures close-set; 10th tergite with median band of sclerotisation. Cercopod (Fig. 179) with 3 terminal retinacula.

Female. Head (Fig. 187) similar to $\sigma$ but eyebridges separated by $6 \cdot 0$ facet diameters; clypeus broad and very angular. Anterior tentorial tube running diagonally forward, similar to $B$. arnhemae, but strongly sclerotised and very constricted at elbow.

Wing (Fig. 188) far narrower than $\%$. Wing length $1.6-1.7 \mathrm{~mm}$.

Subgenital plate and spermathecae, Fig. 189. Distal lobes parallel, spinous in U-shaped emargination between; plate $0.42 \times$ as long as broad, basal thickening without median keel. Dorsal flap bilobed, divided through midline, splitting median sclerotisation. Spermathecae small, rounded, ventral saw-tooth sclerotisation with teeth shorter than $B$. arnhemae; punctate markings also present. Ovipositor $2 \cdot 5 \times$ length of squat subgenital plate.

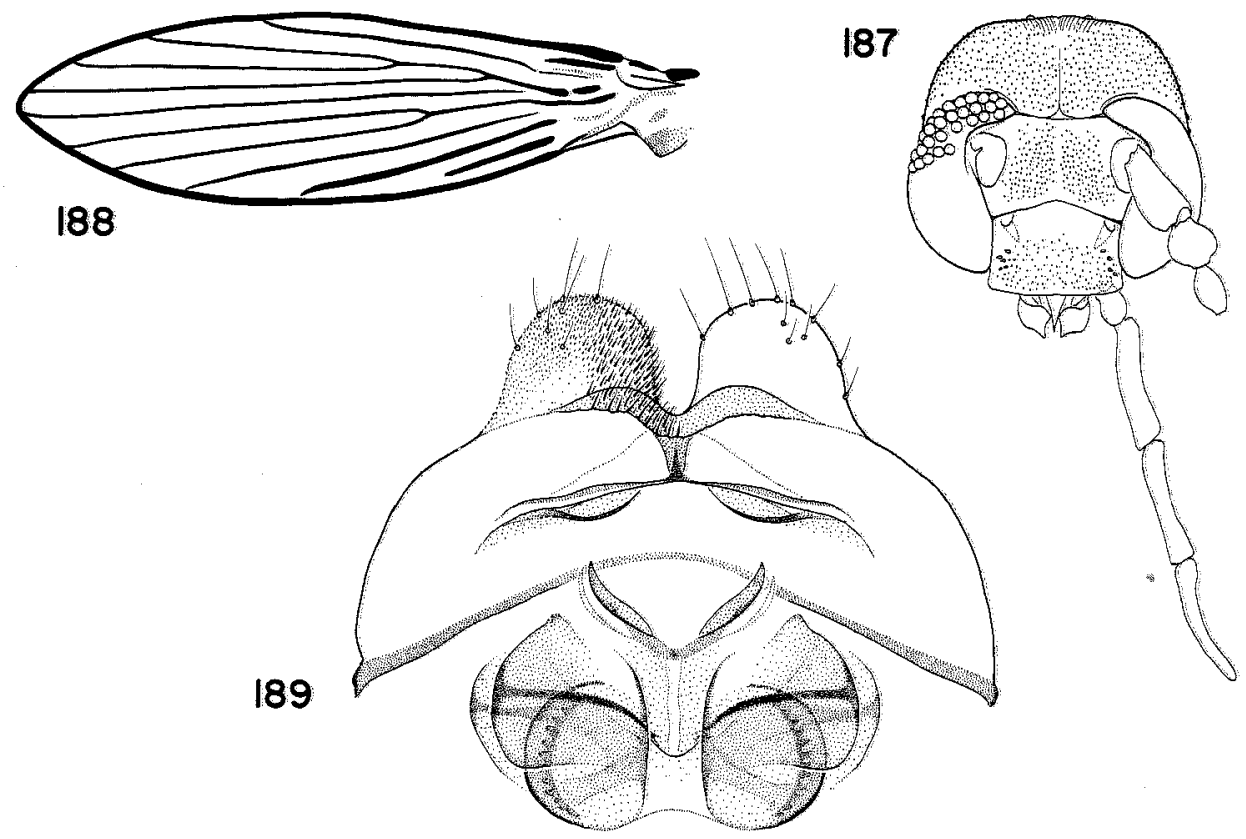

Figs 187-189. Brunettia (Horobrunettia) ancora, sp. nov., female: 187, head; 188, wing; 189, subgenital plate and associated structures.

\section{Unplaced species of Brunettia}

Brunettia clavigera (Quate and Quate), comb. nov., is an anomalous species that does not fit into any subgenus defined above. It appears to be closest to B. (Campanulobrunettia) tenuistyla, but is best left unplaced.

\section{Acknowledgments}

I am grateful to Mrs Ruth Evans for stippling most of my line drawings of gonopods and aedeagus; to my wife, Sylvia, and Mrs Lorna Lucas for typing of drafts and final typescript respectively; and to the following for the gift or loan of specimens: $\mathrm{Dr} D$. H. Colless, ANIC; Professor D. J. Lee, Sydney; Dr Alice Wells, University of Adelaide; Mr Alan Dyce, CSIRO; Dr Peter Cranston, ANIC; and Dr Neal Evenhuis, Bishop Museum. My wife also worked intensively with me during fieldwork in Queensland, sorted many light trap collections, stippled some drawings and criticised the manuscript. 


\section{References}

Annandale, N., 1910. A new genus of psychodid Diptera from the Himalayas and Travancore. Records of the Indian Museum 5, 141-4.

Axelrod, D. I., \& P. H. Raven, 1982. Pp. 919-41 in: 'Biogeography and Ecology of New Guinea'. Ed. J. L. Gressitt. (Dr W. Junk: The Hague.)

Brunetti, E., 1911. New Oriental Nemocera. Records of the Indian Museum 6, 259-316.

Brunetti, E., 1912. Diptera Nematocera (excluding Chironomidae and Culicidae). In: 'The Fauna of British India, including Ceylon and Burma', Ed. A. E. Shipley. 1, 1-581.

Duckhouse, D. A., 1966. Psychodidae (Diptera, Nematocera) of southern Australia: subfamily Psychodinae. Transactions of the Royal Entomological Society of London 118, 153-200.

Duckhouse, D. A., 1968. Psychodidae (Diptera, Nematocera) collected by Mr Plaumann in southern Brazil. Proceedings of the Royal Entomological Society of London. Series B 37, 29-40.

Duckhouse, D. A., 1973. Family Psychodidae. Pp. 226-44 in: "A Catalog of the Diptera of the Oriental Region', 1. Suborder Nematocera. Eds M. D. Delfinado and D. E. Hardy. (University Press of Hawaii: Honolulu.)

Duckhouse, D. A., 1978a. Non-phlebotomine Psychodidae (Diptera, Nematocera) of southern Africa. II. Subfamily Psychodinae: Neoarisemus and the brunettoid and telmatoscopoid genera. Annals of the Natal Museum 23, 305-59.

Duckhouse, D. A., 1978b. Taxonomy, phylogeny and distribution of the genus Trichomyia (Diptera, Psychodidae) in Australia and New Guinea. Systematic Entomology 3, 197-243.

Duckhouse, D. A., 1980. Trichomyia species (Diptera : Psychodidae) from southern Africa and New Zealand, with a discussion of their affinities and of the concept of monophyly in southern hemisphere biogeography. Annals of the Natal Museum 24, 177-91.

Duckhouse, D. A., 1985. A re-examination of Neomaruina (Diptera, Psychodidae), with observations on its life-history and affinities and redefinition of the tribe Psychodini. Annals of the Natal Museum 26, 601-20.

Duckhouse, D. A., 1987. A revision of Afrotropical Setomima, elucidation of their genealogical relationships and descriptions of other Afrotropical Psychodinae (Diptera: Psychodidae). Annals of the Natal Museum 28, 231-82.

Duckhouse, D. A \& D. J. Lewis, 1989. 15. Family Psychodidae. Pp. 166-79 in: 'Catalog of the Diptera of the Australasian and Oceanian Regions'. Ed. N. L. Evenhuis. (Bishop Museum: Honolulu.)

Duckhouse, D. A., 1990. The Australasian genera of pericomoid Psychodidae (Diptera) and the status of related Enderlein genera in the Neotropics. Invertebrate Taxonomy 3, 721-46.

Edwards, F. W., 1928. Nematocera. In: 'Insects of Samoa', 6. Diptera, Fasc. 2, 68-75. (British Museum (Natural History): London.)

Elger, M., 1981. The ultrastructure of special epidermal organs in Psychodidae (Diptera). 1 Appendages on the mesothorax of male Ulomyia fuliginosa (Meigen). Acta Zoologica 62, 1-16.

Enderlein, G., 1937. Klassifikation der Psychodiden (Dipt.). Deutsche Entomologische Zeitschrift 1936, 81-112.

Feuerborn, H. J., 1922. Der sexuelle Reizapparat (Schmuck-, Duft- und Berührungsorgane) der Psychodiden nach biologischen und physiologischen Gesichtspunkten untersucht. Archiv für Naturgeschichte 4, 1-137.

Freeman, P., 1951. Observations on the genus Brunettia Annandale (Dipt., Psychodidae), with descriptions of two new species. Proceedings of the Royal Entomological Society of London. Series $B$ 20, 142-6.

Gauld, I. D., \& L. A. Mound, 1982. Homoplasy and the delineation of holophyletic genera in some insect groups. Systematic Entomology 7, 73-86.

Gressitt, J. L., 1982. Zoogeographical summary. Pp. 897-918 in: 'Biogeography and Ecology of New Guinea'. Ed. J. L. Gressitt. (Dr W. Junk: The Hague.)

Quate, L. W., 1955. A revision of the Psychodidae (Diptera) in America north of Mexico. University of California Publications in Entomology 10, 103-273.

Quate, L. W., 1959. Diptera : Psychodidae. Insects of Micronesia 12, 435-84.

Quate, L. W., 1962a. A taxonomic study of Borneo Psychodinae (Diptera: Psychodidae). Pacific Insects 4, 1-75.

Quate, L. W., 1962b. Psychodidae (Diptera) at the Zoological Survey of India. Proceedings of the Entomological Society of Hawaii 18, 155-88.

Quate, L. W., 1963. Review of G. Enderlein's non-Holarctic genera of Psychodidae and description of a new species (Diptera). Transactions of the Royal Entomological Society of London 115, $181-96$.

Quate, L. W., 1965. A taxonomic study of Philippine Psychodidae (Diptera). Pacific Insects 7, $815-902$. 
Quate, L. W., \& S. H. Quate, 1967. A monograph of Papuan Psychodidae, including Phlebotomus (Diptera). Pacific Insects Monograph 15, 1-216.

Raven, P. H. 1979. Plate tectonics and Southern Hemisphere biogeography. Pp. 3-24 in: 'Tropical Botany'. Eds K. Larsen and L. B. Holm-Nielsen. (Academic Press: London.)

Satchell, G. H., 1950a. The New Zealand Psychodidae: a study based upon the collection and manuscript notes of the late Dr A. L. Tonnoir. Transactions of the Royal Entomological Society of London 101, 147-78.

Satchell, G. H., 1950b. New species of Fijian Psychodidae (Diptera). Proceedings of the Royal Entomological Society of London. Series B 19, 176-85.

Satchell, G. H., 1953a. The Australian Psychodidae (Diptera), Part 1. Australian Journal of Zoology 1, 357-418.

Satchell, G. H., 1953b. New and little known Samoan Psychodidae and a new species from Rarotonga. Proceedings of the Royal Entomological Society of London. Series B 22, 181-8.

Satchell, G. H., 1958. New and little known Psychodidae from Borneo and the Malay Peninsula. Records of the Indian Museum 53, 19-35.

Tokunaga, M., \& E. Komyo, 1955. Japanese Psychodidae, II. Nine new species of moth flies. Philippine Journal of Science 83, 401-17.

Tokunaga, M., 1959. Japanese Psychodidae, V. Descriptions and revisions on the Japanese species of the genera Trichopsychoda, Pericoma, Telmatoscopus, Brunettia, and Trichomyia. Philippine Journal of Science 88, 453-508.

Tonnoir, A. L., 1939. Psychodidae. in: 'Ruwenzori Expedition 1934-5', 1, 35-80. (British Museum (Natural History): London.)

Vaillant, F., 1971. Psychodidae-Psychodinae. Pp. 1-48 in: 'Die Fliegen der Palaearktischen Region', 9d. Ed. E. Lindner. (E. Schweizerbart'sche Verlagsbuchhandlung: Stuttgart.)

Vaillant, F., 1974. Psychodidae-Psychodinae. Pp. 109-42 in: 'Die Fliegen der Palaearktischen Region', 9d. Ed. E. Lindner. (E. Schweizerbart'sche Verlagsbuchhandlung: Stuttgart.)

Vaillant, F., 1975. Psychodidae-Psychodinae. Pp. 143-82 in: 'Die Fliegen der Palaearktischen Region'. 9d. Ed. E. Lindner. (E. Schweizerbart'sche Verlagsbuchhandlung: Stuttgart.)

Vaillant, F., 1982. Quelques précisions au sujet de cinq genres de Psychodidae Psychodinae (Diptères). Travaux du Laboratoire d'Hydrobiologie et de Pisciculture de L'Université de Grenoble 74, 211-17.

Wagner, R., 1984. New European species of genus Atrichobrunettia Satchell (Diptera : Psychodidae). Biologia Gallo-Hellenica 11, 31-6.

Wagner, R., \& F. Vaillant, 1983. The Atrichobrunettia (=Mirousiella) (Diptera, Psychodidae) from Europe. Aquatic Insects 5, 157-62.

Manuscript received 22 May 1989; accepted 3 October 1989 